\title{
Alimentação de crianças do Programa Saúde da Família (PSF): fatores associados à amamentação plena e impacto de um curso de aconselhamento em alimentação infantil nos conhecimentos de trabalhadores da saúde.
}

Tereza Setsuko Toma

Tese apresentada ao Programa de Pós-Graduação em Saúde Pública para obtenção do título de Doutor em Saúde Pública.

Área de concentração: Nutrição

Orientadora: Prof. Dra. Maria Helena D’Aquino Benício Co-orientadora: Prof. Dra. Marina Ferreira Rea

São Paulo 
É expressamente proibida a comercialização deste documento tanto na sua forma impressa como eletrônica. Sua reprodução total ou parcial é permitida exclusivamente para fins acadêmicos e científicos, desde que na reprodução figure a identificação do autor, título, instituição e ano da tese. 
Ser o que sou hoje é, em grande medida, o resultado da interação com muitos sujeitos $\mathrm{e}$ subjetividades. Dedico este trabalho a todas as pessoas que ao longo dos anos me desafiaram, provocaram em mim inquietações. E, com especial carinho, ao meu companheiro Trajano e aos meus filhos Luiza e Olavo, assim como a todas as pessoas com as quais tive oportunidade de obter algumas das respostas, seja por meio de conversas ou da escuta e leitura de suas idéias e argumentos. 


\section{Agradecimentos}

Há muitas pessoas a quem agradecer. Todas são igualmente importantes, pois apenas com sua particular contribuição foi possível chegar até aqui.

- Sou especialmente grata à Dra. Marina Ferreira Rea, cujo projeto de pesquisa financiado pelo CNPq (processo 402278/2005-4) viabilizou a realização desta tese.

- Prof. Dra. Maria Helena D’Aquino Benício, minha orientadora, pelos ensinamentos, prontidão e presteza nas respostas e sugestões.

- Prof. Dra. Marina Ferreira Rea, minha co-orientadora, pela troca de idéias e acompanhamento cotidiano do trabalho, além de ajuda prática que só uma amiga consegue dar.

- Prof. Dr. Carlos Augusto Monteiro e Prof. Dra. Maria Inês Couto de Oliveira, membros da banca de qualificação, pelas recomendações e sugestões que me fizeram trabalhar em dobro, mas foram fundamentais para o adequado desenho do projeto.

- Dr. José Carlos Martines, da Organização Mundial da Saúde, que me cedeu textos relevantes e prestou assessoria técnica na análise inicial dos dados.

- Prof. Drs. José Maria Pacheco de Souza e Maria do Rosário Latorre, pelas horas de assessoria na análise dos dados.

- Prof. Drs. Marli Cardoso, Ivan França Júnior, José Eluf Neto e, em especial, Maria do Rosário Latorre, pelos excelentes cursos que oferecem aos pós-graduandos.

- Prof. Drs. Carlos Augusto Monteiro, Elsa Regina Justo Giugliani, Sonia Isoyama Venâncio e Zuleika Thomson, membros da pré-banca, por suas valiosas contribuições.

- Kátia C. Bassichetto, que me cedeu boa parte do material já traduzido do curso e outros materiais que facilitaram a elaboração dos instrumentos para coleta dos dados. 
- Constanza Vallenas e Peggy Henderson, técnicas da Organização Mundial da Saúde, que gentilmente me enviaram a última versão rascunho do curso.

- Ana Júlia Colameo, que com seus dotes artísticos deixou os diapositivos do curso muito mais atraentes.

- Daniela de Almeida Andretto, Vanessa Martins da Cruz, Lucélia Fernandes e Flávia Zanatta, bolsistas e auxiliares de pesquisa, meus braços, pernas e ouvidos.

- Tereza Etsuko Rosa, que me fez perder o medo de lidar com o programa SPSS.

- Secretários de Saúde de Itapira e Peruíbe, por permitirem a realização do projeto nesses municípios.

- Celene Ferrari Audi, Cezar e Ana Maria Prigenzi, amigos que me abriram as portas dos municípios de Itapira e Peruíbe.

- Thuê Ornellas, coordenadora do PSF de Itapira; Marylande Nunes e Roberta, do escritório de coordenação do PSF de Peruíbe, pelo apoio operacional.

- Agentes comunitários de saúde, médicos, enfermeiros e auxiliares de enfermagem das UBS e equipes de PSF de Itapira e Peruíbe, por sua paciência com todos os membros do projeto de pesquisa.

- Drs. Rubens Kon e Jaqueline Lanaro e residentes de Pediatria do Centro Saúde Escola Prof. Samuel Barnsley Pessoa, por permitirem a realização do pré-teste do formulário para observação de consultas e o treinamento das observadoras.

- Camila Correa, por viabilizar a realização do pré-teste do formulário para avaliação de conhecimentos junto aos trabalhadores do PSF de São Mateus.

- Carlos Eduardo Correa, Maria José G. Mattar, Joana W. Kuzuhara, Maria Lúcia Bom Ângelo, Jeanine M. Salve, Fabiana Müller, Andrea dos Santos, Fabíola Nejar da Silveira, Anália R. Heck, Ione Queiróz, 
Sandra Regina de Souza, excelentes profissionais e facilitadores do curso.

- Edna Aparecida Domingues, Sueli Aparecida de Oliveira, Denise Valeriana da Silva Agapito, Márcia Regina de Souza Lúcio, Andréia Regiane de Souza, Elisa Aparecida Escatton, Anelise Lusvarghi, Luis Flávio Campos, Talita Ferrari, Roberta C. M. Mendes, Kátia Cilene Bassi, Carlos Marcelino T Santos, Silvana de Lima, Bianca viola de Gouveia, Camila Brito França, Gislaine Dos S. Passos, Jananína Franco Bettini, Siumara Pereira Costa, entrevistadores de Itapira e Peruíbe.

- Diane Mesquita, Patrícia Gonzaga, Renata Silva, Diana Soares, Mariângela Nepomuceno, Renata Martins, Sandra Garcia, Vera Machado, Gabriela Vedovato, Vanessa Fernandes Konishi, Tereza Cristina de Oliveira e Oliveira, Natália Fialho Mota, Maria Rosirene Lima Pereira, observadoras de consultas.

- Ana Paula Martins, pela ajuda na seleção das observadoras.

- Maria Cecília Miranda e Mariana Domingues, que me forneceram dados sobre os municípios.

- Sílvia Saldiva, pelo empréstimo das balanças e orientação sobre como realizar de maneira adequada as pesagens das crianças.

- Silvia Konno, pelas sugestões de balanças e locais onde buscá-las.

- Val, do Banco de Leite Humano de Peruíbe, que me cedeu o espaço para as reuniões com os entrevistadores.

- Todo o pessoal do Hospital Municipal de Itapira, que me cedeu uma sala para reuniões com os entrevistadores e a logística para a realização do curso.

- Leoci e todos os motoristas da Secretaria de Estado da Saúde de São Paulo, pela garantia do transporte necessário durante todo o projeto.

- Todas as mães e famílias que participaram da pesquisa.

- Outras pessoas a quem posso ter esquecido. 


\section{ÍNDICE}

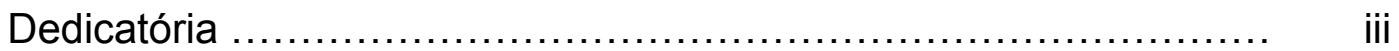

Agradecimentos .......................................................................... iv

Lista de tabelas do Artigo 2 ......................................................... ix

Lista de tabelas, figura e quadro do Artigo 3 ………….................. $\mathrm{x}$

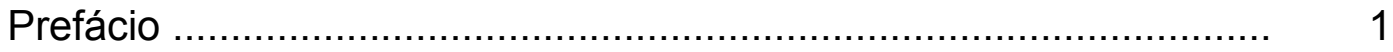

Resumo …....................................................................... 2

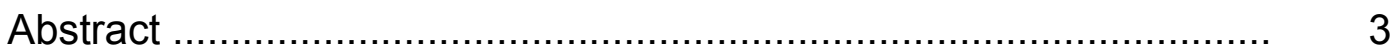

Artigo 1: Benefícios do aleitamento materno e efetividade das ações de promoção, proteção e apoio: um ensaio sobre as evidências científicas .................................................................................. 4

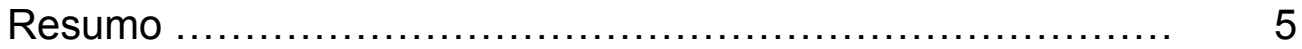

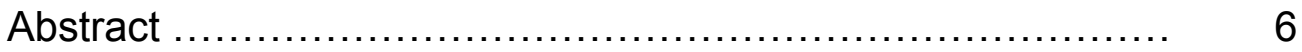

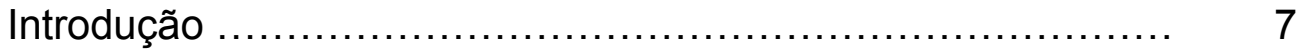

Recomendações atuais sobre alimentação infantil .................... 7

Amamentação no início da vida ............................................ 12

Implicações da amamentação para a saúde da criança ........... 17

Implicações da amamentação para a saúde da mulher .............. 21

Efetividade das ações pró-amamentação ................................. 23

Conclusão .................................................... 28

Referências ......................................................... 29 
Artigo 2: Fatores associados com a amamentação plena de crianças do Programa Saúde da Família: uma análise hierarquizada ............ 36

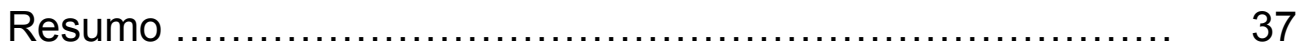

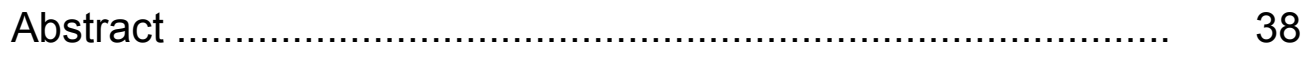

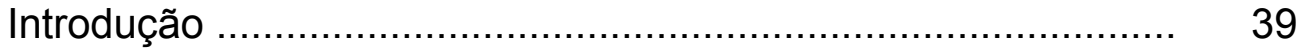

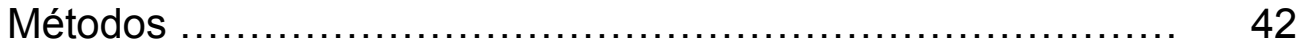

Resultados ............................................................ 46

Discussão ............................................................. 47

Conclusão ........................................................... 52

Referências .......................................................... 53

Artigo 3: Impacto de um curso de aconselhamento em alimentação infantil nos conhecimentos de trabalhadores da saúde: um estudo controlado não randomizado...................................................... 62

Resumo ...................................................................... 63

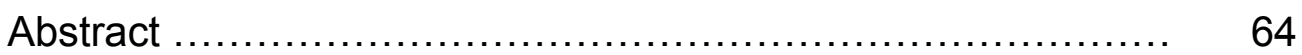

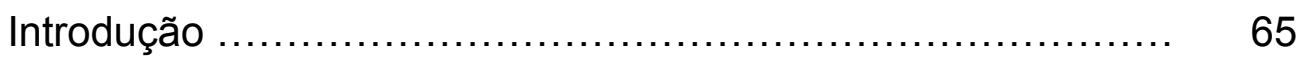

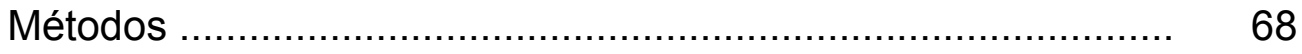

Resultados ................................................................. 73

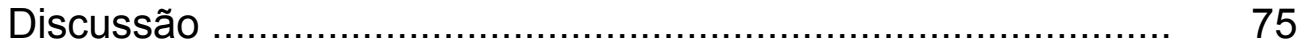

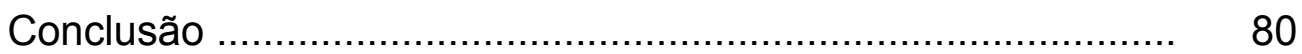

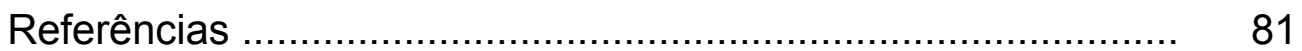

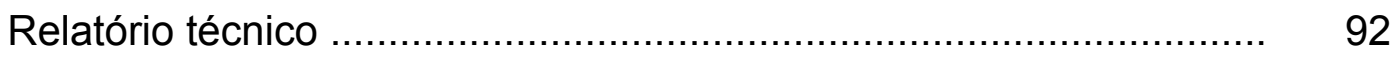

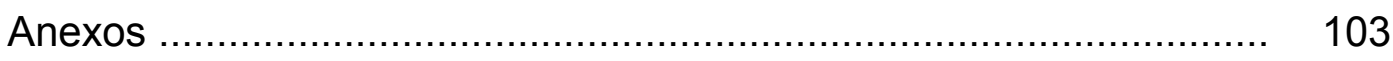




\section{LISTA DE TABELAS DO ARTIGO 2}

Tabela 1. Distribuição das crianças de 0 a 6 meses assistidas pelo Programa Saúde da Família segundo algumas variáveis selecionadas. Itapira e Peruíbe, SP, 2007.

Tabela 2. Análise bivariada entre amamentação plena e variáveis relativas à situação sócio-econômica, trabalho da mãe e organização familiar. Itapira e Peruíbe, SP, 2007.

Tabela 3. Análise bivariada entre amamentação plena e variáveis relativas à estrutura dos serviços e ação dos profissionais de saúde. Itapira e Peruíbe, SP, Brasil, 2007.

Tabela 4. Análise bivariada entre amamentação plena e variáveis relativas à mãe e à criança. Itapira e Peruíbe, SP, Brasil, 2007.

Tabela 5. Análise múltipla de fatores associados com a amamentação plena, segundo modelo hierarquizado. Itapira e Peruíbe, SP, 2007. 


\section{LISTA DE TABELAS, FIGURA E QUADRO DO ARTIGO 3}

Tabela 1. Distribuição dos profissionais que atendem as crianças cadastradas no Programa Saúde da Família, segundo algumas características selecionadas, nos Grupos Intervenção (GI) e Controle (GC). Itapira e Peruíbe, SP, 2007.

Quadro. Sessões do "Aconselhamento em Alimentação de Lactentes e Crianças de Primeira Infância: um curso integrado" e porcentagem de freqüência dos 31 participantes a cada sessão. Itapira e Peruíbe, SP, 2007.

Tabela 2. Média da nota inicial dos profissionais que atendem crianças cadastradas no Programa Saúde da Família segundo blocos de questões sobre nutrição e alimentação infantil, nos Grupos Intervenção $(G I)$ e Controle (GC). Itapira e Peruíbe, SP, 2007.

Tabela 3. Médias das notas inicial e final dos profissionais que atendem crianças cadastradas no Programa Saúde da Família, segundo blocos de questões, nos Grupos Intervenção $(G I)$ e Controle (GC). Itapira e Peruíbe, SP, 2007.

Tabela 4. Incremento médio das notas dos profissionais que atendem crianças cadastradas no Programa Saúde da Família, segundo blocos de questões, nos Grupos Intervenção (GI) e Controle (GC). Itapira e Peruíbe, SP, 2007. 
Figura. Histograma do incremento médio das notas dos profissionais que atendem crianças cadastradas no Programa Saúde da Família. Itapira e Peruíbe, SP, 2007.

Tabela 5. Análise de regressão linear bivariada e múltipla $(N=63)$ : efeito da intervenção e das variáveis de confundimento sobre o incremento médio das notas dos profissionais que atendem crianças cadastradas no Programa Saúde da Família. Itapira e Peruíbe, SP, 2007.

Tabela 6. Análise de regressão linear bivariada e múltipla ( $N=39)$ : efeito da freqüência ao Curso Integrado e das variáveis de confundimento sobre o incremento médio das notas dos profissionais que atendem crianças cadastradas no Programa Saúde da Família. Itapira e Peruíbe, SP, 2007. 


\section{PREFÁCIO}

Esta tese foi redigida no formato de três artigos científicos, um relatório técnico e os anexos.

O primeiro artigo é um ensaio que reúne as evidências científicas recentes sobre a importância do aleitamento materno tanto para a saúde da criança quanto da mulher e a efetividade das ações de promoção, proteção e apoio.

O segundo artigo analisa os fatores associados à amamentação plena (amamentação exclusiva mais amamentação predominante) durante os seis primeiros meses de vida entre crianças assistidas pelo PSF em dois municípios do Estado de São Paulo.

O terceiro artigo compara os conhecimentos em alimentação infantil entre médicos, enfermeiros e auxiliares de enfermagem que participaram do "Aconselhamento em alimentação de lactentes e crianças de primeira infância: um curso integrado" com um grupo controle.

O relatório tem a finalidade de permitir a visualização do projeto em sua totalidade, os instrumentos para coleta dos dados e detalhes que não puderam ser incluídos nos artigos. 


\section{RESUMO}

Toma, TS. Alimentação de crianças do Programa Saúde da Família (PSF): fatores associados à amamentação plena e impacto de um curso de aconselhamento em alimentação infantil nos conhecimentos de trabalhadores da saúde. São Paulo; 2008 [Tese de doutorado - Faculdade de Saúde Pública da USP].

Introdução: A Organização Mundial da Saúde lançou recentemente o "Aconselhamento em alimentação infantil: um curso integrado" $(\mathrm{Cl})$, destinado à capacitação de profissionais de saúde e aconselhadores leigos. Objetivos: Estudar os fatores associados com a amamentação plena de crianças do PSF e avaliar a efetividade do $\mathrm{Cl}$ junto aos profissionais de saúde. Métodos: A tese é apresentada no formato de três artigos: 1. Ensaio sobre as evidências científicas em amamentação; 2. Estudo sobre fatores associados à amamentação plena de 241 crianças até 6 meses de idade, por meio de regressão múltipla hierarquizada; 3 . Análise do incremento nos conhecimentos de profissionais dos grupos intervenção $(n=39)$ e controle $(n=24)$, por meio de regressão linear múltipla ajustada por variáveis de confundimento. Resultados: 2. A amamentação plena mostrou associação estatisticamente significante com: morar com companheiro, não ter dificuldade para amamentar, deixar a criança largar o peito quando satisfeita e dar nota mais baixa às consultas; 3. Após a intervenção houve um incremento estatisticamente significante, porém modesto, nos conhecimentos do grupo intervenção em relação ao controle $(p<0,05)$. Conclusão: A amamentação plena é praticada por cerca de metade das mães de crianças até 6 meses e mostrou-se associada a fatores maternos e da família. $\mathrm{O} \mathrm{Cl}$ foi efetivo em aumentar os conhecimentos dos participantes, embora os resultados sejam modestos. Sua operacionalização junto às equipes de PSF mostrou-se difícil na população estudada.

Descritores: aleitamento materno, Programa Saúde da Família, capacitação de recursos humanos em saúde, estudo de intervenção. 


\begin{abstract}
Toma, TS. Feeding practices of children assisted by the Brazilian Family Health Program (PSF): factors associated to full breastfeeding and impact of an infant feeding counselling course in the health workers' knowledge. São Paulo, SP, Brazil; 2008 [Dissertation - Faculdade de Saúde Pública da USP]
\end{abstract}

Background: The World Health Organization launched recently the "Integrated Infant Feeding Counselling: a training course" (IC), in order to train both health professionals and lay counselors. Objectives: To study the factors associated to full breastfeeding of infants assisted by PSF and to assess the IC effectiveness among health professionals. Methods: The dissertation comprehends three papers $-1^{\text {st }}$. Essay about scientific evidence for breastfeeding; $2^{\text {nd }}$. A survey about factors associated to full breastfeeding through hierarchical logistic regression analysis of data from 241 infants under 6 months old; $3^{\text {rd }}$. Analysis of the knowledge provided by the IC to an intervention group $(n=39)$ compared to a control group $(n=24)$, using multiple linear regression analysis adjusted by confounding variables. Results: $2^{\text {nd }}$ paper: Full breastfeeding has shown significant association with: presence of the partner, having no difficulty to breastfeed, spontaneous release of the breast when baby is satisfied, and mothers giving lower scores to consultations; $3^{\text {rd }}$ paper: After intervention, there has been a statistically significant but little improved knowledge of the intervention group compared to control $(p<0.05)$. Conclusion: Full breastfeeding (exclusive plus predominant) is practiced by around $50 \%$ of the mothers of infants under the 6 months. It has shown associated to the mother and family determinants. The IC was effective in enhancing knowledge of the participants, although showing modest results. One of the challenges is to organize IC for PSF workers in our circumstances.

Key-words: Breastfeeding, Brazilian Family Health Program, human resources training in Health, intervention survey. 
ARTIGO 1:

BENEFÍCIOS DO ALEITAMENTO MATERNO E EFETIVIDADE DAS AÇÕES DE PROMOÇÃO, PROTEÇÃO E APOIO: UM ENSAIO SOBRE AS EVIDÊNCIAS CIENTÍFICAS.

BREASTFEEDING BENEFITS AND ACTIONS TO PROMOTE, PROTECT AND SUPPORT: AN ESSAY TO REVIEW SCIENTIFIC EVIDENCE. 


\section{RESUMO}

Este ensaio reúne uma seleção de estudos, particularmente revisões sistemáticas, que têm contribuído para aumentar a compreensão sobre os benefícios do aleitamento materno para mãe e criança e sua implementação. Realizou-se uma busca de artigos publicados a partir do ano 2000 , sem, no entanto, deixar de lado estudos relevantes para o avanço do conhecimento publicados décadas atrás. Para a seleção dos estudos efetuou-se uma busca na internet a partir das ferramentas disponíveis no Pubmed e Scielo. Além dos aspectos para os quais há consenso, procurou-se incluir também estudos sobre resultados controversos e outros que são instigantes como os provenientes da neurobiologia. Verificam-se mudanças substanciais nas recomendações para políticas públicas em decorrência desses novos conhecimentos. Algumas investigações também têm sido realizadas com o objetivo de avaliar quais intervenções seriam mais efetivas para um aumento das práticas de amamentação. Procurou-se neste artigo dar destaque a: 1. recomendações atuais sobre alimentação da criança pequena; 2. importância de um bom início de vida; 3. implicações do aleitamento materno para a saúde da criança; 4. implicações do aleitamento materno para a saúde da mulher; e 5. efetividade de algumas ações pró-amamentação.

Descritores: aleitamento materno; leite humano; revisão; saúde da mãe; saúde da criança. 


\section{ABSTRACT}

This paper comprehends a selection of studies, especially systematic reviews that have contributed to increase the understanding about the benefits of breastfeeding, both for mothers and children. A search for papers published since the year 2000 has been made, including relevant studies to the advancement of knowledge published in previous decades. An internet browsing after Pubmed's and Scielo's data banking have been accomplished in order to select the studies. Besides the consensual aspects, also controversial results have been included, as well as intriguing ones, from Neurobiology. Recommendations for public policies undergo substantial changes following those new discoveries. Some inquiries have also been performed in order to evaluate which interventions would be more effective to increase breastfeeding rates. This paper highlights: 1 . Current recommendations about child feeding. 2 . The importance of a good life start. 3. The implications of breastfeeding for infant's health. 4. The implications of breastfeeding for woman's health. 5 . The effectiveness of some interventions favoring breastfeeding.

Key-words: Breastfeeding; human milk; review; mother's health; infant's health. 


\section{INTRODUÇÃO}

Pesquisas realizadas nas duas últimas décadas contribuíram muito para aumentar a compreensão sobre os benefícios do aleitamento materno para a criança e para a mãe. A relevância dos achados provocou mudanças substanciais nas recomendações para políticas públicas. Muitos estudos também têm sido realizados com o objetivo de avaliar quais intervenções seriam mais efetivas para favorecer as práticas de amamentação. Este ensaio procurou destacar alguns aspectos dos estudos publicados a partir do ano 2000, particularmente revisões sistemáticas. Muitos destes estudos apresentam resultados de projetos recentes nos quais se procurou utilizar coleta de dados e indicadores comparáveis de aleitamento materno.

O artigo procura abordar: 1 as recomendações atuais sobre alimentação infantil; 2. a amamentação no início de vida; 3. as implicações do aleitamento materno para a saúde da criança; 4. as implicações do aleitamento materno para a saúde da mulher; e 5. a efetividade das ações pró- amamentação.

\section{RECOMENDAÇÕES ATUAIS SOBRE ALIMENTAÇÃO INFANTIL}

Em meados da década de 1980 publicam-se pela primeira vez estudos que comprovam a importância de amamentar exclusivamente, sem qualquer outro líquido, água ou chá, para um menor risco de morbidade (POPKIN e col., 1990) e mortalidade (VICTORA e col., 1987). Estes estudos, sobejamente conhecidos, assim como outros realizados em diversos países, 
forneceram novas bases de recomendação de políticas internacionais, particularmente da Organização Mundial da Saúde (OMS) e do Fundo das Nações Unidas para a Infância (UNICEF). Essas novas diretrizes recomendam que as crianças sejam amamentadas de forma exclusiva até os seis meses e, que após esse período, gradativamente se inicie a alimentação complementar mantendo a amamentação até pelo menos os dois anos de idade (OMS, 2005).

Assim, inicia-se a busca junto a renomados cientistas e profissionais de saúde pública com o objetivo de reunir idéias e ações para compor políticas e programas que possam levar ao aumento da prática do aleitamento materno exclusivo (AME) nos primeiros meses de vida. Propõem-se também Consultas Técnicas sobre alimentação complementar concomitante com a amamentação, integrando-se propostas de capacitação profissional que, já neste século, passam a cobrir o período do nascimento ao segundo ano de vida. Mais ainda, incorporam-se nos anos recentes as propostas de ação nas emergências, endemias e epidemias (como a Aids), eventos que certamente interferem nas decisões sobre alimentação da criança pequena (OMS, 2005).

Nos anos 90, analisando-se os dados do Demographic and Health Surveys (DHS) para diversos países, observa-se que o AME até 4 meses cresceu de 46 para $53 \%$, cerca de $15 \%$ portanto. E quando se considera AME até 6 meses, esse crescimento foi de 34 para 39\%. Isto se deveu principalmente à implementação da Iniciativa Hospital Amigo da Criança e do Código Internacional de Comercialização de Substitutos do Leite Materno (LABBOK e col., 2006). Depois do ano 2000 espera-se que a Estratégia Global sobre Alimentação de Lactentes e Crianças de Primeira Infância seja a política pública a levar a um maior aumento dessas práticas (OMS, 2005).

Amamentar exclusivamente até o sexto mês de vida tornou-se recomendação baseada em revisão extensa da literatura, solicitada pela 
OMS a partir de duas buscas independentes (KRAMER e KAKUMA, 2004). Estas incluíram os bancos de dados: MEDLINE (desde 1966), Index Medicus (antes de 1966), CINAHL, HealthSTAR, BIOSIS, CAB Abstracts, EMBASEMedicine, EMBASE-Psychology, Econlit, Index Medicus para a Região da OMS Eastern Mediterranean, African Index Medicus, Lilacs, EBM ReviewsBest Evidence, Revisões sistemáticas do Cochrane Database e Cochrane Controlled Trials Register. As buscas levaram a 2.668 trabalhos publicados sobre o tema. Vinte estudos foram selecionados: 9 de países em desenvolvimento (dois dos quais de Honduras, experimentos controlados) e 11 de países desenvolvidos (todos observacionais). Nenhum deles mostrou que amamentar exclusivamente por seis meses pode comprometer o ganho de peso ou altura. Bebês amamentados exclusivamente apresentaram menor morbidade por diarréia quando comparados àqueles que receberam leite materno junto com alimentos complementares aos 3-4 meses. Com relação a ferro e anemia, no entanto, verifica-se que em algumas circunstâncias a AME sem suplementação com ferro pode comprometer a situação hematológica das crianças. Não houve redução significativa de risco de eczema, asma e outras atopias. AME mostrou-se também importante para a saúde da mulher; quando praticado por seis meses esteve associado a retardo na volta da menstruação e maior rapidez na perda de peso pós-parto (KRAMER e KAKUMA, 2004).

Por muito tempo persistiam críticas sobre provável crescimento mais lento de crianças amamentadas em comparação às alimentadas com fórmula infantil, quando se utilizava o referencial do Centro Nacional para Estatísticas em Saúde dos Estados Unidos, conhecidas como curvas NCHS. O reconhecimento das limitações desta referência internacional desencadeou a construção de novos padrões (DE ONIS e VICTORA, 2004). A OMS lança, em 2006, as curvas elaboradas a partir de uma amostra de crianças vivendo em condições que permitiam o alcance de seu potencial genético de crescimento. Estas curvas, mais do que uma referência são consideradas um padrão por ser o resultado de um estudo multicêntrico do 
qual participaram Brasil, Gana, Índia, Noruega, Omã e Estados Unidos e terem sido incluídas apenas crianças amamentadas de famílias em boa situação econômica, filhas de mulheres não fumantes (DE ONIS e col., 2006). Os resultados mostram a similaridade de crescimento de crianças desses diferentes países quando há condições adequadas para o seu desenvolvimento. Entretanto, por se tratar de um novo parâmetro, as implicações práticas ainda não totalmente avaliadas de sua adoção em larga escala pelas agências e países têm sido motivo de interesse dos estudiosos do tema (SEAL e KERAC, 2007).

Em que pese a grande insistência que se tem sobre o não uso de outros fluidos que não o leite materno nos primeiros seis meses, um estudo envolvendo cerca de 10.000 crianças e mães de Gana, Índia e Peru mostrou que bebês predominantemente amamentados foram também protegidos quanto a mortalidade, apresentando riscos de morte similares aos exclusivamente amamentados (BAHL e col., 2005); no entanto, bebês não amamentados tiveram um alto risco de morte quando comparados aos predominantemente amamentados, ou mesmo parcialmente amamentados. Os autores sugerem que em locais onde a amamentação predominante é prevalente (amamentação mais uso de água ou chá nos primeiros seis meses de vida) os esforços de promoção devem se concentrar em sustentar essas práticas ao invés de tentar insistir em AME (BAHL e col., 2005).

Após os seis meses, iniciar o consumo de alimentos complementares é recomendável para que todas as necessidades nutricionais de uma criança em franco crescimento sejam adequadamente atendidas. Contudo, manter a amamentação também é importante porque o aporte de cerca de $500 \mathrm{ml}$ diários de leite materno ainda será capaz de fornecer cerca de $75 \%$ das necessidades de energia, $50 \%$ das de proteína e $95 \%$ das de vitamina $A$, além da proteção imunológica (OMS, 2001). 
Em março de 2003, publicou-se um número especial do Food and Nutrition Bulletin com base nos resultados da Consulta Técnica sobre Alimentação Complementar, organizada pela OMS. Esta revista traz importantes contribuições com respeito à atualização de aspectos técnicos, promoção e apoio para melhorar as práticas alimentares, formas de melhorar a disponibilidade de alimentos e de lidar com as tecnologias no âmbito domiciliar. Em um de seus artigos, DEWEY e BROWN (2003) argumentam que as publicações sobre alimentação infantil têm enfatizado a importância de continuar a amamentação após o início da alimentação complementar, porém não costumam discutir como as mães podem manter uma boa produção de leite. Sabe-se que as crianças têm capacidade de auto-regular a ingestão de calorias de acordo com suas necessidades, portanto se receberem a energia necessária de outros alimentos diminuirão a ingestão de leite materno. Nesse sentido, segundo esses autores, é plausível pensar que o grau de substituição do leite materno seja influenciado por fatores como a freqüência e a densidade energética dos alimentos, o horário das mamadas e o modo como são oferecidos os alimentos. Quais seriam, então, possíveis recomendações úteis para uma alimentação apropriada nesta fase da vida? Frente à escassez de dados de pesquisa e a dificuldade de estabelecer qual o número adequado de mamadas em diferentes faixas de idade seria importante recomendar que a mãe amamentasse de acordo com o desejo da criança. Sobre o uso de mamadeiras, além de maior risco de contaminação, de longa data acreditase que estes artefatos têm mais chance de substituir a amamentação do que quando se alimenta com copo ou colher. Nesse sentido, outra recomendação seria evitar o uso de mamadeiras. Uma questão sensível é ensinar o cuidador a observar e responder aos sinais de fome e saciedade da criança, alimentando-a até que recuse o alimento e sem forçá-la a comer. E nos casos em que a grande preferência da criança pela amamentação prejudica o consumo de alimentos complementares seria recomendável que estes fossem dados antes das mamadas (DEWEY e BROWN, 2003). 


\section{AMAMENTAÇÃO NO INÍCIO DA VIDA}

Em anos recentes põe-se novamente em destaque a importância de se iniciar precocemente a amamentação. Estudo realizado em quatro distritos rurais de Gana envolveu 11.316 crianças não gêmeas nascidas entre julho de 2003 a junho de 2004, sobreviventes ao segundo dia após o nascimento e que haviam iniciado a amamentação (EDMOND e col., 2006). Os principais achados apontam que a amamentação precoce pode levar a uma considerável redução na mortalidade neonatal. A mortalidade neonatal por todas as causas poderia ser reduzida em $16,3 \%$ se todas as crianças iniciassem a amamentação no primeiro dia de vida e em $22,3 \%$ se a amamentação ocorresse na primeira hora. Os efeitos da amamentação sobre a redução da mortalidade infantil já são conhecidos há alguns anos, como citado acima, mas este parece ter sido o trabalho pioneiro com relação a discutir a importância da amamentação precoce na prevenção da mortalidade neonatal. Os autores procuram justificar como a amamentação precoce poderia afetar o risco de morrer no período neonatal. Os mecanismos seriam pelo menos os seguintes: 1. as mães que amamentam logo após o parto têm maior chance de serem bem sucedidas na prática da amamentação; 2. os alimentos pré-lácteos, comumente oferecidos aos bebês antes da amamentação, podem ocasionar lesões no intestino imaturo; 3. o colostro acelera a maturação do epitélio intestinal e protege contra agentes patogênicos; 4. o contato pele a pele previne a ocorrência de hipotermia (EDMOND e col., 2006). Alguns destes aspectos são discutidos a seguir com maior aprofundamento.

A preocupação com a hipoglicemia neonatal logo após o parto tem sido responsável por interrupção do AME em muitos hospitais devido ao uso de soro glicosado em recém-nascidos. No entanto, segundo WIGHT (2006) a hipoglicemia parece ser comum entre os mamíferos como um processo 
adaptativo e auto-limitado, na medida em que os níveis de glicose acabam por aumentar espontaneamente em poucas horas. A amamentação precoce e exclusiva atende às necessidades dos recém-nascidos a termo, por isso desaconselha-se o uso de soro glicosado, água ou fórmula infantil que podem interferir no estabelecimento da amamentação e nos mecanismos metabólicos compensatórios do bebê. Recomenda-se que o monitoramento dos níveis glicêmicos seja realizado apenas nos recém-nascidos de risco ou com sintomas clínicos de hipoglicemia, uma vez que os exames de rotina em bebês saudáveis podem interferir negativamente na relação mãe-bebê e na amamentação (WIGHT, 2006).

Crianças nascidas de parto normal domiciliar e amamentadas exclusivamente apresentam uma flora intestinal benéfica, com maior quantidade de bifidobactérias e menos Clostridium dificile e Escherichia coli (PENDERS e col., 2006). De acordo com este estudo, no qual foram examinadas as fezes de 1.032 bebês holandeses de até um mês de idade, os principais fatores determinantes da microflora intestinal no início da vida são o tipo de parto, a alimentação infantil, a idade gestacional, a hospitalização e o uso de antibióticos. Já em 1905, havia registros de diferenças na composição da microflora intestinal de crianças amamentadas em comparação a crianças desmamadas (NEWBURG e col., 2005). A partir da descoberta do fator bifidus, na década de 1970, torna-se cada vez mais conhecido o mecanismo pelo qual ocorre a proteção da mucosa intestinal contra os agentes patogênicos. Sabe-se hoje que vários tipos de oligossacarídeos e glicoconjugados presentes no leite materno, conhecidos como agentes pré-bióticos, estimulam a colonização do intestino por microrganismos benéficos. Esses agentes atuam na primeira etapa essencial da patogênese ao impedir que um microrganismo se fixe na parede celular (NEWBURG e col., 2005).

Algumas práticas durante $\mathrm{o}$ trabalho de parto e logo após 0 nascimento podem facilitar o início da amamentação. Entre elas incluem-se 
a implementação da Iniciativa Hospital Amigo da Criança, o não uso de sedativo particularmente próximo ao final do primeiro estágio do trabalho de parto, a não separação entre mãe e bebê e o contato pele a pele logo após o parto (FORSTER e McLACHLAN, 2007). Nesta revisão, as autoras discutem também a importância de proporcionar cuidados apropriados à mulher, uma vez que experiências estressantes de parto estão associadas a menor sucesso na amamentação e retardo no início do processo de lactação.

Uma revisão sistemática sobre o contato precoce logo após o parto, pele a pele entre mãe e recém-nascido (MOORE e col., 2007) encontrou efeitos positivos sobre a primeira mamada, amamentação de um a quatro meses pós-parto, duração da amamentação, ingurgitamento mamário e reconhecimento do odor do leite materno pelo bebê. Nenhum efeito negativo foi identificado.

O contato precoce entre mãe e recém-nascido, entretanto, parece não receber ainda a devida atenção por parte dos profissionais de saúde responsáveis pela condução da grande maioria dos partos e nascimentos nos dias atuais.

MERCER e col., (2007) realizaram um levantamento das evidências científicas a respeito dos procedimentos comumente utilizados na atenção ao recém-nascido A conclusão é que muitas dessas práticas não têm uma eficácia comprovada e deveriam ser modificadas por interferirem negativamente na relação mãe-bebê. O clampeamento do cordão, por exemplo, de acordo as evidências disponíveis, deveria ser postergado como medida de prevenção da anemia na infância. Os estudos não demonstram benefícios das aspirações rotineiras da boca e nariz ao nascer e estas deveriam ser abolidas em recém-nascidos normais. A aspiração gástrica mostrou ser danosa e não deveria ser utilizada como cuidado de rotina. Até mesmo na manobra de ressuscitação, a tendência é recomendar o uso do ar ambiente em primeiro lugar, deixando o oxigênio a $100 \%$ para os casos de 
não resposta. O contato pele a pele, por sua vez, apresenta-se como um procedimento seguro, barato e apropriado para regulação da temperatura corporal do recém-nascido sadio, além de apresentar benefícios em curto e longo prazos para mães e crianças (MERCER e col., 2007).

Por outro lado, o contato pele a pele desencadeia uma série de eventos hormonais importantes para a relação mãe-bebê. O toque, o odor e o calor estimulam o nervo vago e isto faz com que a mãe libere ocitocina, hormônio responsável, entre outras ações, pela saída e ejeção do leite. Este hormônio faz com que a temperatura das mamas aumente e aqueça o bebê. Por outro lado, a ocitocina reduz a ansiedade materna, aumenta sua tranqüilidade e responsividade social. (MERCER e col., 2007; MOORE e col., 2007; UVNAS-MOBERG, 1998).

Outro aspecto menos destacado nos estudos sobre amamentação é quanto sua prática pode facilitar o desenvolvimento de um forte apego ao cuidador, aspecto fundamental para a sobrevivência daquelas espécies cujo desenvolvimento ocorre em grande parte fora do útero. Os aspectos comportamentais do apego têm sido bastante estudados e, mais recentemente, surgem dados também sobre sua neurobiologia. Embora provenientes de estudos com animais, os achados têm sido úteis para a compreensão cada vez maior da importância desses fenômenos entre os humanos. Em 2005, dois estudiosos avaliaram o circuito neural que possibilita um rápido apego dos filhotes de ratos ao seu cuidador, ação necessária para sua sobrevivência no ninho (MORICEAU e SULLIVAN, 2005). Os achados sugerem que o cérebro neonatal não é uma versão imatura do cérebro adulto; pelo contrário, ele parece ter sido desenhado de uma maneira única para aperfeiçoar o apego ao cuidador.

Outro estudo em que foram acompanhados 174 pares mãe-bebê durante o primeiro ano após o nascimento, conclui que o fator preditivo mais importante para um apego seguro é a qualidade da interação diádica na 
infância (BRITTON e col., 2006). A amamentação não apresentou uma relação direta com o apego seguro, entretanto os dados sugerem que as mães que optam por amamentar aparentam ser mais responsivas aos sinais de suas crianças durante o processo de interação no início da vida. Então, indiretamente a amamentação contribuiria para fomentar um apego seguro. Uma criança que tenha uma representação mental de pais responsivos e disponíveis teria maior probabilidade de apresentar um apego seguro, ao passo que o apego inseguro ocorre quando falta este tipo de representação. A importância disso, é que os pais, para uma criança adequadamente apegada, representam uma base segura a partir da qual poderá explorar o ambiente. A sensibilidade materna também se mostrou associada com a intenção e a duração pretendida de amamentar durante o período pré-natal, dado sugestivo de que essa intenção poderia ser um marcador precoce da posterior sensibilidade da mãe com relação ao bebê (BRITTON e col., 2006).

A teoria do apego, cujo modelo teórico foi desenvolvido por BOWLBY (1984) na década de sessenta, tem sido utilizada até hoje nos estudos avaliativos deste campo. Sua teoria foi considerada revolucionária por introduzir na discussão conceitos relativos à adaptabilidade evolutiva do homem. O apego, que Bowlby diferencia de vínculo, implica em um comportamento no qual a criança busca manter a proximidade com uma figura específica e seu cerne é o estabelecimento do senso de segurança. As bases teóricas elaboradas por esse pesquisador receberam grande contribuição das observações de crianças da tribo Ganda realizadas por Ainsworth (BOWLBY, 1984; BRUM e SCHERMANN, 2004). A qualidade das relações de apego, classificada por Ainsworth em três categorias, seria dependente das interações entre cuidador e criança: 1. bebês apegados de maneira segura à mãe; 2 . bebês esquivos e apegados de maneira ansiosa e 3. bebês resistentes e apegados de maneira ansiosa.

Estudos como estes têm contribuído para o quadro das evidências científicas que reforçam as recomendações feitas em 1989 pela OMS e 
UNICEF, posteriormente incorporadas pela já mencionada Iniciativa Hospital Amigo da Criança (OMS, 2001), que sintetiza 10 passos para uma amamentação bem sucedida, entre os quais: iniciar a amamentação na primeira hora de vida (passo 4), não dar outros líquidos além do leite materno a recém-nascidos (passo 6) e não separar mães e bebês desnecessariamente (passo 7).

\section{IMPLICAÇÕES DA AMAMENTAÇÃO PARA A SAÚDE DA CRIANÇA}

Estimativas recentes quanto a diversas formas de ação e suas conseqüências para a saúde da criança mostraram que a promoção do AME é a intervenção na área da saúde pública que isoladamente tem o maior potencial para diminuir a mortalidade na infância.

Interessante discussão sobre a questão da sobrevivência infantil no mundo e, em particular, nas Américas mostra que existe uma impressão equivocada acerca do controle da mortalidade infantil e a escassez de recursos (VICTORA e BARROS, 2005). Estes autores afirmam que uma possível justificativa para compreender a diminuição nos investimentos financeiros neste setor seria sua destinação para outros problemas de saúde relevantes. No entanto, a cada ano ainda morrem mais de dez milhões de crianças menores de cinco anos no mundo e parece difícil atingir a quarta das oito Metas do Milênio das Nações Unidas, que é reduzir em dois terços a mortalidade de crianças abaixo de cinco anos de 1990 a 2015. Esse fato levou à formação do Grupo de Estudos da Sobrevivência Infantil de Bellagio, que publicou uma série de cinco artigos na revista The Lancet, em 2003 (VICTORA e BARROS, 2005). 
Nas Américas, Brasil e México estão entre os 42 países onde ocorre a maioria dessas mortes. A amamentação e a alimentação complementar estão incluídas entre as 23 intervenções viáveis, efetivas e de baixo custo identificadas por esse grupo de estudiosos (VICTORA e BARROS, 2005).

Em 2005, a revista The Lancet publica outra série de artigos com foco sobre sobrevivência neonatal (VICTORA e BARROS, 2005). Discute-se que, embora as mortes no período neonatal sejam o principal componente da mortalidade infantil hoje em dia, isso tem sido ignorado pelas agências financiadoras. Nesta série, estimou-se que $38 \%$ das mortes de crianças menores de cinco anos ocorrem nas primeiras quatro semanas de vida e 16 possíveis intervenções foram identificadas. A amamentação foi considerada uma intervenção para a qual existem evidências incontestáveis sobre eficácia e que, com base em estudos de efetividade, mostrou ser viável para implementação em larga escala (DARMSTADT e col., 2005).

Com relação às crianças brasileiras, os dados mostram uma clara desvantagem das crianças pobres quanto à cobertura das intervenções de sobrevivência infantil. Além disso, os autores discutem que não basta alcançar uma boa cobertura, uma vez que para serem efetivas as intervenções precisam ser de boa qualidade (VICTORA e BARROS, 2005).

Há evidências de que, tanto nos países em desenvolvimento quanto nos desenvolvidos a amamentação protege as crianças contra infecções dos tratos gastrintestinal e respiratório, sendo maior a proteção quando a criança é amamentada de forma exclusiva e por tempo prolongado (KRAMER e col., 2001).

Os efeitos protetores da amamentação contra infecções do ouvido e pulmão têm-se tornado mais evidentes nos últimos anos. $A$ imunoglobulina $A$ $(\lg A)$ secretora é um anticorpo resultante da resposta da mãe à exposição 
prévia a agentes infecciosos. Ela tem como característica sobreviver nas membranas das mucosas respiratória e gastrintestinal e ser resistente à digestão proteolítica. Além de impedir que agentes patogênicos se fixem nas células da criança amamentada, ela limita os efeitos danosos do processo inflamatório (JACKSON e NAZAR, 2006).

A amamentação exclusiva protege as crianças pequenas de evoluírem para quadros mais graves de infecção respiratória. Estudo de caso-controle aninhado realizado em Pelotas por CESAR e col. (1999) analisou as internações por pneumonia no período pós-neonatal de uma coorte de 5.304 crianças. Crianças não amamentadas apresentaram risco 17 vezes maior de serem internadas por pneumonia do que crianças que recebiam apenas leite materno. A não-amamentação afetou ainda mais as crianças abaixo de 3 meses de idade, cujo risco relativo para internação por pneumonia foi de 61. A amamentação predominante por pelo menos seis meses e a amamentação parcial até um ano de idade podem reduzir também a prevalência de infecções respiratórias na infância. ODDY e col. (2003), em uma coorte prospectiva de 2.602 crianças australianas desde o nascimento, analisaram a relação entre duração do aleitamento materno e doenças respiratórias e infecções durante o primeiro ano de vida. Os autores relatam que a amamentação predominante por pelo menos seis meses mostrou ser fator protetor significativo, reduzindo a freqüência de consultas médicas e internações, particularmente por infecções respiratórias do trato superior e chiado. Interromper a amamentação antes dos 12 meses mostrou ser fator de risco para consultas médicas por doença respiratória.

Sabe-se que a bronquiolite é importante causa de morbidade em crianças pequenas. Na Grécia, pesquisa com 240 crianças abaixo de dois anos internadas por bronquiolite, observou que a amamentação por mais de quatro meses melhora o quadro de gravidade mesmo em crianças de famílias de fumantes (CHATZIMICHAEL e col., 2007). 
Quanto à morbidade por algumas causas especificas, os resultados são controversos. No caso da asma, KUIPER e col. (2007) mostraram que amamentar protegeu crianças oriundas de 221 famílias com história de atopia comparada com 308 de famílias com história negativa. MIHRSHAHI e col. (2007), na Austrália, observaram uma coorte de 516 crianças aos cinco anos, também oriundas de famílias com história de atopia, mas não encontraram associação entre tempo prolongado de amamentação e presença de asma, eczema ou atopia. Existem também diferenças na presença de atopia por sexo da criança e conforme seu pai ou sua mãe tenham sido portadores de asma (MANDHANE e col., 2007). Outro estudo prospectivo de mais de 1.000 crianças belgas seguidas desde a gravidez até 12 meses de vida mostrou que no primeiro ano de vida a amamentação não tem efeito protetor quanto a eczema (SARIACHVILI e col., 2007). KRAMER e col. (2007) afirmam que os resultados têm sido mais consistentes com relação a efeitos benéficos da amamentação para eczema atópico na infância. Com o objetivo de avaliar se amamentação exclusiva e prolongada reduzem o risco de asma e alergia, esses autores realizaram um experimento randomizado com 17.046 crianças bielorrusas, das quais $81,5 \%$ foram acompanhadas até a idade de seis anos e meio. Conclui-se que apesar da ocorrência de um grande aumento na duração e exclusividade da amamentação na população estudada não houve redução no risco de asma, febre do feno ou eczema aos 6 anos e meio de idade (KRAMER e col., 2007).

Há controvérsia também sobre a alimentação artificial como fator de risco para morte súbita. Ao passo que alguns estudos observaram maior prevalência de alimentação artificial entre os casos do que entre os controles, outros não apontaram qualquer diferença. Foi observada uma associação entre amamentação exclusiva e redução da síndrome da morte súbita, após controlar para variáveis de confusão, tais como fumo durante a gravidez, emprego paterno, posição ao dormir e idade da criança (ALM e col., 2002). O papel da amamentação como mecanismo de proteção contra 
morte súbita ainda não foi completamente elucidado. Entre as possíveis explicações estão a menor incidência de infecções, as mamadas freqüentes e o contato mais estreito entre mãe e criança.

Quanto à infecção urinária, avaliou-se um possível efeito protetor da amamentação contra o primeiro episódio acompanhado de febre em crianças suecas menores de seis anos. Os 200 casos de infecção urinária foram comparados a 336 controles pareados por idade e gênero. Observouse um efeito protetor nas crianças que estavam em amamentação exclusiva, assim como uma proteção mesmo em crianças desmamadas até os dois anos de idade (MARILD e col., 2004).

A amamentação também apresenta efeitos benéficos em longo prazo. Uma revisão sistemática com dados obtidos do MEDLINE (1966 a março de 2006) e do Scientific Citation Index Databases concluiu que as evidências disponíveis sugerem que ela oferece benefícios (HORTA e col., 2007). Os resultados mostraram que crianças amamentadas apresentaram médias mais baixas de pressão sanguínea e de colesterol total e melhor desempenho em testes de inteligência. As prevalências de sobrepeso/obesidade e diabetes tipo 2 também foram menores.

\section{IMPLICAÇÕES DA AMAMENTAÇÃO PARA A SAÚDE DA MULHER}

As implicações da amamentação para a saúde materna ainda precisam ser mais amplamente estudadas. Diversos estudos publicados recentemente eliminam a controvérsia sobre a diminuição do risco de câncer de mama entre as mulheres que amamentaram por tempo mais longo. 
Revisão da literatura foi publicada no Brasil por REA (2004) e novos estudos têm sido apresentados em países, culturas e etnias diversas.

Sobre a proteção contra câncer de mama, recentemente foram avaliados 256 casos comparados a 536 controles em Israel por SHEMA e col. (2007); os resultados mostraram que mulheres judias com duração mais curta de amamentação, início tardio da primeira mamada e percepção de "leite insuficiente" mostraram maiores riscos de desenvolver câncer de mama. Entre coreanas, estudo de 753 casos de câncer de mama e igual número de controles observou um efeito protetor dose-dependente, em que 11-12 meses de amamentação reduziu em 54\% o risco comparado a 1-4 meses (KIM e col., 2007). Uma revisão de 47 estudos realizados em 30 países envolvendo cerca de 50 mil mulheres com câncer de mama e 97 mil controles (CGHFBC, 2002) sugere que o aleitamento materno pode ser responsável por dois terços da redução estimada no câncer de mama. A amamentação foi tanto mais protetora quanto mais prolongada: o risco relativo de ter câncer decresceu 4,3\% a cada 12 meses de duração da amamentação, independentemente da origem das mulheres (países desenvolvidos versus não-desenvolvidos), idade, etnia, presença ou não de menopausa e número de filhos. Estimou-se que a incidência de cânceres de mama nos países desenvolvidos seria reduzida a mais da metade (de 6,3 para $2,7 \%$ ) se as mulheres amamentassem por mais tempo.

Por outro lado, ter sido amamentada quando bebê também mostrou relação com a incidência de câncer de mama na idade adulta. Análise de uma coorte de 4.999 sujeitos iniciada nos anos 30 e uma extensa metanálise de outros estudos concluiu que ter sido amamentada está relacionado a menor risco de câncer na pré-menopausa (MARTIN e col., 2005).

Estudo caso-controle realizado em hospital japonês envolvendo 155 mulheres com câncer do endométrio e 96 controles encontrou um maior risco desse câncer entre as multíparas que nunca haviam amamentado. Os 
autores referem que o aumento verificado nos casos de câncer de endométrio pode estar relacionado à diminuição da prática de amamentar e da paridade de mulheres no Japão (OKAMURA e col., 2006).

Indaga-se sobre o efeito da amamentação no menor risco de morte por artrite reumatóide. Há controvérsia também acerca da proteção contra certos tipos de fraturas ósseas, especialmente coxofemorais, pois há indícios de que mulheres que amamentam apresentam menos osteoporose e menos fraturas (REA, 2004).

Muitos trabalhos foram publicados mostrando como a amamentação se relaciona à amenorréia pós-parto e ao maior espaçamento intergestacional. Outros benefícios para a mulher que amamenta são o retorno ao peso pré-gestacional mais precocemente e o menor sangramento uterino pós-parto (conseqüentemente, menos anemia), devido à involução uterina mais rápida (REA, 2004).

A relação entre duração da amamentação e diminuição do peso pósparto foi demonstrada em estudo brasileiro com 405 mulheres em que a cada mês a mais de amamentação houve uma média de redução de 0,44 kg no peso da mãe (KAC e col., 2004).

\section{EFETIVIDADE DAS AÇÕES PRÓ-AMAMENTAÇÃO}

Estudos realizados em diferentes países consideram a Iniciativa Hospital Amigo da Criança (IHAC) uma ação extremamente efetiva, que leva ao incremento na prevalência e duração da amamentação exclusiva e total (KRAMER e col., 2001; LUTTER e col., 1997; MERTEN e col., 2005). Na 
Suíça, o incremento nas taxas de amamentação que o país tem vivenciado desde 1994 deve-se em parte ao número crescente de Hospitais Amigos da Criança. Os serviços utilizam o título de Amigo da Criança como forma de se promover $\mathrm{e}$ isto têm influenciado as mulheres que desejam amamentar sobre a escolha do local para dar à luz (MERTEN e col., 2005).

Avaliação sobre experiências dos países com a implementação das metas da Declaração de Innocenti mostrou que propostas como os Dez Passos são facilmente compreendidas e aceitas, porém sua sustentabilidade parece mais efetiva quando vinculada a uma abordagem que inclui política, legislação, reforma do sistema de saúde e intervenções na comunidade (UNICEF, 2005). Os desafios para a implementação da IHAC elencados por essa avaliação incluem: grande rotatividade de profissionais da saúde; estratégias para controle e manutenção do padrão de qualidade dos hospitais credenciados; sua inclusão no orçamento dos governos; adequado investimento no apoio à mãe após a alta da maternidade; clareza sobre como lidar com as mulheres HIV positivo; aperfeiçoamento da atenção à mulher durante o trabalho de parto e o parto e integração com outras iniciativas em apoio às Metas do Milênio para o Desenvolvimento (UNICEF, 2005).

A sustentabilidade da IHAC foi avaliada no Brasil por ARAÚJO e col. (2003). Na análise dos questionários de 137 Hospitais Amigos da Criança observou-se que $92 \%$ cumpriram todos os dez passos. Os passos 1, 3, 6, 7, 8 e 9 apresentaram mais de $98 \%$ de cumprimento. O passo 5 foi o menos cumprido. Comparando-se as regiões do país, observou-se que no Nordeste, Sul e Sudeste $90 \%$ dos hospitais foram aprovados em todos os dez passos. Na região Norte apenas $50 \%$ dos hospitais os cumpriram integralmente.

Revisão sistemática de 59 estudos foi realizada com o objetivo de avaliar as evidências sobre programas efetivos para aumentar o número de 
mulheres que iniciam a amamentação (FAIRBANK e col., 2000). Estes foram agrupados segundo os temas educação em saúde; iniciativas gerais do setor saúde; Iniciativa Hospital Amigo da Criança; capacitação de profissionais da saúde; programa de suplementação nutricional; apoio social de profissionais da saúde; apoio de pares; campanhas em meios de comunicação e outras intervenções. Atividade em grupos pequenos durante o pré-natal, educação face a face, apoio de pares antes e após o parto mostraram efetividade como intervenções isoladas. Pacotes de intervenção que incluem apoio de pares e/ou campanhas em meios de comunicação associados a mudanças estruturais do setor saúde e/ou atividades educativas também se mostraram efetivos. Com relação aos serviços de saúde, mostraram-se relevantes as mudanças estruturais nas práticas de promoção do aleitamento materno nos hospitais, sendo o alojamento conjunto uma ação-chave (FAIRBANK e col., 2000).

A efetividade do aconselhamento e de outras intervenções para melhorar a prática da amamentação foi avaliada por meio de revisão sistemática que incluiu apenas experimentos randomizados controlados e estudos de coorte provenientes de países desenvolvidos (GUISE e col., 2003). A busca foi direcionada para estudos que envolvessem aconselhamento ou intervenção comportamental aplicados em consultórios ou hospitais, excluindo-se, portanto, aqueles de origem comunitária ou de grupos de apoio mãe a mãe. Após levantamento em cinco importantes bancos de dados, 1.048 resumos foram selecionados e destes, restaram para análise 22 experimentos randomizados controlados, 8 nãoexperimentos e 5 revisões sistemáticas. Dois estudos foram considerados de boa qualidade, 12 regulares e 16 ruins. Os resultados indicaram que, de maneira geral, as intervenções parecem apresentar maiores efeitos em populações com baixos índices de amamentação como ponto de partida e que contribuíram para a melhoria das taxas de início e de continuidade da amamentação, porém com pouco efeito sobre duração prolongada. 
BRITTON e col. (2007) em revisão sistemática de 34 estudos concluíram que o apoio de profissionais é efetivo para prolongar a duração da amamentação, mas o mesmo não se pode afirmar para amamentação exclusiva. O apoio de pessoas leigas mostrou-se efetivo em aumentar a duração da amamentação exclusiva. Além disso, os cursos da OMS e UNICEF parecem ser efetivos para a capacitação de profissionais.

Importante estudo brasileiro sobre os efeitos de profissionais capacitados sobre as práticas de aleitamento materno de mulheres em quatro cidades de Pernambuco foi publicado no The Lancet (COUTINHO e col., 2005). Uma fase pré-intervenção incluiu 318 mulheres que foram acompanhadas durante seis meses. Na segunda etapa, um ensaio randomizado, acompanhou 350 mães que deram a luz em dois hospitais cujas equipes haviam sido capacitadas por meio do curso de 18 horas da IHAC. Metade dessas mulheres foi sorteada para receber visitas domiciliares de promoção e apoio da amamentação enquanto a outra metade não recebeu as visitas. Desta maneira, pode-se observar se profissionais capacitados nos hospitais ou profissionais capacitados mais visitas domiciliares tinham efeitos similares sobre as taxas de amamentação exclusiva. Os resultados mostraram que o treinamento das equipes dos hospitais levou a uma taxa de $70 \%$ de amamentação exclusiva intrahospitalar. Entretanto, isso não se sustentou após a volta para casa, quando apenas $30 \%$ das crianças amamentavam exclusivamente aos 10 dias de vida. Daí, os autores concluírem sobre a necessidade de combinar ações em prol da amamentação também em nível comunitário.

Outro estudo brasileiro conduzido por OLIVEIRA e col. (2005) avaliou uma política de promoção, proteção e apoio ao aleitamento materno desenvolvida em Unidades Básicas de Saúde (UBS). Essa política conhecida como Iniciativa Unidade Básica Amiga da Amamentação (IUBAAM), organizada em dez passos à semelhança da IHAC, foi lançada pela Secretaria Estadual de Saúde do Rio de Janeiro em 1999. Na avaliação 
realizada em 24 UBS de nove municípios, 13 unidades apresentavam desempenho regular e 11 desempenho fraco. Constatou-se que 47,9\% das mães já forneciam água, chá, suco ou outros alimentos a seus bebês no primeiro mês de vida. Contudo, a prevalência da amamentação exclusiva foi maior no bloco de UBS com desempenho regular. Os autores concluem que a implementação deste tipo de iniciativa pode contribuir para o aumento da prevalência da amamentação exclusiva no país, além de possivelmente melhorar a relação custo-efetividade das ações de promoção do aleitamento materno.

Sobre a prática de distribuir brindes para as mães ao deixar a maternidade são citados cinco estudos (GUISE e col., 2003), entre os quais uma revisão sistemática de 9 experimentos randomizados cuja conclusão foi que o recebimento de brindes contendo amostras ou cupons de fórmula infantil leva à redução da prática de amamentação exclusiva. Por isso, é de fundamental relevância a implementação das recomendações do Código Internacional, das resoluções subseqüentes e das legislações nacionais de proteção do aleitamento materno.

A influência da promoção comercial sobre as práticas de alimentação infantil e suas conseqüências sobre o desmame precoce, a desnutrição e a mortalidade infantil foram bastante discutidas nas décadas de 1960 e 1970. Em conseqüência disso, a OMS e o UNICEF (1979) realizaram a Reunião Conjunta sobre Alimentação do Lactente e da Criança Pequena em Genebra. Ao final da reunião, recomendou-se a criação de um conjunto de normas, fundamentadas em princípios éticos, para nortear a promoção comercial de substitutos do leite materno. Então em 1981, a Assembléia Mundial da Saúde aprova o Código Internacional de Comercialização de Substitutos do Leite Materno (WHO e UNICEF, 1981).

Até 2005, 64 países haviam adotado medidas para a implementação do Código. O Brasil o adotou como norma em 1988, abrangendo 
praticamente todas as suas disposições (SOKOL, 2005). Uma análise dos avanços de nosso código, a Norma Brasileira de Comercialização de Alimentos para Lactentes e Crianças de Primeira Infância, Bicos, Chupetas e Mamadeiras (NBCAL), foi realizada por ARAÚJO e col. (2006). Esta norma passou por duas revisões e atualmente é regida pela Lei 11.265 (BRASIL, 2006).

A implementação da NBCAL tem sido analisada como um empreendimento bem sucedido no Brasil em comparação com outros países, talvez por uma combinação de legislação abrangente, monitoramento regular e participação de grupos organizados (SOKOL, 2005). A International Baby Food Action Network (IBFAN), uma rede mundial de ativistas em defesa do direito de amamentar criada em 1979 com a finalidade de acompanhar a implementação do Código, desde então monitora as práticas de marketing relacionadas a produtos que competem com a amamentação. No Brasil, os resultados do monitoramento mais recente realizado em 8 cidades de 4 estados, cujos dados foram coletados por pessoas capacitadas para a utilização de instrumentos padronizados (DE DIVITIIS e col., 2006), dão conta de que houve avanços porém persistem infrações à NBCAL na rotulagem dos produtos, na promoção comercial e nas informações disponíveis nas páginas eletrônicas.

\section{CONCLUSÃO}

O conjunto de estudos apresentados neste artigo reforça a já difundida idéia na comunidade cientifica de que se acumulam as evidências sobre os benefícios da amamentação, tanto para a criança como para a mulher. 
Verifica-se também o crescente interesse acerca da necessidade e das conseqüências do tipo de cuidado dispensado à criança no início da vida.

Estudos de impacto sobre como implementar esta prática, no entanto, são ainda escassos. Uma das razões pode ser a dificuldade de não se conseguir isolar e estudar um único fato (ou intervenção), devido à interrelação de fatores ambientais e sócio-culturais que atuam na prática de amamentar, mesclando políticas públicas, benefícios, rotinas, ações de profissionais, apoio de pares, etc. De toda a maneira, permanece o desafio aos acadêmicos e profissionais de saúde pública, já que intervenções nesta área devem observar prioridades de custo e efetividade.

\section{REFERÊNCIAS}

Alm B, Wennergren G, Norvenius SG, Skjærven R, Lagercrantz H, HelwegLarsen K, Irgens LM, On Behalf Of The Nordic Epidemiological Sids Study. Breast feeding and the sudden infant death syndrome in Scandinavia, 199295. Arch Dis Child. 2002;86:400-2.

Araújo MFM, Otto AFN, Schmitz BAS. Primeira avaliação do cumprimento dos "Dez Passos para o Sucesso do Aleitamento Materno" nos Hospitais Amigos da Criança do Brasil. Rev Bras Saúde Matern Infant. 2003;3(4):4119.

Araújo MFM, Rea MF, Pinheira KA, Schmitz BAS. Avanços na Norma brasileira de comercialização de alimentos para idade infantil. Rev Saúde Pública. 2006;40(3):513-20.

Bahl R, Frost C, Kirkwood BR, Edmond K, Martines J, Bhandari N, Arthur P. Infant feeding patterns and risks of death and hospitalization in the first half of infancy: multicentre cohort study . Bull World Health Organ. 2005;83(6):418-26. 
Bowlby J. Apego: volume 1 da Trilogia Apego e perda. São Paulo: Editora Martins Fontes, 1984.

Brasil. Lei n. 11.265, de 3 de janeiro de 2006. Regulamenta a comercialização de alimentos para lactentes e crianças de primeira infância e também a de produtos de puericultura correlatos. Diário Oficial da União, Brasília, ano CXLIII n. 3, 4 jan. 2006. Seção 1.

Britton JR, Britton HL, Gronwaldt V. Breastfeeding, sensitivity, and attachment. Pediatrics. 2006;118:e1436-43 (acesso em 1 novembro 2006). Disponível em: http:// www.pediatrics.aappublications.org/cgi/content/abstract/118/5/e1436

Britton C, McCormick FM, Renfrew MJ, Wade A, King SE. Support for breastfeeding mothers. (Cochrane Review). In: The Cochrane Library, Issue 4, 2007. Oxford: Update Software (acesso em 23 janeiro 2008). Disponível em:

http://cochrane.bvsalud.org/cochrane/main.php?lib=COC\&searchExp=suppor $\mathrm{t} \% 20$ and $\% 20$ for\%20and\%20breastfeeding $\% 20$ and $\% 20$ mothers\&lang=pt

Brum EHM, Schermann L. Vínculos iniciais e desenvolvimento infantil: abordagem teórica em situação de nascimento de risco. Ciênc Saúde Coletiva. 2004;9(2):457-67.

Cesar JA, Victora CG, Barros FC, Santos IS, Flores JA. Impact of breast feeding on admission for pneumonia during postneonatal period in Brazil: nested case-control study. Br Med J. 1999;318:1316-20.

Chatzimichael A, Tsalkidis A, Cassimos D, Gardikis S, Tripsianis G, Deftereos S, Ktenidou-Kartali S, Tsanakas I. The role of breastfeeding and passive smoking on the development of severe bronchiolitis in infants. Minerva Pediatr. 2007;59(3):199-206.

CGHFBC - Collaborative Group on Hormonal Factors in Breast Cancer. Breast cancer and breastfeeding: collaborative reanalysis of individual data from 47 epidemiological studies in 30 countries, including 50302 women with breast cancer and 96973 women without the disease. Lancet. 2002;360:18795.

Coutinho SB, de Lira PIC, Lima MC, Ashworth A. Comparison of the effect of two systems for the promotion of exclusive breastfeeding. Lancet. 2005;366:1094-100.

Darmstadt GL, Bhutta ZA, Cousens S, Adam T, Walker N, De Bernis L, for the Lancet Neonatal Survival Steering Team. Evidence-based, cost-effective 
intervention: how many newborn babies can we save? Lancet. 2005;365:977-88.

De Divitiis R, Salve J, Toma TS. Monitoramento 2006 [resumo na internet]. São Paulo: IBFAN Brasil; 2006 (acesso em 15 agosto 2007). Disponível em: http://www.ibfan.org.br/monitoramento

De Onis M, Garza C, Onyango AW, Martorell R. WHO child growth standards. Acta Paediatr. 2006;95(450 Supl):5-6.

De Onis M, Victora CG. Gráficos de crescimento para bebês alimentados com leite materno. J Pediatr. (Rio J). 2004;80(2):85-7.

Dewey KG, Brown $\mathrm{KH}$. Update on technical issues concerning complementary feeding of young children in developing countries and implications for intervention programs. Food Nutr Bull. 2003;24(1):5-28.

Edmond KM, Zandoh C, Quigley MA, Amenga-Etego S, Owusu-Agyei S, Kirkwood BR. Delayed breastfeeding initiation increases risk of neonatal mortality. Pediatrics. 2006;117:380-6.

Fairbank L, O’Meara S, Renfrew MJ, Woolridge M, Sowden AJ, Lister-Sharp D. A systematic review to evaluate the effectiveness of interventions to promote the initiation of breastfeeding: executive summary. Health Technol Assess. 2000;4(25) (acesso em 06 março 2006). Disponível em: http://www.ncchta.org/execsumm/summ425.htm

Forster DA, McLachlan HL. Breastfeeding initiation and birth setting practices: a review of the literature. J Midwifery Womens Health. 2007;52(3):273-80 (acesso em 04 agosto 2007). Disponível em: http://www.medscape.com/viewarticle/558119

Guise JM, Palda V, Westhoff C, Chan BKS, Helfand M, Lieu TA. The effectiveness of primary care-based interventions to promote breastfeeding: evidence review and meta-analysis for the U.S. Preventive Services Task Force. Ann Fam Med. 2003;1:70-80.

Horta BL, Bahl R, Martines JC, Victora CG. Evidence on the long-term effects of breastfeeding: systematic reviews and meta-analyses. Geneva: World Health Organization, 2007 (acesso em 1 junho 2007). Disponível em: http:// www.who.int/child-adolescenthealth/New_Publications/NUTRITION/ISBN_92_4_159523_0.pdf

Jackson $\mathrm{K} \mathrm{M}$, Nazar A. M. Breastfeeding, the immune response, and longterm health. J Am Osteopath Assoc. 2006;106:203-7 (acesso em 10 maio 2007). Disponível em http://www.jaoa.org/cgi/content/abstract/106/4/203 
Kac G, Benicio MHD, Melendez GV, Valente JG, Struchiner CJ. Breastfeeding and postpartum weight retention in a cohort of Brazilian women. Am J Clin Nutr. 2004;79(3):487-93.

Kim Y, Choi JY, Lee KM, Park SK, Ahn SH, Noh DY, Hong YC, Kang D, Yoo $\mathrm{KY}$. Dose-dependent protective effect of breast-feeding against breast cancer among ever-lactated women in Korea. Eur J Cancer Prev. 2007;16(2):124-9.

Kramer MS, Chalmers B, Hodnett ED, Sevkovskaya Z, Dzikovich I, Shapiro $S$, for The Probit Study Group. Promotion of Breastfeeding Intervention Trial (Probit): a randomized trial in the Republic of Belarus. J Am Med Assoc. 2001;285(4):413-20.

Kramer MS, Kakuma R. The optimal duration of exclusive breastfeeding: a systematic review. Adv Exp Med Biol. 2004;554:63-77.

Kramer MS, Matush L, Vanilovich I, Platt R, Bogdanovich N, Sevkovskaya Z, Dzikovich I, Shishko G, Mazer B and the Promotion of Breastfeeding Intervention Trial (Probit) Study Group. Effect of prolonged and exclusive breast feeding on risk of allergy and asthma: cluster randomized trial. Br Med J. 2007;335:815 (acesso em 17 janeiro 2008). Disponível em http://www.bmj.com/cgi/content/full/335/7624/815\#BIBL

Kuiper S, Muris JW, Dompeling E, Kester AD, Wesseling G, Knottnerus JA, van Schayck CP. Interactive effect of family history and environmental factors on respiratory tract-related morbidity in infancy. J Allergy Clin Immunol. 2007;120(2):388-95.

Labbok MH, Wardlaw T, Blanc A, Clark D, Terreri N. Trends in exclusive breastfeeding: findings from the 1990s. J Hum Lact. 2006;22(3):272-6.

Lutter CK, Perez-Escamilla R, Segall A, Sanghvi T, Teruya K, Wickham T. The effectiveness of a hospital-based program to promote exclusive breastfeeding among low-income women in Brazil. Am J Public Health. 1997;87:659-63.

Mandhane PJ, Greene JM, Sears MR. Interactions between breast-feeding, specific parental atopy, and sex on development of asthma and atopy. J Allergy Clin Immunol. 2007;119(6):1359-66.

Marild S, Hansson S, Jodal U, Odén A, Svedberg K. Protective effect of breastfeeding against urinary tract infection. Acta Paediatr. 2004;93:164-8.

Martin RM, Middleton N, Gunnell D, Owen CG, Smith GD. Breastfeeding and cancer: The Boyd Orr Cohort and a Systematic Review with Meta-analysis. J Natl Cancer Inst. 2005;97(19):1446-57. 
Mercer JS, Erickson-Owens DA, Graves B, Haley MM. Evidence-based practices for the fetal to newborn transition. J Midwifery Womens Health. 2007;52(3):262-72 (acesso em 4 agosto 2007). Disponível em: http://www.medscape.com/viewarticle/558124

Merten S, Dratva J, Ackermann-Liebrich U. Do baby-friendly hospitals influence breastfeeding duration on a national level? Pediatrics. 2005;116(5):702-8.

Mihrshahi S, Ampon R, Webb K, Almqvist C, Kemp AS, Hector D, Marks GB; CAPS Team. The association between infant feeding practices and subsequent atopy among children with a family history of asthma. Clin Exp Allergy. 2007;37(5):671-9.

Moore E, Anderson GC, Bergman N. Early skin-to-skin contact for mothers and their healthy newborn infants (Cochrane Review). In: The Cochrane Library, Issue 4, 2007. Oxford: Update Software (acesso em 23 janeiro 2008). Disponível em: http://cochrane.bvsalud.org/cochrane/main.php?lib=COC\&searchExp=suppor t\%20and\%20for\%20and\%20breastfeeding\%20and\%20mothers\&lang=pt

Moriceau S, Sullivan RM. Neurobiology of infant attachment. NIH Public Access. Author Manuscript (acesso em 23 julho 2007). Disponível em: http://www.pubmedcentral.nih.gov/a. Fcgi?Artid=1868528

Newburg DS, Ruiz-Palacios GM, Morrow A. L. Human milk glycans protect infants against enteric pathogens. Annu Rev Nutr. 2005;25:37-58.

Oddy WH, Sly PD, de Klerk NH, Landau LI, Kendall GE, Holt PG et al. Breast feeding and respiratory morbidity in infancy: a birth cohort study. Arch Dis Child. 2003;88:224-8.

Okamura C, Tsubono Y, Ito K, Niikura H, Takano T, Nagase S et al. Lactation and risk of endometrial cancer in Japan: a case-control study. Tohoku J Exp Med. 2006;208:109-15.

Oliveira MIC, Camacho LAB, Souza IEO. Promoção, proteção e apoio à amamentação na atenção primária à saúde no Estado do Rio de Janeiro, Brasil: uma política de saúde pública baseada em evidências. Cad Saúde Pública. 2005;21(6):1901-10.

OMS - Organização Mundial da Saúde. Estratégia global para a alimentação de lactentes e crianças de primeira infância. São Paulo: IBFAN Brasil, 2005 (acesso em 11 agosto 2007). Disponível em: http://www.ibfan.org.br/documentos. 
OMS - Organização Mundial da Saúde. Evidências científicas dos dez passos para o sucesso no aleitamento materno. Brasília: Organização PanAmericana da Saúde, 2001.

OMS e UNICEF - Organização Mundial da Saúde, Fundo das Nações Unidas para a Infância. Reunião Conjunta OMS/Unicef sobre a Alimentação de Lactentes e Crianças Pequenas: declaração e recomendações. Genebra: OMS, 1979.

Penders J, Thijs C, Vink C, Stelma FF, Snijders B, Kummeling I, et al. Factors influencing the composition of the intestinal microbiota in early infancy. Pediatrics. 2006;118;511-21.

Popkin BM, Adair L, Akin JS, Black R, Briscoe J, Flieger W. Breast-feeding and diarrhoeal morbidity. Pediatrics. 1990; 86(6):874-82.

Rea MF. Os Benefícios da amamentação para a saúde da mulher. J Pediatr. (Rio J). 2004;80(5):S142-S146.

Sariachvili $M$, Droste J, Dom S, Wieringa $M$, Vellinga $A$, Hagendorens $M$, Bridts C, Schayck CP. Is breast feeding a risk factor for eczema during the first year of life? Pediatr Allergy Immunol. 2007;18(5):370-1 (acesso em 10 julho 2007). Disponível em: http://www.blackwellsynergy.com/doi/abs/10.1111/j.1399-3038.2007.00618.x [Epub ahead of print]

Seal A, Kerac M. Operational implications of using 2006 World Health Organization growth standards in nutrition programmes: secondary data analysis. Br Med J. 2007;334;733-8.

Shema L, Ore L, Ben-Shachar M, Haj M, Linn S. The association between breastfeeding and breast cancer occurrence among Israeli Jewish women: a case control study. J Cancer Res Clin Oncol. 2007;133(8):539-46 (acesso em 10 de julho de 2007). Disponível em: http://www.citeulike.org/article/1533939 [Epub ahead of print]

Sokol EJ. The Code handbook: a guide to implementing the International Code of Marketing of Breastmilk Substitutes. 2. ed. Den Haag: ICDC, 2005.

UNICEF - The United Nations Children's Fund. Celebrating the Innocenti Declaration on the Protection, Promotion and Support of Breastfeeding: past achievements, present challenges and the way forward for infant and young child feeding. Florencia: UNICEF Innocenti Research Centre, 2005.

Uvnas-Moberg K. Oxytocin may mediate the benefits of positive social interactions and emotions. Psychoneuroendocrinology. 1998;23:819-35. 
Victora C, Barros FC. A questão da sobrevivência infantil no mundo e sua relevância para as Américas. Cadernos ESP. 2005;1(1) (acesso em 6 agosto 2007).

Disponível

em:

http://www.esp.ce.gov.br/images/documentos/cad_esp_vol01_n01.pdf

Victora CG, Smith PG, Vaughan JP, Nobre LC, Lombardi C, Teixeira AM, et al. Evidence for protection by breast-feeding against infant deaths from infectious diseases in Brazil. Lancet. 1987;2:319-22.

Wight NE. Hypoglycemia in breastfed neonates. Breastfeed Med. 2006;1(4):253-62.

WHO e UNICEF - World Health Organization and The United Nations Children's Fund. The International Code of Marketing of Breast-Milk Substitutes. Geneva: WHO, 1981. 
ARTIGO 2:

FATORES ASSOCIADOS COM A AMAMENTAÇÃO PLENA DE CRIANÇAS ASSISTIDAS PELO PROGRAMA SAÚDE DA FAMÍLIA: UMA ANÁLISE HIERARQUIZADA.

FACTORS ASSOCIATED TO FULL BREASTFEEDING AMONG CHILDREN CARED BY BRAZILIAN FAMILY HEALTH PROGRAM (PSF): A HIERARCHICAL ANALYSIS. 


\section{RESUMO}

Introdução: A amamentação plena (amamentação exclusiva - AME mais predominante - AP) protege as crianças contra infecções e internações hospitalares. Por isso, é importante conhecer os fatores que a determinam em diferentes comunidades. Objetivo: Estudar fatores associados à amamentação plena entre crianças assistidas pelo Programa Saúde da Família (PSF). Método: Realizou-se um estudo transversal em dois municípios do Estado de São Paulo com serviços de saúde semelhantes. Os dados foram obtidos por meio de entrevistas domiciliares com 241 mães de crianças de 0 a 6 meses de idade. A análise de regressão logística múltipla hierarquizada trabalhou com sete níveis, contendo variáveis sócioeconômicas, trabalho da mãe, composição da família, estrutura dos serviços de saúde, ação dos profissionais e comportamento da mãe e da criança. Resultados: Cerca de metade das mães praticam a amamentação plena $(\mathrm{AME}+\mathrm{AP})$ nos primeiros 6 meses. $A$ análise de regressão múltipla entre $o$ conjunto de variáveis explanatórias e o desfecho "amamentação plena" mostrou uma associação significante com: morar com o companheiro $(p=0,004)$, não ter tido dificuldade para amamentar $(p=0,001)$, deixar a criança largar o peito quando satisfeita $(p=0,000)$ e dar notas mais baixas às consultas nas unidades básicas de saúde $(p=0,001)$. Conclusão: $A$ amamentação plena é praticada por cerca de metade das mães. São escassos os estudos que utilizam como desfecho "amamentação plena de crianças na faixa de idade até os seis meses", o que dificulta a comparabilidade dos resultados.

Descritores: amamentação plena, fatores determinantes, estudo transversal, análise de regressão logística múltipla hierarquizada 


\section{ABSTRACT}

Background: Full breastfeeding (exclusive - EBF plus predominant breastfeeding - PBF) protects infants against infections and hospitalization as well. Therefore, it is important to know its determinants. Objective: To study associated factors to full breastfeeding among children assisted by Brazilian Family Health Program (PSF). Method: Cross-sectional survey performed in two similar towns of the state of São Paulo. Data refer to home interviews of 241 mothers of 0-6 month old infants. The analysis has been carried out through hierarchical logistic multiple regression containing seven levels of variables: socioeconomics, mother's work, family composition, health services structure, health workers action, mother and baby behaviors. Results: Full breastfeeding rate (EBF + PBF) is practiced by mothers till the $6^{\text {th }}$ month. The multiple regression analysis of whole explanatory variables and the outcome "full breastfeeding" has shown a statistical significant association to: presence of the partner $(p=0.004)$, no breastfeeding difficulties $(p=0.001)$, spontaneous release of the breast when baby is satisfied $(p=0.000)$, and mothers giving lower scores to health basic units' consultations $(p=0.001)$. Conclusion: Full breastfeeding is practiced by around $50 \%$ of the mothers of infants during first 6 months. Studies using the outcome "full breastfeeding during first 6 months" is rare, so this difficult to compare results.

Key-words: Full breastfeeding, determinant factors, transversal survey, hierarchical regression analysis. 


\section{INTRODUÇÃO}

O padrão ideal de alimentação da criança pequena foi foco de ampla discussão coordenada pela Organização Mundial da Saúde no início deste século. Com base em evidências científicas e epidemiológicas, assim como na análise das realizações passadas e em andamento, chegou-se à elaboração da Estratégia Global para a Alimentação de Lactentes e Crianças de Primeira Infância (OMS, 2005). A Estratégia Global recomenda como medida de saúde pública que se propiciem condições para que todas as crianças sejam amamentadas exclusivamente nos seis primeiros meses de vida e, que após esse período, continuem a ser amamentadas e recebam alimentos complementares seguros e adequados do ponto de vista nutricional.

Uma revisão das pesquisas de âmbito nacional de 94 países mostrou ser baixo o cumprimento a essas recomendações nos países em desenvolvimento (LAUER e col., 2004). A prevalência de amamentação exclusiva entre as crianças menores de seis meses foi de $39 \%$ e a prevalência de amamentação continuada foi de $86 \%$ e $68 \%$, respectivamente para crianças de 6-11 meses e 12-23 meses. Os autores discutem a importância de dar atenção a esses achados e monitorar sua tendência, mas alertam que os dados parecem apresentar um viés sistemático para cima, particularmente com relação ao aleitamento materno exclusivo.

No Brasil, constata-se que as ações adotadas pelo governo e outras organizações levaram a um aumento na duração da amamentação e amamentação exclusiva, porém os índices encontram-se muito aquém do esperado (REA, 2003). Dados de pesquisa realizada pelo Ministério da Saúde (MS, 2001) nas capitais brasileiras e no Distrito Federal em 1999 
mostraram uma prevalência de amamentação de $88 \%$ no primeiro mês de vida e de $44 \%$ no final do primeiro ano. A amamentação exclusiva mostrou ser evento raro nos grandes centros urbanos, apresentando uma prevalência de $53 \%$ no primeiro mês, mas caindo a $10 \%$ no sexto mês de vida.

Considerando-se esse padrão de alimentação infantil dos países em desenvolvimento, LUTTER (2000) argumenta que para alcançar o máximo impacto sobre a saúde os esforços deveriam ser direcionados para a compreensão do comportamento da amamentação exclusiva. A importância da amamentação exclusiva na prevenção das mortes infantis por diarréia e o risco aumentado pela simples introdução de outros líquidos na dieta de crianças pequenas foi discutida por VICTORA e col. (1987). Em revisão sistemática que serviu de base para a atual recomendação de amamentação exclusiva, KRAMER e KAKUMA (2004) relataram que crianças amamentadas exclusivamente por seis meses apresentavam menor morbidade por doença gastrointestinal em comparação a crianças alimentadas com leite materno mais outro leite.

No Estado de São Paulo, VENANCIO e col. (2002) analisaram a situação do aleitamento materno de 33.735 crianças menores de um ano, a partir de dados coletados em 84 municípios durante campanhas de imunização. Verificou-se que apenas $32 \%$ dos municípios apresentam uma prevalência de amamentação exclusiva nos primeiros quatro meses superior a $20 \%$, ao passo que para amamentação predominante essa mesma prevalência foi encontrada em $85,7 \%$ dos municípios. Essa baixa prevalência da amamentação exclusiva impõe dificuldades para a exploração de seus fatores determinantes nos estudos transversais cuja amostra não seja robusta o suficiente.

Estudo multicêntrico envolvendo 9424 crianças ganenses, indianas e peruanas (BAHL e col., 2005) encontrou risco semelhante de mortalidade infantil para crianças amamentadas de forma exclusiva ou predominante, 
enquanto crianças alimentadas parcial ou totalmente com leites artificiais apresentaram maior risco de morte. Os autores ponderam que naqueles locais em que a prática de amamentação predominante é elevada os esforços deveriam ser concentrados em promover a manutenção deste padrão ao invés de tentar mudá-lo para amamentação exclusiva. $\mathrm{Na}$ Espanha, estudo de seguimento de 1.385 crianças (PARICIO TALAYERO e col., 2006) mostrou que a amamentação plena poderia reduzir o número de internações por doenças infecciosas entre as crianças menores de um ano. Estimou-se uma prevenção de $56 \%$ das internações caso todas as crianças de quatro meses de idade estivessem em amamentação plena. Entre as crianças norte-americanas, a amamentação plena por seis meses em comparação a quatro meses mostrou reduzir o risco de adoecer por pneumonia ou otite média (CHANTRY e col., 2006).

Nos últimos anos, observa-se um crescente número de publicações sobre taxas e determinantes da amamentação e da amamentação exclusiva em municípios brasileiros, provenientes de levantamentos realizados em campanhas de imunização (AUDI e col., 1999; FRANÇA e col., 2007) ou de estudos prospectivos (CHAVES e col., 2007). Observa-se também o interesse acerca da atuação dos trabalhadores do Programa Saúde da Família (PSF) e a prática da amamentação nas famílias por eles assistidas (CICONI e col., 2004; PARADA e col., 2005).

Embora a importância do aleitamento materno exclusivo esteja bem documentada, sabe-se que a introdução precoce de líquidos não nutritivos, leites artificiais e alimentos complementares é muito comum em diversas culturas. O objetivo deste artigo é analisar os fatores associados com a amamentação plena entre crianças de 0 a 6 meses assistidas pelo PSF. 


\section{MÉTODOS}

\subsection{DESENHO DO ESTUDO}

Realizou-se um estudo transversal em dois municípios do Estado de São Paulo selecionados por sua semelhança com relação a tamanho de população, índice de mortalidade infantil, presença de Hospital Amigo da Criança, número de Unidades Básicas de Saúde (UBS) e de equipes de PSF.

Itapira, situada no norte do Estado, é um município agroindustrial e possui dois hospitais, um municipal credenciado como Amigo da Criança e outro filantrópico. Conta com sete UBS e dez equipes de PSF na área urbana. Peruíbe é uma cidade litorânea, cuja subsistência baseia-se no setor de serviços. Possui um Hospital Amigo da Criança e, na área urbana, seis UBS e oito equipes de PSF.

\subsection{POPULAÇÃO E SUJEITOS DA PESQUISA}

A população de estudo incluiu todas as crianças de 0 a 6 meses assistidas pelo PSF. Os critérios de exclusão foram crianças não cadastradas no PSF, moradoras de área rural, com doenças graves ou gemelares. A listagem das crianças, suas respectivas mães e endereços foram fornecidos pelos agentes comunitários de saúde.

\subsection{COLETA DE DADOS}

As entrevistas foram realizadas nos domicílios, por meio de formulário semi-estruturado. O quadro de entrevistadores foi composto por pessoas residentes nos dois municípios, com pelo menos segundo grau de 
escolaridade e sem vínculo de trabalho com as UBS e/ou PSF. A capacitação dos entrevistadores consistiu de leitura do formulário, simulação de entrevistas e realização de uma a duas entrevistas-teste com mães de crianças menores de dois anos. Consideraram-se como perdas: pessoas que recusaram participar da pesquisa ou que não puderam ser localizadas nos endereços após três tentativas. Cerca de $20 \%$ das entrevistas foram checadas por telefone com relação ao comportamento do entrevistador e à consistência da resposta a algumas questões do formulário. Nos casos em que a pessoa entrevistada foi um cuidador, os dados pessoais e informações sobre a atenção recebida na maternidade foram completados por meio de conversa telefônica com a mãe da criança.

Os dados sobre alimentação foram obtidos a partir da resposta a uma lista de produtos. A entrevistada respondia se a criança consumia ou não cada um dos produtos citados pelo entrevistador. Para leite materno, outros leites, comida salgada e lanche investigou-se quantas vezes a criança os ingeriu nas últimas 24 horas.

\subsection{BANCO DE DADOS E ANÁLISE}

Os formulários preenchidos foram codificados pela autora e transportados para a folha de códigos com ajuda de uma auxiliar de pesquisa. Os dados digitados por duas auxiliares de pesquisa em bancos separados foram testados quanto à consistência, utilizando-se o programa Epi-info 6.0.

Após listagem das freqüências de todas as variáveis, realizou-se análise de regressão logística bivariada entre as variáveis explanatórias e a variável desfecho "amamentação plena". A Organização Mundial da Saúde (WHO, 1991) recomenda o uso do termo full breastfeeding quando se quer estudar em conjunto a população de crianças em amamentação exclusiva e predominante. Alguns estudos têm utilizado o correspondente em português 
"amamentação plena ou completa". Entretanto, outros pesquisadores recomendam a não utilização destes termos (KITOKO e col., 2000). Por sua vez, "amamentação exclusiva" significa que a criança recebe apenas leite materno sem outros líquidos, exceto medicamentos em gotas ou xarope e "amamentação predominante" que a criança recebe leite materno e outros líquidos não lácteos (WHO, 1991).

A definição da categoria de base de cada variável explanatória foi feita a partir da plausibilidade sugerida pela literatura quando disponível. As variáveis que apresentaram um $p \leq 0,20$ na análise bivariada foram selecionadas para a análise de regressão logística múltipla, realizada de forma hierarquizada (VICTORA e col., 1997; HOSMER e LEMESHOW, 1989). Utilizou-se o software SPSS for Windows 13.0 para o processamento da análise.

O modelo hierárquico foi composto por sete níveis contendo variáveis relativas à situação sócio-econômica da família (Bloco I), situação de trabalho da mãe (Bloco II), composição da família (Bloco III), estrutura do hospital-maternidade (Bloco IV), prática da amamentação e ação dos profissionais de saúde (Bloco V), perfil da mãe (Bloco VI) e perfil da criança (Bloco VII).

Os níveis hierárquicos foram definidos a partir do modelo teórico proposto por HECTOR e col. (2005), segundo o qual no nível mais distal encontra-se a sociedade com seus valores, no nível intermediário os diversos grupos que podem influenciar as decisões e no nível proximal a mãe e a criança. O nível da sociedade refere-se a fatores que influenciam a aceitabilidade e expectativas com relação à amamentação; inclui normas culturais sobre amamentação e cuidado, papel da mulher na sociedade, amamentar em público, importância econômica dos produtos que competem com a amamentação. O nível do grupo inclui os atributos do meio em que mãe e criança vivem, assim como os atributos que propiciam a prática da 
amamentação, tais como as medidas facilitadoras em hospitais e outros serviços de saúde, as características da família e do domicílio, o ambiente de trabalho, benefícios como licença e creche. O nível do indivíduo refere-se diretamente à mãe, à criança e à relação entre eles; inclui a intenção de amamentar, o conhecimento, as habilidades, experiências com filhos anteriores, experiência do parto, situação de saúde e tipo de interação entre mãe e criança.

No processo de modelagem foram introduzidas, de início, as variáveis idade da criança e município. A seguir, as variáveis do Bloco I, o mais distal, foram incluídas uma a uma. Permaneceram no modelo as que apresentaram associação estatisticamente significativa $(p<0,05)$ com o desfecho ou as que alteraram em mais de $10 \%$ os OR dos demais fatores de estudo do bloco em questão. Na seqüência, foram incorporadas as variáveis do Bloco II. Procedimento análogo foi adotado para a introdução das variáveis e análise dos demais blocos.

Para a análise de regressão logística foram considerados "casos" as 114 crianças em amamentação plena e "controles" as demais $(n=127)$. O estudo apresentou um poder de $80 \%$ para identificar, com nível de $5 \%$ de significância, odds ratio igual ou superior a 3,0 para fatores com proporção de exposição entre 20 e $60 \%$ nas crianças que não se encontravam em amamentação plena (COUSENS e col., 1995).

\subsection{ASPECTOS ÉTICOS}

O estudo foi aprovado pelo Comitê de Ética em Pesquisa da Faculdade de Saúde Pública da Universidade de São Paulo. As mães e outros cuidadores entrevistados assinaram um termo de consentimento livre e esclarecido. 


\section{RESULTADOS}

Os resultados referem-se a 241 crianças de 0 a 6 meses cadastradas nos PSF de Itapira e Peruíbe. As entrevistas foram realizadas com as próprias mães em $99 \%$ dos casos. As perdas devido a recusas e famílias não encontradas foram, respectivamente, 20 e $24 \%$ em cada município.

Os dados da Tabela 1 mostram que há diferenças significativas entre as mulheres entrevistadas nos dois municípios com relação à situação sócioeconômica, ao padrão de amamentação e à atenção recebida nos serviços de saúde.

Os sete blocos de variáveis selecionadas para a análise de regressão logística são apresentados nas Tabelas 2, 3 e 4, com os respectivos valores de OR, IC 95\% e p resultantes da análise bivariada entre as variáveis independentes e a variável desfecho "amamentação plena".

$\mathrm{Na}$ análise de regressão logística múltipla hierarquizada (Tabela 5) observa-se que as mulheres que não moram com o companheiro, que relataram ter tido dificuldade para amamentar e que não deixam a criança largar o peito como medida de saciedade apresentam, respectivamente, 31, 22 e 17\% menos chance de "amamentação plena", independentemente do município em que moram e da idade de suas crianças. As mulheres que atribuíram notas mais baixas para a qualidade da consulta das UBS aparecem com chance quase quatro vezes maior de "amamentação plena".

Aproximadamente $24 \%$ das mães relataram ter vivenciado dificuldades com a amamentação, entre as quais: dor e rachadura nos mamilos, problemas de pega, leite insuficiente e ingurgitamento mamário. 


\section{DISCUSSÃO}

O padrão da amamentação encontrado entre as crianças estudadas está em consonância com o fato já conhecido de que a grande maioria das crianças brasileiras é amamentada no início da vida, mas que logo nos primeiros meses ou dias também recebe água, chá ou outros leites que não o materno (MS, 2001). Constata-se, porém, uma diferença significativa nas prevalências de amamentação e amamentação exclusiva entre os dois municípios. Isso vai ao encontro dos achados de VENANCIO e col. (2002) sobre as diferenças importantes entre os municípios do Estado de São Paulo, o que justificaria a realização de levantamentos locais.

Este estudo possui limitações que é preciso ressaltar. Trata-se de um estudo de crianças cadastradas no PSF, portanto não deve ser feita qualquer extrapolação para as crianças em geral. Sobre as perdas, é possível que se relacionem com as condições sócio-econômicas mais precárias de algumas famílias.

Outro aspecto relevante a se considerar é que, em geral, os estudos referem-se a determinantes da amamentação exclusiva e utilizam a faixa de idade de 0 a 4 meses, conforme os indicadores propostos pela OMS anterior à recomendação de amamentar exclusivamente por seis meses (WHO, 1991). Ao estudar "amamentação plena" entre crianças de 0 a 6 meses, portanto, enfrenta-se a dificuldade de fazer comparações com outros estudos.

A análise de regressão múltipla hierarquizada possibilitou estudar os fatores de acordo com seus diferentes níveis de influência sobre a tomada de decisão e o processo de amamentação. Dada sua forte interferência sobre o desfecho, "município" e "idade da criança em meses" entraram na 
análise de regressão como variáveis de controle. VICTORA e col. (1997) discutem que há situações em que a relação complexa entre os fatores determinantes pode ser melhor compreendida utilizando-se a análise hierarquizada. Ela permite estudar os fatores de acordo com seu pertencimento a um determinado nível de hierarquia em relação ao desfecho, a partir da definição de um modelo conceitual.

Os fatores que se mostraram protetores da amamentação plena foram: morar com o companheiro, não ter enfrentado dificuldade para amamentar, deixar a criança largar sozinha o peito quando satisfeita e atribuir notas mais baixas ao atendimento nas consultas das UBS. Em outras palavras, essas condições contribuíram para a não introdução de outros leites ou alimentos complementares nos seis primeiros meses de vida.

A presença do companheiro como fonte de estímulo e apoio à amamentação aparece em vários estudos na década de noventa despertando o interesse quanto à importância da educação e participação dos pais (FREED e col., 1992, GIUGLIANI, 1994). Um bom relacionamento entre o casal mostrou ter influência positiva sobre o apoio do companheiro na amamentação e maior envolvimento no cuidado da criança (FALCETO e col., 2004). É possível também que a mulher que vive com o companheiro passe menos tempo sob influência das avós da criança quanto a introduzir água, chá ou outros leites (SUSIN e col., 2005). Contudo, verifica-se que o companheiro pode ser decisivo tanto para a amamentação quanto para o desmame precoce. Revisão de literatura realizada por BAR-YAM e DARBY (1997) relata que a influência do companheiro aparece relacionada em particular com a decisão de amamentar, a ajuda na primeira mamada e durante a amamentação e como fator de risco para o uso de mamadeira. De acordo com o estudo realizado por ARORA e col. (2000) o fator mais significativo para a introdução da alimentação por mamadeira foi a percepção da mãe quanto à atitude do companheiro para com a amamentação. Por isso, é importante que o pai da criança seja incluído nos 
programas de educação em aleitamento materno. Um experimento controlado conduzido por PISACANE e col. (2005) mostrou que ensinar o pai sobre como prevenir e lidar com as dificuldades mais comuns durante a lactação esteve associado a taxas mais elevadas de amamentação plena aos 6 meses.

A maioria das crianças havia nascido em Hospitais Amigos da Criança e praticamente todas permaneceram em alojamento conjunto, porém cerca de $30 \%$ não tiveram contato precoce com suas mães. O alojamento conjunto e o contato precoce são ações prioritárias devido ao efeito positivo na amamentação (PALDA e col., 2004), assim como está cada vez mais evidente a importância do Hospital Amigo da Criança (CALDEIRA e GONÇALVES, 2007; KRAMER e col., 2001; MERTEN e col., 2005). Porém, a implantação incompleta dos dez passos da Iniciativa Hospital Amigo da Criança parece ser menos efetiva conforme apontado pelo estudo realizado por COUTINHO e col. (2005) em Palmares, PE.

A ação coletiva como uma política de promoção do aleitamento materno na maternidade, embora tenha seu valor intrínseco, não pode prescindir da atenção individualizada em determinadas circunstâncias. Há mães que podem necessitar de um cuidado mais freqüente e/ou especializado. As dificuldades relatadas por uma parcela das mães estão ligadas ao início do processo de amamentação e poderiam facilmente ser superadas com apoio e orientação adequados (GIUGLIANI, 2004). Nesse sentido, é possível que a avaliação rotineira das mamadas no início da vida possa contribuir para a identificação precoce e redução desses problemas. CARVALHAES e CORREA (2003), por meio da avaliação das mamadas na maternidade, estimaram a quantidade de mães que necessitariam de mais apoio. Respectivamente, $18 \%$ e $34 \%$ dos pares mãe-bebê apresentaram escores regulares e ruins para mau posicionamento e interação inadequada. 
HEINIG e col. (2006) utilizaram grupos focais para estudar a relação entre crenças maternas, intenção quanto à alimentação e comportamento da alimentação infantil entre 65 mães atendidas pelo Programa Women, Infants and Children (WIC) destinado à população de baixa renda dos Estados Unidos. A maioria das mulheres relatou que antes do bebê nascer pretendia amamentar, mas muitas mudaram os planos frente às circunstâncias, como por exemplo, dificuldade com a amamentação, dúvida sobre a quantidade de leite materno, problemas de pega e retardo na produção do leite.

Outro estudo norte-americano, realizado em Boston (TAVERAS e col., 2004), acompanhou 228 mulheres até doze semanas pós-parto e entrevistou médicos e enfermeiras dos setores de pediatria e obstetrícia de 121 clínicas. As mulheres que interromperam precocemente a amamentação exclusiva tiveram maior probabilidade de problemas com a pega e sucção do bebê ou do profissional de saúde ter recomendado o uso de fórmula infantil. Os médicos relataram ter pouco tempo para lidar com os problemas de amamentação. Enquanto os profissionais da obstetrícia eram menos confiantes em lidar com as mães que se queixavam de leite insuficiente, os profissionais da pediatria eram menos confiantes em solucionar as dificuldades com mamas e mamilos doloridos ou mamilos com rachadura. Nesse contexto, as mães que têm uma maior crítica sobre a qualidade da atenção que recebem nas consultas, conforme aponta nosso estudo, estariam mais protegidas quanto a manter o padrão de amamentação.

Um achado relevante foi a associação da amamentação plena com o comportamento da mãe de deixar o bebê largar o peito como sinal de saciedade. Os cursos de manejo do aleitamento materno orientam deixar que a criança mame até largar o peito por ela mesma, uma vez que isso propicia a obtenção do leite posterior rico em gordura, responsável por manter a criança saciada por mais tempo. Essas crianças tenderiam a chorar menos e a ganhar mais peso (MS, 2003). O maior esvaziamento da 
mama também contribuiria para manter a produção adequada de leite (GIUGLIANI, 2004).

Com relação à chupeta, verificou-se uma prevalência de uso muito abaixo da média nacional (MS, 2001). Ela não se mostrou associada à amamentação plena após ajuste por outras variáveis. A chupeta tem sido associada com a interrupção da amamentação exclusiva (AUDI e col., 1999; FRANÇA e col., 2007), redução no período de amamentação (VICTORA e col., 1997), menor número de mamadas e encurtamento na duração da sucção em 24 horas (AARTS e col. 1999).

Os resultados dos estudos indicam a necessidade de buscar medidas eficientes para apoiar as mulheres também nas Unidades Básicas de Saúde e na comunidade. Há evidências de que pode ser efetiva a provisão de programas estruturados de educação pré-natal e apoio ao aleitamento materno após o parto (PALDA e col., 2004). No Rio de Janeiro, OLIVEIRA e CAMACHO (2002) avaliaram o impacto de um conjunto de procedimentos e estratégias realizadas durante o pré-natal e no seguimento após o parto. As estratégias mais eficientes foram identificadas como: realizar grupos de mulheres tanto no pré-natal quanto no pós-parto, visitas domiciliares com envolvimento dos familiares e sessões individuais freqüentes. $O$ aconselhamento por pessoas leigas, segundo MORROW e col. (1999), também se mostrou efetivo em provocar um aumento tanto na prevalência do aleitamento materno exclusivo quanto na duração do aleitamento entre mulheres mexicanas. 


\section{CONCLUSÃO}

Trata-se de um estudo sobre a amamentação plena entre crianças de 0 a 6 meses assistidas pelo PSF. Portanto, os resultados podem não refletir o comportamento da amamentação das crianças em geral.

Observou-se que, assim como em outros estudos, a grande maioria das crianças iniciou a amamentação mas foi elevada a prevalência de uso precoce de líquidos não nutritivos e outros leites ou alimentos.

A análise múltipla hierarquizada mostrou que as mulheres que vivem com seus companheiros, que não tiveram dificuldade em amamentar, que permitem que seus bebês deixem de mamar por si mesmos quando saciados e que são mais críticas com relação ao atendimento recebido nas consultas em UBS apresentaram maior chance de manter a amamentação plena.

A importância de retardar a introdução de outros leites fala a favor da utilidade de estudos sobre determinantes da amamentação plena, os quais são passíveis de serem realizados em estudos transversais com amostras não muito robustas. 


\section{REFERÊNCIAS}

Aarts C, Hörnell A, Kylberg E, Hofvander Y, Gebre-Medhin M. Breastfeeding patterns in relation to thumb sucking and pacifier use. Pediatrics. 1999;104(4):e50-60 (acesso em 23 outubro 2007). Disponível em: http:// pediatrics.aappublications.org/cgi/content/full/104/4/e50

Audi CAF, Correa MAS, Latorre MRDO. Alimentos complementares e fatores associados ao aleitamento materno e ao aleitamento materno exclusivo em lactentes até 12 meses de vida em Itapira, São Paulo, 1999. Rev Bras Saúde Matern Infant. Recife 2003;3(1):85-93.

Bahl R, Frost C, Kirkwood BR, Edmond K, Martines J, Bhandari N, Arthur P. Infant feeding patterns and risks of death and hospitalization in the first half of infancy: multicentre cohort study. Bull World Health Organ. 2005;83(6):418-26.

Bar-Yam NB e Darby L. Fathers and breastfeeding: a review of the literature. J Hum Lact. 1997;13(1):45-50.

Caldeira AP, Gonçalves E. Avaliação do impacto da implantação da Iniciativa Hospital Amigo da Criança. J Pediatr. (Rio J). 2007;83(2):127-32.

Carvalhaes $\mathrm{MAB}$, Correa $\mathrm{CRH}$. Identificação de dificuldades no início do aleitamento materno mediante aplicação de protocolo. J Pediatr. (Rio J). 2003;79(1):13-20.

Chantry CJ, Howard CR, Auinger P. Full breastfeeding duration and associated decrease in respiratory tract infection in US children. Pediatrics. 2006;117(2):425-32.

Chaves RG, Lamounier JA, César CC. Factors associated with duration of breastfeeding. J Pediatr. (Rio J). 2007;83(3):241-6.

Ciconi RCV, Venancio SI, Escuder MML. Avaliação dos conhecimentos de equipes do Programa de Saúde da Família sobre o manejo do aleitamento materno em um município da região metropolitana de São Paulo. Rev Bras Saúde Matern Infant. 2004;4(2):193-202.

Cousens SN, Mertens TE, Kirkwood BR, Smith PG, Feachem RGA. Case control studies of common childhood diseases: the example of diarrhoea. London: WHO/MacMillan; 1995. 
Coutinho SB, Lima MC, Ashworth A, Lira PIC. Impacto de treinamento baseado na Iniciativa Hospital Amigo da Criança sobre práticas relacionadas à amamentação no interior do nordeste. J Pediatr. (Rio J). 2005;81(6):471-7.

Falceto OG, Giugliani ERJ, Fernandes CLC. Couples' relationships and breastfeeding: is there an association? J Hum Lact. 2004;20(1):46-55.

França GVA, Brunken GS, da Silva SM, Escuder MM, Venancio SI. Determinantes da amamentação no primeiro ano de vida em Cuiabá, Mato Grosso. Rev Saúde Pública. 2007;41(5):711-8.

Freed GL, Fraley JK, Schanler RJ. Attitudes of expectant fathers regarding breast-feeding. Pediatrics. 1992;90(2):224-7.

Giugliani EJ. Amamentação: como e por que promover. J Pediatr. (Rio J). 1994; 70(3):138-51.

Giugliani EJ. Problemas comuns na lactação e seu manejo. J Pediatr. (Rio J). 2004;80(5 Supl):S147-S154.

Hector D, King L, Webb K. Factors affecting breastfeeding practices: applying a conceptual framework. NSW Public Health Bull. 2005;16(3-4):525.

Heinig MJ, Follett JR, Ishii KD, Kavanagh-Prochaska K, Cohen R, Panchula $\mathrm{J}$. Barriers to compliance with infant-feeding recommendations among lowincome women. J Hum Lact. 2006;22(1):27-38.

Hosmer DM, Lemeshow S. Applied logistic regression. New York: J. Wiley; 1989.

Kitoko PM, Rea MF, Venancio SI, Vasconcelos ACCP, Santos EKA, Monteiro CA. Situação do aleitamento materno em duas capitais brasileiras: uma análise comparada. Cad Saúde Pública. 2000;16(4):1111-19.

Kramer MS, Chalmers B, Hodnett ED et al for The PROBIT Study Group. Promotion of breastfeeding intervention trial (PROBIT): a randomized trial in the Republic of Belarus. J Am Med Assoc. 2001;285(4):413-20.

Kramer MS, Kakuma R. The optimal duration of exclusive breastfeeding: a systematic review. Adv Exp Med Biol. 2004;554:63-77.

Lauer JA, Betrán AP, Victora CG, de Onis M, Barros AJD. Breastfeeding patterns and exposure to suboptimal breastfeeding among children in developing countries: review and analysis of nationally representative 
children. BMC Med. 2004;2(26) (acesso 19 setembro 2007). Disponível em: www.biomedcentral.com/1741-7015/2/26

Lutter CK. Breastfeeding promotion - Is it effectiveness supported by scientific evidence and global changes in breastfeeding behaviours? In Short and long term effects of breastfeeding on child health. Edited by Berthold Koletzko et al. Kluwer Academic/Plenum Publishers, 2000.

Merten S, Dratva J, Ackermann-Liebrich U. Do Baby-Friendly Hospitals influence breastfeeding duration on a national level? Pediatrics. 2005;116(5):e702-8 (acesso em 1 novembro 2005). Disponível em: http:// pediatrics.aappublications.org/cgi/content/abstract/116/5/e702

MS - Ministério da Saúde. Secretaria de Políticas de Saúde. Área de Saúde da Criança. Prevalência de aleitamento materno nas capitais brasileiras e no Distrito Federal. Brasília, 2001.

MS - Ministério da Saúde. Manejo e Promoção do Aleitamento Materno: curso de 18 horas para equipes de maternidades. Brasília, 2003.

Morrow AL, Guerrero ML, Shults J, Calva JJ, Lutter C, Bravo J, RuizPalacios G, Morrow RC, Butterfoss FD. Efficacy of home-based peer counseling to promote exclusive breastfeeding: a randomized controlled trial. Lancet. 1999;353:1226-31.

Oliveira MIC e Camacho LAB. Impacto das Unidades Básicas de Saúde na duração do aleitamento materno exclusivo. Rev Bras Epidemiol. 2002;5(1):41-51.

OMS - Organização Mundial da Saúde. Estratégia Global para a Alimentação de Lactentes e Crianças de Primeira Infância. Traduzido ao português por IBFAN Brasil, setembro 2005 (acesso em 11 agosto 2007). Disponível em: http://www.ibfan.org.br/documentos.

Palda VA, Guise J-M, Wathen CN, with the Canadian Task Force on Preventive Health Care. Interventions to promote breast-feeding: applying the evidence in clinical practice. CMAJ. 2004;170(6):976-8.

Parada CMGL, Carvalhaes MABL, Winckler CC, Winckler LA, Winckler VC. Situação do aleitamento materno em população assistida pelo programa de saúde da família. Rev Latino-am Enfermagem. 2005;13(3):407-14.

Paricio Talayero JM, Lizán-Garcia M, Otero Puime A, Benlloch Muncharaz MJ, Beseler Soto B, Sánchez-Palomares M, Santos Serrano L, Rivera LL. Full breastfeeding and hospitalization as a result of infections in the first year of life. Pediatrics 2006;118(1):e92-9 (acesso em 3 julho 2006). Disponível em: http://www.pediatrics.org/cgi/content/full/118/1/e92 
Pisacane A, Grazia IC, Aldinucci M, D’Amora S, Continisio P. A controlled trial of the father's role in breastfeeding promotion. Pediatrics. 2005;116(4):e494-e8 (acesso em 20 janeiro 2008). Disponível em: http://www.pediatrics.org/cgi/content/full/116/4/e494

Rea MF. Reflexões sobre a amamentação no Brasil: de como passamos a 10 meses de duração. Cad Saúde Pública. 2003;19(1 Supl):S37-S45.

Susin LRO, Giugliani ERJ, Kummer SC. Influência das avós na prática do aleitamento materno. Rev Saúde Pública. 2005;39(2):11-7.

Taveras EM, Ruowei L, Grummer-Strawn L, Richardson M, Marshall R, Rego $\mathrm{VH}$, Miroshnik I, Lieu TA. Opinions and practices of clinicians associated with continuation of exclusive breastfeeding. Pediatrics. 2004;113(4):e283-90 (acesso em 22 setembro 2006). Disponível em: http:// pediatrics.aappublications.org/cgi/content/abstract/113/4/e283

Venancio SI, Escuder MML, Kitoko P, Rea MF, Monteiro CA. Freqüência e determinantes do aleitamento materno em municípios do Estado de São Paulo. Rev Saúde Pública. 2002;36(3):313-8.

Victora CG, Behague DP, Barros FC, Olinto MTA, Weiderpass E. Pacifier use and short breastfeeding duration: cause, consequence, or coincidence? Pediatrics. 1997;99(3):445-53.

Victora CG, Smith PG, Vaughan JP, Nobre LC, Lombardi C, Teixeira AM, et al. Evidence for protection by breast-feeding against infant deaths from infectious diseases in Brazil. Lancet. 1987;2:319-22.

Victora CG, Huttly SR, Fuchs SC, Olinto MT. The role of conceptual frameworks in epidemiological analysis: a hierarchical approach. Int $\mathrm{J}$ Epidemiol. 1997;26:224-7.

WHO - World Health Organization. Division of Diarrhoeal and Acute Respiratory Disease Control. Indicators for assessing breast feeding practices. Report of an Informal Meeting 11-12 June 1991, Geneva. 
Tabela 1. Distribuição das crianças de 0 a 6 meses assistidas pelo Programa Saúde da Família segundo algumas variáveis selecionadas. Itapira e Peruíbe, SP, 2007.

\begin{tabular}{|c|c|c|c|}
\hline \multirow[t]{2}{*}{ Variáveis } & Itapira $(\mathrm{N}=149)$ & Peruíbe (N=92) & \multirow[b]{2}{*}{$\mathbf{p}^{*}$} \\
\hline & $\bar{x}(s)$ & $\bar{x}(s)$ & \\
\hline Idade da criança em meses & $4(2)$ & $4(2)$ & 0,259 \\
\hline Idade da mãe & $26(6)$ & $25(6)$ & 0,405 \\
\hline Número de filhos vivos & $2(1)$ & $3(2)$ & 0,007 \\
\hline Anos de estudo & $9(3)$ & $8(3)$ & 0,079 \\
\hline \multirow[t]{2}{*}{ Renda per capita } & $1091,17(732,29)$ & $691,76(534,30)$ & 0,000 \\
\hline & $\%$ & $\%$ & $\mathbf{p}^{* *}$ \\
\hline$\vec{E}$ cadastrada no programa bolsa família & 19,5 & 41,3 & 0,000 \\
\hline Família tem convênio saúde & 31,5 & 9,8 & 0,000 \\
\hline Água da rede pública dentro de casa & 100,0 & 92,4 & 0,001 \\
\hline Acesso à rede pública de esgotos & 98,7 & 50,0 & 0,000 \\
\hline Considera-se não branca & 43,6 & 67,4 & 0,000 \\
\hline Trabalha fora & 34,2 & 21,7 & 0,039 \\
\hline Mora com o companheiro & 75,8 & 72,8 & 0,601 \\
\hline Mora com os pais ou sogros & 30,2 & 26,1 & 0,492 \\
\hline Fez acompanhamento pré-natal & 98,7 & 96,7 & 0,310 \\
\hline O parto foi vaginal & 49,0 & 64,1 & 0,022 \\
\hline O parto ocorreu em HAC & 77,2 & 94,6 & 0,000 \\
\hline Teve contato precoce com o bebê & 57,7 & 76,1 & 0,004 \\
\hline Amamentou na sala de parto & 54,4 & 56,0 & 0,799 \\
\hline Permaneceu em AC & 94,6 & 97,8 & 0,227 \\
\hline Teve dificuldade para amamentar & 24,8 & 22,8 & 0,723 \\
\hline Recebe visita do PSF & 88,6 & 95,7 & 0,059 \\
\hline Freqüenta consultas na UBS & 93,3 & 97,8 & 0,116 \\
\hline Peso ao nascer $<2500$ gramas & 4,7 & 10,9 & 0,069 \\
\hline Em amamentação (0-6 meses) & 81,9 & 93,5 & 0,011 \\
\hline Em amamentação exclusiva ( $0-6$ meses) & 18,1 & 34,8 & 0,003 \\
\hline Em amamentação plena ( $0-6$ meses) & 40,9 & 57,6 & 0,012 \\
\hline Usa mamadeira & 62,4 & 43,5 & 0,004 \\
\hline Usa chupeta & 38,9 & 25,0 & 0,026 \\
\hline Foi internada alguma vez & 8,1 & 2,2 & 0,058 \\
\hline
\end{tabular}

${ }^{\star}$ Teste $t$-Student; **Teste do qui-quadrado de Pearson. 
Tabela 2. Análise bivariada entre amamentação plena e variáveis relativas à situação sócio-econômica, trabalho da mãe e organização familiar. Itapira e Peruíbe, SP, 2007.

\begin{tabular}{|c|c|c|c|c|c|}
\hline \multirow[t]{2}{*}{ Variáveis e categorias } & \multicolumn{5}{|c|}{ Amamentação plena entre crianças de 0 a 6 meses } \\
\hline & $\mathbf{N}$ & $\operatorname{Sim}(\%)$ & Não (\%) & OR (IC 95\%) & p (Wald) \\
\hline \multicolumn{6}{|l|}{ Bloco I } \\
\hline \multicolumn{6}{|l|}{ Renda per capita (Reais) } \\
\hline $256,00-1667,00$ & 71 & 47,9 & 52,1 & 1,00 & 0,435 \\
\hline $166,00-255,00$ & 52 & 44,2 & 55,8 & $0,78(0,39-1,55)$ & 0,476 \\
\hline $98,00-165,00$ & 57 & 56,1 & 43,9 & $1,39(0,69-2,81)$ & 0,355 \\
\hline $0,00-97,00$ & 60 & 41,7 & 58,3 & $0,86(0,42-1,77)$ & 0,688 \\
\hline \multicolumn{6}{|l|}{ Pessoa por dormitório } \\
\hline $0,75-2,00$ & 112 & 42,0 & 58,0 & 1,00 & 0,368 \\
\hline $2,10-3,00$ & 64 & 51,6 & 48,4 & $1,47(0,79-2,73)$ & 0,220 \\
\hline $3,10-4,00$ & 31 & 58,1 & 41,9 & $1,92(0,86-4,29)$ & 0,114 \\
\hline $4,10-10,00$ & 34 & 47,1 & 52,9 & $1,23(0,57-2,66)$ & 0,600 \\
\hline \multicolumn{6}{|l|}{ Casa própria ou alugada } \\
\hline $\operatorname{sim}$ & 145 & 52,4 & 47,6 & 1,00 & 0,052 \\
\hline não & 96 & 39,6 & 60,4 & $0,60(0,35-1,00)$ & \\
\hline \multicolumn{6}{|l|}{ Recebe cesta básica } \\
\hline sim & 64 & 48,4 & 51,6 & 1,00 & 0,832 \\
\hline não & 177 & 46,9 & 53,1 & $0,94(0,53-1,67)$ & \\
\hline \multicolumn{6}{|l|}{ Tem convênio saúde } \\
\hline sim & 56 & 53,6 & 46,4 & 1,00 & 0,285 \\
\hline não & 185 & 45,4 & 54,6 & $1,39(0,40-1,31)$ & \\
\hline \multicolumn{6}{|l|}{ Bloco II } \\
\hline \multicolumn{6}{|l|}{ Mãe trabalha fora } \\
\hline não & 170 & 50,6 & 49,4 & 1,00 & 0,115 \\
\hline $\operatorname{sim}$ & 71 & 39,4 & 60,6 & $0,64(0,36-1,12)$ & \\
\hline \multicolumn{6}{|l|}{ Horário de trabalho } \\
\hline diário e parcial & 14 & 64,3 & 35,7 & 1,00 & 0,040 \\
\hline outro & 57 & 33,3 & 66,7 & $0,28(0,08-0,95)$ & \\
\hline \multicolumn{6}{|l|}{ Trabalha em casa } \\
\hline & 41 & 51,2 & 48,8 & 1,00 & 0,876 \\
\hline $\begin{array}{l}\text { sim } \\
\text { não }\end{array}$ & 200 & 46,5 & 53,5 & $0,96(0,58-1,60)$ & \\
\hline \multicolumn{6}{|l|}{ Bloco III } \\
\hline \multicolumn{6}{|l|}{ Principal cuidador } \\
\hline mãe & 209 & 51,7 & 48,3 & 1,00 & 0,001 \\
\hline outro & 32 & 18,8 & 81,2 & $0,22(0,09-0,55)$ & \\
\hline \multicolumn{6}{|l|}{ Mora com companheiro } \\
\hline $\operatorname{sim}$ & 180 & 51,7 & 48,3 & 1,00 & 0,021 \\
\hline não & 61 & 34,4 & 65,6 & $0,49(0,27-0,90)$ & \\
\hline \multicolumn{6}{|l|}{ Mora com pais/sogros } \\
\hline não & 172 & 50,0 & 50,0 & 1,00 & 0,187 \\
\hline sim & 69 & 40,6 & 59,4 & $0,68(0,39-1,20)$ & \\
\hline
\end{tabular}


Tabela 3. Análise bivariada entre amamentação plena e variáveis relativas à estrutura dos serviços e ação dos profissionais de saúde. Itapira e Peruíbe, SP, Brasil, 2007.

\begin{tabular}{|c|c|c|c|c|c|}
\hline \multirow[t]{2}{*}{ Variáveis e categorias } & \multicolumn{5}{|c|}{$\begin{array}{c}\text { Amamentação plena entre crianças de } 0 \text { a } 6 \\
\text { meses }\end{array}$} \\
\hline & $\mathbf{N}$ & $\begin{array}{l}\text { Sim } \\
(\%)\end{array}$ & $\begin{array}{l}\text { Não } \\
(\%)\end{array}$ & OR (IC 95\%) & $\begin{array}{c}p \\
\text { (Wald) }\end{array}$ \\
\hline \multicolumn{6}{|l|}{ Bloco IV } \\
\hline \multicolumn{6}{|l|}{ Parto em HAC } \\
\hline $\operatorname{sim}$ & 202 & 48,5 & 51,5 & 1,00 & 0,392 \\
\hline não & 39 & 41,0 & 59,0 & $0,74(0,37-1,48)$ & \\
\hline \multicolumn{6}{|l|}{ Permanência em AC } \\
\hline $\operatorname{sim}$ & 231 & 48,9 & 51,1 & 1,00 & 0,043 \\
\hline não & 10 & 10,0 & 90,0 & $0,12(0,01-0,93)$ & \\
\hline \multicolumn{6}{|l|}{ Bloco V } \\
\hline \multicolumn{6}{|l|}{ Orientação pré-natal } \\
\hline $\operatorname{sim}$ & 161 & 39,1 & 60,9 & 1,00 & 0,000 \\
\hline não & 75 & 66,7 & 33,3 & $3,11(1,75-5,53)$ & \\
\hline \multicolumn{6}{|l|}{ Contato precoce pós-parto } \\
\hline 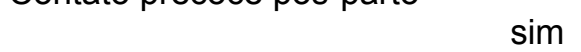 & 156 & 47,4 & 52,6 & 1,00 & 0,955 \\
\hline não & 85 & 47,1 & 52,9 & $0,99(0,58-1,67)$ & \\
\hline \multicolumn{6}{|l|}{ Amamentação precoce } \\
\hline 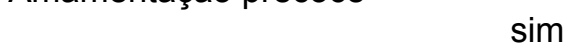 & 132 & 44,7 & 55,3 & 1,00 & 0,337 \\
\hline não & 108 & 50,9 & 49,1 & $1,28(0,77-2,14)$ & \\
\hline \multicolumn{6}{|l|}{ Ajuda para amamentar no hospital } \\
\hline sim & 169 & 47,3 & 52,7 & 1,00 & 0,496 \\
\hline não & 65 & 52,3 & 47,7 & $1,22(0,69-2,16)$ & \\
\hline \multicolumn{6}{|l|}{ Dificuldade amamentar } \\
\hline (1) & 183 & 51,9 & 48,1 & 1,00 & 0,012 \\
\hline $\operatorname{sim}$ & 58 & 32,8 & 67,2 & $0,45(0,24-0,84)$ & \\
\hline \multicolumn{6}{|l|}{ Recebeu visita de ACS } \\
\hline 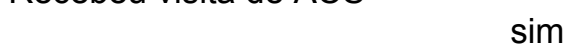 & 220 & 45,0 & 55,0 & 1,00 & 0,026 \\
\hline não & 21 & 71,4 & 28,6 & $3,06(1,14-8,17)$ & \\
\hline \multicolumn{6}{|l|}{ Vai a consultas na UBS } \\
\hline $\operatorname{sim}$ & 229 & 45,9 & 54,1 & 1,00 & 0,063 \\
\hline não & 12 & 75,0 & 25,0 & $3,54(0,94-13,43)$ & \\
\hline \multicolumn{6}{|l|}{ Aconselhamento visita (escore)* } \\
\hline bom & 183 & 47,0 & 53,0 & 1,00 & 0,189 \\
\hline ruim/regular & 37 & 35,1 & 64,9 & $0,61(0,29-1,27)$ & \\
\hline \multicolumn{6}{|l|}{ Aconselhamento consulta (escore) $)^{*}$} \\
\hline bom & 156 & 43,6 & 56,4 & 1,00 & 0,316 \\
\hline ruim/regular & 73 & 50,7 & 49,3 & $1,33(0,76-2,32)$ & \\
\hline \multicolumn{6}{|l|}{ Qualidade da visita $(\text { nota })^{* *}$} \\
\hline boa & 187 & 44,9 & 55,1 & 1,00 & 0,955 \\
\hline ruim/regular & 33 & 45,5 & 54,5 & $1,02(0,49-2,15)$ & \\
\hline \multicolumn{6}{|l|}{ Qualidade da consulta (nota) ${ }^{\star *}$} \\
\hline boa & 148 & 38,5 & 61,5 & 1,00 & 0,003 \\
\hline ruim/regular & 81 & 59,3 & 40,7 & $2,32(1,34-4,04)$ & \\
\hline
\end{tabular}

${ }^{*} \mathrm{O}$ escore de habilidades de aconselhamento utilizadas nas visitas e consultas variou de 0 a 1; considerou-se um bom padrão de aconselhamento quando o escore foi $>=0,75$.

${ }^{* *} A$ qualidade das visitas e consultas recebeu notas de 0 a 2; considerou-se boa qualidade quando a nota foi igual a 2. 
Tabela 4. Análise bivariada entre amamentação plena e variáveis relativas à mãe e à criança. Itapira e Peruíbe, SP, Brasil, 2007.

\begin{tabular}{|c|c|c|c|c|c|}
\hline \multirow[t]{2}{*}{ Variáveis e categorias } & \multicolumn{5}{|c|}{ Amamentação plena entre crianças de 0 a 6 meses } \\
\hline & $\mathbf{N}$ & Sim (\%) & Não (\%) & OR (IC 95\%) & $\begin{array}{c}p \\
\text { (Wald) }\end{array}$ \\
\hline \multicolumn{6}{|l|}{ Bloco VI } \\
\hline \multicolumn{6}{|l|}{ Idade da mãe (anos) } \\
\hline $30-46$ & 56 & 48,2 & 51,8 & 1,00 & 0,939 \\
\hline $20-29$ & 147 & 47,6 & 52,4 & $0,87(0,38-1,99)$ & 0,740 \\
\hline $13-19$ & 38 & 44,7 & 55,3 & $0,98(0,53-1,81)$ & 0,940 \\
\hline \multicolumn{6}{|l|}{ Estudo da mãe (anos) } \\
\hline 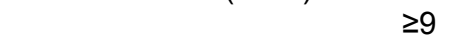 & 130 & 51,5 & 48,5 & 1,00 & 0,155 \\
\hline $0-8$ & 111 & 42,3 & 57,7 & $0,69(0,42-1,15)$ & \\
\hline \multicolumn{6}{|l|}{ Filhos vivos } \\
\hline$\geq 3$ & 69 & 52,2 & 47,8 & 1,00 & 0,407 \\
\hline 2 & 64 & 50,0 & 50,0 & $0,68(0,37-1,25)$ & 0,213 \\
\hline 1 & 108 & 42,6 & 57,4 & $0,92(0,46-1,81)$ & 0,802 \\
\hline \multicolumn{6}{|l|}{ Cor auto-referida } \\
\hline não branca & 127 & 44,1 & 55,9 & 1,00 & 0,293 \\
\hline branca & 114 & 50,9 & 49,1 & $1,31(0,79-2,18)$ & \\
\hline \multicolumn{6}{|l|}{ Tipo de parto } \\
\hline vaginal & 132 & 49,2 & 50,8 & 1,00 & 0,507 \\
\hline cesariana & 109 & 45,0 & 55,0 & $0,84(0,51-1,40)$ & \\
\hline \multicolumn{6}{|l|}{ Usa choro para alimentar } \\
\hline não & 88 & 40,9 & 59,1 & 1,00 & 0,146 \\
\hline $\operatorname{sim}$ & 152 & 50,7 & 49,3 & $1,48(0,87-2,52)$ & \\
\hline \multicolumn{6}{|l|}{ Usa horário para alimentar } \\
\hline não & 193 & 50,8 & 49,2 & 1,00 & 0,022 \\
\hline $\operatorname{sim}$ & 47 & 31,9 & 68,1 & $0,45(0,23-0,89)$ & \\
\hline \multicolumn{6}{|l|}{ Usa sinais para alimentar } \\
\hline $\operatorname{sim}$ & 70 & 61,4 & 38,6 & 1,00 & 0,005 \\
\hline não & 170 & 41,2 & 58,8 & $0,44(0,25-0,78)$ & \\
\hline \multicolumn{6}{|l|}{ Deixa criança largar } \\
\hline $\operatorname{sim}$ & 124 & 70,2 & 29,8 & 1,00 & 0,000 \\
\hline não & 116 & 22,4 & 77,6 & $0,12(0,07-0,22)$ & \\
\hline \multicolumn{6}{|l|}{ Espera criança recusar } \\
\hline 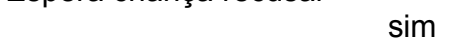 & 65 & 12,3 & 87,7 & 1,00 & 0,000 \\
\hline não & 175 & 60,0 & 40,0 & $10,69(4,81-23,77)$ & \\
\hline \multicolumn{6}{|l|}{ Bloco VII } \\
\hline \multicolumn{6}{|l|}{ Sexo } \\
\hline masculino & 123 & 46,3 & 53,7 & 1,00 & 0,760 \\
\hline feminino & 118 & 48,3 & 51,7 & $1,08(0,65-1,79)$ & \\
\hline \multicolumn{6}{|l|}{ Nasceu com saúde } \\
\hline $\operatorname{sim}$ & 231 & 48,5 & 51,5 & 1,00 & 0,098 \\
\hline não & 10 & 20,0 & 80,0 & $0,27(0,06-1,28)$ & \\
\hline \multicolumn{6}{|l|}{ Peso ao nascer } \\
\hline$\geq 2500 \mathrm{~g}$ & 224 & 47,3 & 52,7 & 1,00 & 0,983 \\
\hline$<2500 \mathrm{~g}$ & 17 & 47,1 & 52,9 & $0,99(0,37-2,66)$ & \\
\hline \multicolumn{6}{|l|}{ Chupa chupeta } \\
\hline não & 160 & 56,3 & 43,7 & 1,00 & 0,000 \\
\hline $\operatorname{sim}$ & 81 & 29,6 & 70,4 & $0,33(0,19-0,58)$ & \\
\hline Ja tol Internado & 227 & 48,5 & 51,5 & 1,00 & 0,159 \\
\hline sim & 14 & 28,6 & 71,4 & $0,43(0,13-1,40)$ & \\
\hline
\end{tabular}


Tabela 5. Análise múltipla de fatores associados com a amamentação plena, segundo modelo hierarquizado. Itapira e Peruíbe, SP, 2007.

\begin{tabular}{|c|c|c|c|}
\hline Variáveis e categorias & $\overline{\text { ORb* }^{*}}$ & ORa** & $p$ (Wald) \\
\hline Mora com companheiro ${ }^{1}$ & $\begin{array}{c}1,00 \\
0,31(0,14-0,69)\end{array}$ & $\begin{array}{c}1,00 \\
0,31(0,14-0,69)\end{array}$ & 0,004 \\
\hline $\begin{array}{r}\begin{array}{r}\text { Nota para qualidade da consulta } \\
\text { boa }\end{array} \\
\text { ruim/regular }\end{array}$ & $\begin{array}{c}1,00 \\
2,90(1,43-5,88)\end{array}$ & $\begin{array}{c}1,00 \\
3,79(1,74-8,24)\end{array}$ & 0,001 \\
\hline $\begin{array}{l}\text { não } \\
\text { sim }\end{array}$ & $\begin{array}{c}1,00 \\
0,33(0,15-0,71)\end{array}$ & $\begin{array}{c}1,00 \\
0,22(0,09-0,55)\end{array}$ & 0,001 \\
\hline $\begin{array}{l}\text { Deixa criança largar o peito }^{3} \\
\qquad \begin{array}{l}\text { sim } \\
\text { não }\end{array}\end{array}$ & $\begin{array}{c}1,00 \\
0,16(0,08-0,32)\end{array}$ & $\begin{array}{c}1,00 \\
0,17(0,08-0,37)\end{array}$ & 0,000 \\
\hline $\begin{array}{l}\text { não } \\
\text { sim }\end{array}$ & $\begin{array}{c}1,00 \\
0,48(0,24-0,97)\end{array}$ & $\begin{array}{c}1,00 \\
0,88(0,38-2,05)\end{array}$ & 0,772 \\
\hline
\end{tabular}

${ }^{*}$ OR bruto com intervalo de confiança de $95 \%$, controlado por município e idade da criança. ${ }^{* *}$ OR ajustado com intervalo de confiança de $95 \%$, controlado por município e idade da criança.

${ }^{1}$ Modelo I: morar com companheiro.

${ }^{2}$ Modelo II: morar com companheiro, qualidade da consulta, dificuldade para amamentar.

${ }^{3}$ Modelo III: morar com companheiro, qualidade da consulta, dificuldade para amamentar, deixa criança largar o peito.

${ }^{4}$ Modelo IV: morar com companheiro, qualidade da consulta, dificuldade para amamentar, deixa criança largar o peito, chupeta. 
ARTIGO 3:

IMPACTO DE UM CURSO DE ACONSELHAMENTO EM ALIMENTAÇÃO INFANTIL NOS CONHECIMENTOS DE TRABALHADORES DA SAÚDE: UM ESTUDO CONTROLADO NÃO RANDOMIZADO.

IMPACT OF AN INFANT FEEDING COUNSELLING COURSE IN THE HEALTH WORKERS' KNOWLEDGE: A NONRANDOMIZED CONTROLLED TRIAL. 


\section{RESUMO}

Introdução: A Organização Mundial da Saúde lançou recentemente o "Aconselhamento em Alimentação de Lactentes e Crianças de Primeira infância: um curso integrado" $(\mathrm{Cl})$. Objetivo: Avaliar a efetividade do $\mathrm{Cl}$ em aumentar os conhecimentos de profissionais que atendem crianças do Programa Saúde da Família (PSF) em municípios do Estado de São Paulo. Método: Estudo de intervenção controlado, não randomizado, realizado nos municípios de Itapira (intervenção) e Peruíbe (controle). A intervenção consistiu em oferecer $\circ \mathrm{Cl}$ e distribuir material didático. Os conhecimentos foram avaliados antes e depois mediante formulário contendo 70 questões. $O$ efeito da intervenção foi analisado por meio de regressão linear múltipla. Resultados: 63 profissionais participaram do estudo, 39 no grupo intervenção e 24 no grupo controle. Os profissionais do grupo intervenção atuam há mais tempo na área da saúde e maior proporção deles recebeu cursos de aleitamento materno $(p<0,05)$. A participação no $\mathrm{Cl}$ foi baixa e irregular. Não houve diferença entre os grupos quanto aos conhecimentos antes da intervenção. Houve um aumento significante, embora modesto, no incremento médio das notas no grupo intervenção $(p=0,044)$. Na regressão linear, houve associação entre a intervenção e o desfecho "incremento", mesmo após ajuste para variáveis de confundimento $(p=0,018)$. As notas finais aumentaram conforme aumentou a freqüência ao $\mathrm{Cl} \quad(p=0,047)$. Conclusão: $\mathrm{O} \mathrm{Cl}$ mostrou-se efetivo em aumentar o conhecimento dos profissionais em alimentação infantil. No entanto, parece difícil a operacionalização junto a equipes de PSF no nosso meio.

Descritores: aleitamento materno; alimentação infantil; aconselhamento; capacitação de profissionais de saúde. 


\section{ABSTRACT}

Background: The World Health Organization has recently launched the "Integrated Infant Feeding Counselling: a training course" (IC). Objective: To assess the effectiveness of the IC on knowledge of health professionals from Brazilian Family Health Program (PSF) in two towns of the state of São Paulo. Method: A non-randomized intervention trial, performed in the towns of Itapira (intervention group - IG) and Peruíbe (control group CG). The intervention consisted in offering the IC, providing didactical material. Knowledge, in both groups, has been assessed, before and after the intervention, through a 70-question form. The effect of the intervention has been analyzed through multiple linear regression analysis. Results: 63 professionals have participated, 39 in the intervention group, and 24 as control subjects. The professionals of the IG have more years of working in health care services than the GC, most of them having attended breastfeeding courses before $(p=0.05)$. The general participation in the IC was low and irregular. There was no difference between the groups regarding knowledge before intervention. There was a modest but significant increase in the mean scores in the IG compared to CG $(p=0.044)$. In the linear regression, there has been an association between intervention and "increase", even after adjustment for confounding variables $(p=0.018)$. The higher the score the higher the frequency to the IC $(p=0.047)$. Conclusion: The IC has been effective in enhancing professional knowledge in child feeding. However, operational constraints could limit IC implementation among PSF teams.

Key-words: Breastfeeding; child feeding; counseling; health professionals training. 


\section{INTRODUÇÃO}

As recomendações atuais sobre alimentação ideal na infância destacam a importância da amamentação exclusiva durante os seis primeiros meses de vida e a continuidade da amamentação, após o início da alimentação complementar, até os dois anos de idade ou mais (OMS, 2005; MONTE e GIUGLIANI, 2004; MS, 2002).

Para que este objetivo seja alcançado é necessária a efetivação de uma política abrangente de promoção, proteção e apoio ao aleitamento materno, segundo o compromisso assumido pelos países na Declaração de Innocenti, reiterada e ampliada em reunião comemorativa de seus 15 anos (UNICEF, 2005). O Brasil conta com uma política de incentivo ao aleitamento materno desde o início da década de oitenta e um dos pontos fortes para sua implementação tem sido a capacitação de profissionais de saúde em larga escala (REA, 2003).

Propostas bem estruturadas de capacitação, que possibilitam a formação de agentes multiplicadores, são instrumentos fundamentais para se buscar mudanças substanciais nas práticas dos trabalhadores de saúde e nas rotinas dos serviços. Desde o lançamento da Iniciativa Hospital Amigo da Criança (IHAC) em 1992, técnicos da Organização Mundial da Saúde (OMS) tem se empenhado na elaboração de cursos de capacitação que reúnam conteúdo relevante e técnicas apropriadas de ensino e que, ao mesmo tempo, sejam compatíveis com a agenda do trabalho em saúde. Nessa linha, foram desenvolvidos cursos para impulsionar a implantação da IHAC (MS, 2003; OMS e UNICEF, 1999) e cursos de aconselhamento que incorporam conteúdos voltados também ao interesse dos profissionais de Unidades Básicas de Saúde (UBS) e de aconselhadores leigos (OMS e 
UNICEF, 1997; OMS, UNICEF e UNAIDS, 2003; WHO, 2003; SANTOS e col., 2002).

O conhecimento e o domínio da técnica pelos profissionais de saúde embora muito importantes não são suficientes para ajudar as mulheres a realizarem seus planos com relação à alimentação dos filhos. Conforme propõe AYRES (2001) a tarefa prática da saúde coletiva de tratar, curar ou controlar seria enriquecida ao se adotar uma noção de cuidado que passa pelas competências técnicas, mas não se restringe a elas. Entretanto, como fazer para que se processe essa mudança? GARRICK (1979) argumenta que o aconselhamento pode ser aprendido, porém não pode ser ensinado de uma maneira usual. Caberia ao professor proporcionar exemplos e experiências que facilitem a aquisição dessas habilidades pelo estudante.

Os cursos de aconselhamento da OMS procuram lidar com essa preocupação ao propor o uso de técnicas que podem facilitar a comunicação. Alguns estudos metodologicamente bem conduzidos já apontaram vantagens desses cursos na melhoria das práticas das mães e dos profissionais de saúde com relação à nutrição e alimentação infantis (REA e col., 1999; SANTOS e col., 2002).

A elaboração de cursos como os da OMS e UNICEF exige a reunião de especialistas e, nesse sentido, são processos longos e custosos. Por isso, parece lógico utilizá-los, levando em conta as adaptações apropriadas a cada país.

A proposta mais recente da OMS é o "Aconselhamento em alimentação de lactentes e crianças de primeira infância: um curso integrado" (Curso Integrado). A relevância do Curso Integrado repousa no fato de condensar em um único pacote os três cursos de aconselhamento anteriormente elaborados. Desta forma, espera-se atender a dois aspectos cruciais para a implementação das atuais recomendações sobre alimentação 
da criança pequena: 1. cobrir tópicos relacionados ao aconselhamento em amamentação, alimentação complementar e alimentação em circunstâncias particularmente difíceis (crianças de mulheres HIV positivo); 2. oferecer uma carga horária compatível com a possibilidade dos serviços de saúde. O Curso Integrado também traz como novidade em relação aos cursos de aconselhamento anteriormente elaborados, um Guia de orientações para o seguimento dos participantes após o curso e uma lista de competências esperadas, que incluiu conhecimentos técnicos e habilidades de aconselhamento (WHO, 2005).

O Curso Integrado mostrou-se efetivo em aperfeiçoar conhecimentos e práticas de médicos e nutricionistas em recente avaliação realizada no município de São Paulo (BASSICHETTO e REA, 2008).

Na década de 1990, começa a ser implementado no país o Programa Saúde da Família (PSF) como estratégia para ajudar na construção e consolidação do Sistema Único de Saúde (SUS). A proposta do PSF, afirma ALVES (2005), trazia em seu bojo a expectativa de reorientar o modelo de assistência a partir da atenção básica. Atualmente, 27.500 equipes são responsáveis pela cobertura de 80 milhões de pessoas (TEMPORÃO, 2007).

O objetivo deste estudo foi avaliar em que medida o Curso Integrado poderia aumentar os conhecimentos de profissionais do PSF sobre aconselhamento em alimentação das crianças pequenas. 


\section{MÉTODOS}

\subsection{DESENHO DO ESTUDO}

Trata-se de um estudo de intervenção do tipo "antes-depois", controlado, não randomizado, em que um grupo de profissionais que prestam assistência a crianças cadastradas no Programa Saúde da Família recebeu a intervenção e é comparado a outro grupo que não a recebeu.

\subsection{LOCAL E PARTICIPANTES}

O estudo foi realizado em dois municípios do Estado de São Paulo. Itapira fora selecionada como local para aplicar a intervenção. Peruíbe serviu de município controle por atender aos seguintes critérios de semelhança: tamanho de população, número de Unidades Básicas de Saúde e de equipes do Programa Saúde da Família e contar com pelo menos um Hospital Amigo da Criança. Itapira, ao norte do Estado, tinha 10 equipes do PSF atuando em 7 UBS. Peruíbe, cidade litorânea, tinha 7 equipes em 6 UBS.

Antes da intervenção, todos os profissionais do PSF dos dois municípios foram convidados a participar da pesquisa. Ao todo, 72 profissionais aceitaram participar da pesquisa, sendo 41 do grupo intervenção e 31 do grupo controle. Houve perda de 9 profissionais, desligados do PSF ou transferidos para serviços que não faziam parte da 
abrangência da pesquisa, 2 do grupo intervenção (perda de 4,9\%) e 7 controles (perda de 22,6\%).

Em ambos os municípios os médicos pediatras incluídos na amostra não tinham vínculo empregatício com o PSF, embora atendam as crianças cadastradas no programa. Os médicos do PSF de Itapira não atendem crianças, com exceção de 2 com especialização em Pediatria.

\subsection{INTERVENÇÃO}

A intervenção consistiu em oferecer o Curso Integrado aos médicos, enfermeiros e auxiliares de enfermagem que prestam atendimento nas UBS às crianças cadastradas no Programa Saúde da Família. Os profissionais que não participaram do $\mathrm{Cl}$ também receberam o Manual do Participante e, portanto, foram considerados pertencentes ao grupo intervenção.

O curso foi realizado de fevereiro a junho de 2007, todas as sextas feiras no período da tarde, conforme estipulado pela coordenação local do PSF. Como não era possível a dispensa de todos os profissionais ao mesmo tempo para o $\mathrm{Cl}$, os participantes foram divididos em dois grupos de maneira que o encontro com cada grupo ocorria em um intervalo de duas semanas.

O Curso Integrado tem uma carga horária de 35 horas. O conteúdo das 39 sessões, apresentado no Quadro anexo, está distribuído da seguinte forma: fundamentos da alimentação infantil e do aleitamento materno (sessões 1, 2 e 3), como lidar com as situações relacionadas à prática do aleitamento materno (sessões 4, 8, 9, 13, 14, 15, 16, 19, 20, 37), habilidades de aconselhamento (sessões $5,6,7,10,11,12,36$ ), fundamentos e como lidar com a alimentação de crianças filhas de mulheres HIV positivo (sessões $17,18,21,22,23,24,27)$, políticas de saúde e aleitamento materno 
(sessões 25, 26), fundamentos e como lidar com a alimentação complementar (sessões 28, 29, 30, 31, 32, 33, 34, 35, 38), orientações para o seguimento dos participantes após o curso (sessão 39). Quatro são sessões práticas, duas realizadas junto a mães em alojamento conjunto (sessões 7 e 12), uma junto a mães na UBS (sessão 35) e uma na cozinha sobre preparo de leites (sessão 24). Três sessões destinam-se a realizar exercícios escritos individuais sobre aconselhamento (sessões 6, 11 e 32).

O conjunto de materiais do curso é composto por: Guia do coordenador (com orientações sobre como organizar o curso), Guia do Facilitador (com as orientações sobre como conduzir as sessões, as técnicas de ensino e os materiais necessários), Manual do participante (com o conteúdo resumido das sessões e os exercícios), Álbum seriado (para ajudar o processo de tomada de decisão no caso de mães HIV positivo); diapositivos utilizados em cada sessão e Guia para o seguimento após o curso. O material foi traduzido e adaptado ao português, exceto o Álbum seriado, para atender às finalidades deste estudo e de outro realizado por BASSICHETTO e REA (2008).

Doze facilitadores (3 médicos pediatras, 5 enfermeiras, 2 nutricionistas, 1 fonoaudióloga e 1 psicóloga) conduziram as sessões do Curso Integrado. Esses profissionais, com experiência em dar cursos sobre aconselhamento e manejo da lactação, foram capacitados mediante preparação e administração das sessões entre si, simulando a realização do curso.

\subsection{COLETA DE DADOS}

Os conhecimentos foram avaliados por meio da auto-aplicação de um questionário contendo 70 questões que aceitavam as respostas sim, não, não sei. As questões foram elaboradas de maneira a cobrir o conteúdo das 
sessões do Curso Integrado. Um pré-teste do formulário foi realizado com profissionais do PSF na zona leste de São Paulo. A resolução do teste foi feita individualmente ou com os profissionais reunidos em uma sala de aulas ou na própria unidade de saúde. Um membro da equipe da pesquisa sempre esteve presente para acompanhar o processo e esclarecer as dúvidas.

O teste de conhecimentos foi aplicado antes (teste inicial) e depois (teste final) da realização do $\mathrm{Cl}$, tanto aos profissionais do grupo intervenção quanto do grupo controle,

\subsection{BANCO DE DADOS E ANÁLISE}

Os formulários com o teste de conhecimentos foram avaliados pela autora e as notas calculadas como proporção de acertos, variando de 0,00 a 1,00. O banco de dados foi criado com o programa Epi-info 6.0, digitado independentemente por duas auxiliares de pesquisa e checado quanto à consistência.

$\mathrm{Na}$ análise, foram incluídos apenas os profissionais que responderam a ambos os testes de conhecimentos (inicial e final), totalizando 39 no grupo intervenção e 24 no grupo controle. O número de indivíduos passíveis de serem analisados em cada grupo confere ao estudo um poder de teste igual a $61 \%$ para detectar diferença de no mínimo 50\% entre o incremento médio das notas obtidas pelos grupos intervenção e controle,com alfa de 0,05 e teste monocaudal (BROWNER e col., 2006). A análise foi baseada na "intenção de tratar", em que foram considerados todos os profissionais elegíveis do grupo intervenção mesmo que não tenham participado do Cl (HOLLIS e CAMPBELL, 1999).

As notas e o "incremento das notas" (nota final menos a nota inicial) foram comparados com relação à média total e às médias dos blocos de 
questões, assim definidos: 16 questões sobre fundamentos da amamentação, 27 sobre práticas de amamentação, 7 sobre políticas de amamentação, 7 sobre alimentação infantil e HIV e 13 sobre alimentação complementar.

A comparação entre as médias das notas inicial e final foi feita por meio do teste não paramétrico de Wilcoxon para duas amostras pareadas. Para a comparação das médias das notas inicial e final e do incremento médio das notas entre os dois grupos foram utilizados o teste não paramétrico de Mann-Whitney e o teste $t$-Student, ambos destinados à análise de duas amostras independentes.

O efeito de potenciais variáveis de confundimento para a associação entre a variável explanatória (grupo intervenção vs. grupo controle) e o desfecho (incremento das notas) foi estudado por meio de regressão linear bivariada e múltipla. As variáveis que poderiam estar associadas ao desfecho foram incluídas uma a uma na análise de regressão linear múltipla, independentemente do valor de $p$ apresentado na análise bivariada. Permaneceram no modelo as variáveis que modificaram em mais de $10 \%$ o valor de $\beta$ da variável de estudo. Para o processamento dos dados utilizouse o programa SPSS for Windows 13.0.

Investigação de um possível efeito dose-resposta entre o "percentual de freqüência ao curso" e o "incremento das notas" entre os profissionais do grupo intervenção também foi realizada mediante regressão linear múltipla.

\subsection{ASPECTOS ÉTICOS}

O projeto de pesquisa foi aprovado pelo Comitê de Ética em Pesquisa da Faculdade de Saúde Pública da Universidade de São Paulo. Todos os profissionais assinaram um Termo de Consentimento Livre e Esclarecido. Os 
profissionais de Peruíbe foram informados sobre sua condição de grupo controle e para os quais o curso será oferecido posteriormente.

\section{RESULTADOS}

Os resultados referem-se a 63 profissionais que responderam ao teste de conhecimentos inicial e final: 39 do grupo intervenção (GI) e 24 do grupo controle (GC).

Observando-se as categorias profissionais (Tabela 1) nota-se que no GC o número de auxiliares de enfermagem é cerca de um terço do $\mathrm{Gl}$, ocorrendo o oposto com relação ao número de médicos do PSF.

Como se pode notar, há algumas características dos profissionais que são estatisticamente diferentes entre os dois grupos (Tabela 1). Os profissionais do Gl apresentam uma média de 16 anos de trabalho na área de saúde, o dobro do tempo dos controles. O Gl, em comparação ao GC, conta com uma maior proporção de profissionais que participaram anteriormente de cursos sobre aconselhamento e manejo da lactação $(84,6$ vs. $62,5 \%$ ), porém menor proporção deles referiu dedicar pelo menos metade do tempo ao atendimento das famílias (61,5 vs. $95,8 \%$ ).

Dos 39 profissionais do GI convidados a participar do Curso Integrado compareceram 31 (79,5\%). Apenas um deles era médico. O comparecimento ao curso foi irregular como pode ser visto no Quadro, devido a férias, licenças ou necessidade de participar das campanhas de câncer de colo uterino e imunização de idosos. Nenhum dos participantes compareceu a todas as sessões. A freqüência individual variou de 6 a $89 \%$ 
das sessões, sendo que $42 \%$ dos participantes assistiram a menos da metade das sessões.

A freqüência maior ao curso ocorreu nas primeiras sessões que tratam dos fundamentos da amamentação e nas sessões finais sobre alimentação complementar (Quadro). As sessões que fundamentam as noções de aconselhamento sobre "como construir a confiança e dar apoio" tiveram a presença de menos de $30 \%$ dos profissionais. As sessões relativas à alimentação e HIV, assim como aquelas sobre políticas de saúde relacionadas à amamentação apresentaram um comparecimento em torno de 35 a $40 \%$.

$\mathrm{Na}$ Tabela 2 são apresentadas as médias das notas obtidas no teste inicial. Observa-se não haver diferença significante nos conhecimentos entre os profissionais de ambos os grupos. A média de acertos das questões sobre fundamentos da amamentação é bastante elevada (cerca de 80\%), enquanto as médias mais baixas referem-se à alimentação infantil e HIV (cerca de 40\%). Uma diferença próxima do nível de significância é observada na média de conhecimentos sobre alimentação complementar, que é mais elevada no $G C(p<0,066)$.

Ao comparar as médias das notas do teste final com as notas do teste inicial (Tabela 3), verifica-se que houve um aumento estatisticamente significante nas médias totais e dos blocos em ambos os grupos, com exceção dos "fundamentos da amamentação" no GC.

O incremento médio total no $\mathrm{Gl}$ foi de 12 pontos percentuais em comparação a 8 no GC ( $p=0,044)$. Não se verificam, entretanto, diferenças significantes nos incrementos médios referentes aos blocos de questões (Tabela 4). 
O fato de a variável "incremento das notas" apresentar uma distribuição próxima da curva normal (Figura) permitiu a utilização da análise de regressão linear para avaliar a influência da intervenção sobre o aumento de conhecimento dos profissionais de saúde.

Os dados das análises de regressão linear bivariada e múltipla para o desfecho "incremento das notas" são apresentadas na Tabela 5. A análise múltipla indica que a variável "grupo" mantém uma associação positiva com significância estatística $(p=0,018)$ após ajuste para a variável de confundimento "tempo de atuação na área da saúde". Pertencer ao GI representou um ganho de 6 pontos percentuais na nota após a intervenção.

Entre os profissionais do grupo intervenção $(n=39)$, após ajuste pela variável de confundimento "tempo de atuação na área da saúde", observa-se na Tabela 6 que quanto maior a freqüência ao $\mathrm{Cl}$ maior foi a nota final $(p=0,047)$. A cada aumento de um ponto percentual na freqüência ao curso ocorreu um ganho de cerca de $10 \%$ na nota após a intervenção em relação a quem não participou do curso.

\section{DISCUSSÃO}

Trata-se do primeiro estudo de intervenção, cujo objetivo foi avaliar a efetividade de um novo curso da Organização Mundial da Saúde - o "Aconselhamento em alimentação de lactentes e crianças de primeira infância: um curso integrado" - no Programa Saúde da Família.

Este artigo destaca apenas os resultados quanto a conhecimentos dos profissionais submetidos à intervenção comparados aos que não 
participaram dela. De acordo com WASS e col. (2001), a discussão acerca da limitação das avaliações feitas por meio de testes de múltipla escolha ou por testes do tipo "verdadeiro/falso" tem levado a um interesse maior por meios que avaliam como o profissional lida com uma situação clínica dentro de um contexto específico. Testes de conhecimentos avaliam se o profissional sabe sobre um determinado assunto, ou seja, exploram apenas parte da base de uma pirâmide de competências.

Miller, citado por WASS e col. (2001), foi quem elaborou a pirâmide de competências, um modelo conceitual que delineia os aspectos envolvidos em estudos sobre validade. $\mathrm{Na}$ base desta pirâmide estariam os componentes relativos ao conhecimento - sabe e sabe como - que podem ser avaliados por testes escritos. No entanto, outros métodos mais sofisticados seriam necessários para avaliar as facetas mais importantes da competência - demonstra como e faz.

As principais limitações do estudo foram o tamanho reduzido da amostra, a não randomização dos indivíduos e a baixa freqüência dos profissionais ao curso.

As dificuldades operacionais foram grandes, o que deve ser levado em conta na organização de cursos futuros. A aplicação do Curso Integrado se estendeu por cinco meses. O efeito negativo deste arranjo foi a ocorrência de férias e campanhas de saúde pública que impediram a participação dos profissionais em todas as sessões. Por outro lado, a elevada proporção dos que já haviam feito anteriormente outros cursos sobre aleitamento materno (curso de 18 horas da Iniciativa Hospital Amigo da Criança e curso de Aconselhamento em amamentação) pode explicar, em parte, essa participação irregular.

A dificuldade de afastamento dos profissionais de suas tarefas habituais também não permitiu a formação de multiplicadores do curso 
dentro do município, o que seria desejável para a supervisão, manutenção de programas de reciclagem e capacitação de novos funcionários. Por isso, embora a última sessão do Curso Integrado seja dedicada ao desenho de uma proposta de seguimento após o curso, ela não foi objeto deste estudo. A capacitação de um supervisor local é altamente recomendável, conforme já constatado por REA e col., (1999) que avaliaram o Curso de Aconselhamento em Amamentação. Seu papel seria incentivar os participantes a utilizarem os conhecimentos e habilidades adquiridos durante o curso.

BASSICHETTO e REA (2008) avaliaram conhecimentos e práticas de médicos e nutricionistas submetidos ao Curso Integrado, por meio de estudo randomizado controlado. Os resultados mostraram que o curso foi efetivo em aumentar os conhecimentos e melhorar as práticas de anamnese alimentar, porém não levou a um aumento nas práticas de aconselhamento.

Em nosso estudo, observou-se um incremento médio nas notas, tanto no grupo intervenção quanto no controle. Embora pequeno, o incremento médio foi maior e estatisticamente significante no grupo intervenção. Pode ter contribuído para esse efeito modesto, a maior proporção de médicos no grupo controle em detrimento dos auxiliares de enfermagem. $O$ fato do grupo controle também apresentar médias mais elevadas nas notas do teste final poderia ser justificado pelo menos de três maneiras: o teste final ter sido mais fácil que o inicial, os profissionais deste grupo terem participado de algum evento sobre alimentação infantil ou terem lido sobre assunto durante o intervalo entre os dois testes.

Com relação ao aumento no incremento médio conforme o aumento na freqüência ao curso observado no estudo, não é possível descartar um maior interesse entre aqueles que tiveram maior freqüência ao curso. 
De forma geral, os profissionais sabiam bastante sobre os fundamentos da amamentação, sua importância para a saúde maternoinfantil e seus mecanismos fisiológicos. As médias das notas no teste de conhecimentos tendem a ser mais baixas nos itens "práticas de amamentação", “alimentação complementar" e, particularmente, "alimentação infantil e HIV". Com relação ao último, poderia ser justificado pelo fato de que nas situações de HIV as famílias são atendidas em unidades especializadas e, portanto, o tema seja menos debatido no PSF. Quanto à alimentação complementar pode-se explicar pelo fato deste tema ainda não ter sido incorporado nos cursos de capacitação com a mesma ênfase que o aleitamento materno.

No entanto, com relação a "práticas de amamentação" seria esperada uma maior proporção de acertos, uma vez que a maioria dos profissionais, especialmente no grupo intervenção, havia participado anteriormente de dois cursos sobre manejo da lactação. Avaliação de conhecimentos e práticas de 41 profissionais das equipes de PSF realizada em Montes Claros, MG (CALDEIRA e col., 2007), mostrou escores baixos nos conhecimentos sobre como lidar com os principais problemas de amamentação, sendo melhor o desempenho dos enfermeiros do que dos médicos.

Em Itapira (grupo intervenção), prevalece o modelo convencional de atenção apesar da implantação do PSF. As consultas quase sempre são realizadas pelos médicos, enquanto os enfermeiros e auxiliares realizam as pré-consultas. Nesse sentido, há pouca oportunidade destes profissionais colocarem em prática os conhecimentos adquiridos nos cursos sobre alimentação infantil. BEZERRA e col. (2007) ao avaliar 84 equipes de Saúde da Família e 42 UBS em Recife, discutem a situação de vulnerabilidade dos programas de incentivo ao aleitamento materno, seja nas unidades de saúde convencionais seja no PSF, que parecem ter piorado em comparação a anos anteriores. Notaram também que a maioria dos locais não conseguiu romper com o modelo curativo, mantendo um processo de trabalho fragmentado. 
Considerando a ausência dos médicos no curso, há que se perguntar até que ponto a intervenção poderá influenciar as práticas de aconselhamento das famílias de crianças pequenas. Os enfermeiros costumam realizar também atendimentos domiciliares nos quais são identificadas e orientadas as dificuldades com a amamentação, porém o mesmo não ocorre com os auxiliares. Um estudo qualitativo feito no Distrito Federal analisou a prática do auxiliar de enfermagem que atua no PSF (SHIMIZU e col., 2004). Constatou-se que esse profissional desenvolve tarefas de diferentes complexidades, porém com forte influência do modelo clínico. Os autores discutem a importância de resgatar a função educativa do auxiliar de enfermagem junto à comunidade.

Os enfermeiros de Maringá, PR, por sua vez, apontam o PSF como uma estratégia favorável para uma discussão crítica em busca da superação do paradigma biomédico da atenção à saúde (OLIVEIRA e MARCON, 2007). Nesse sentido, argumentam os autores, seria necessária uma maior ousadia na educação permanente dos profissionais.

Outras propostas dirigidas a UBS, como a Iniciativa Unidade Básica Amiga da Amamentação (IUBAAM), merecem ser levadas em consideração. Apesar de não discutir como lidar com a alimentação complementar, ela propõe modelos educativos para trabalhar o conteúdo de aleitamento materno junto às mulheres, que não são abordadas no Curso Integrado. OLIVEIRA e col. (2005) sugerem que a capacitação de profissionais de saúde, a conformação do trabalho em equipe e a implantação de normas e rotinas adequadas poderiam melhorar o aproveitamento do potencial da rede de atenção básica para o incentivo do aleitamento materno. Ao avaliar o resultado da implantação da IUBAAM, que foi lançada em 1999 pela Secretaria Estadual do Rio de Janeiro, os autores apontaram um possível efeito dose-resposta entre o número de UBS que implantaram essa proposta de trabalho e o aumento no índice de aleitamento materno do município. 
Segundo ROWE e col. (2005), nos países de baixa e média rendas os trabalhadores de saúde são muito importantes para colocar em prática as intervenções necessárias, porém com freqüência seu desempenho inadequado torna-se um problema. A análise de 11 revisões sobre 15 estratégias sugere que a distribuição de material escrito em geral é ineficiente, que a supervisão e auditoria costumam ser efetivos e que uma combinação de intervenções dá mais resultado do que uma intervenção isolada. Sugerem também que a educação à distância poderia apresentar a mesma efetividade do ensino convencional e seria mais barato.

\section{CONCLUSÃO}

Este estudo avaliou a efetividade do "Aconselhamento em alimentação de lactentes e crianças de primeira infância: um curso integrado", em aumentar os conhecimentos dos profissionais que atendem crianças cadastradas no PSF.

Aplicar o Curso Integrado na realidade do PSF no município selecionado mostrou-se operacionalmente difícil. As principais limitações do estudo foram o tamanho reduzido da amostra, a não randomização dos participantes e a freqüência irregular dos profissionais ao curso.

Houve uma melhora estatisticamente significante, embora modesta, nos conhecimentos dos participantes do "grupo intervenção" em comparação ao "grupo controle". Verificou-se também que a cada aumento percentual na freqüência ao curso ocorreu um ganho de cerca de $10 \%$ na nota após a intervenção em relação a quem não participou do curso. 
O investimento necessário para garantir a qualidade do curso aliada à dificuldade operacional levam ao questionamento acerca da adequação desse tipo de proposta de capacitação às equipes de PSF.

\section{REFERÊNCIAS}

Alves VS. Um modelo de educação em saúde para o Programa saúde da Família: pela integralidade da atenção e reorientação do modelo assistencial. Interface Comun Saúde Educ. 2005;9(16):39-52.

Ayres JRCM. Sujeito, intersubjetividade e práticas de saúde. Ciênc Saúde Coletiva. 2001;6(1):63-72.

Bassichetto KC, Rea MF. Aconselhamento em alimentação infantil: um estudo de intervenção. J Pediatr. (Rio J). 2008;84(1). No prelo.

Bezerra LCA, Frias PG, Vidal AS, Macedo VC, Vanderlei LC. Aleitamento materno: avaliação da implantação do programa em unidades básicas de saúde do Recife, Pernambuco. Ciênc Saúde Coletiva. 2007;12(5):1309-17.

Browner WS, Newman TB, Cummings SR, Hulley SB. Estimando o tamanho de amostra e o poder estatístico: pontos básicos. In: Hulley SB (coord.) Delineando a pesquisa clínica: uma abordagem epidemiológica. Trad. de Michael Schmidt Duncan e Ana Rita Peres. 2. ed. São Paulo: Artmed; 2006. p. 83-110.

Caldeira AP, Aguiar GN, Magalhães WAC, Fagundes GC. Conhecimentos e práticas de promoção do aleitamento materno em Equipes de Saúde da Família em Montes Claros, MG, Brasil. Cad Saúde Pública. 2007;23(8):196570.

Garrick C. Teaching for counselling skills. Med J Aust. 1979;2:358-9.

Hollis S, Campbell F. What is meant by intention to treat analysis? Survey of published randomized controlled trials. Br Med J. 1999;319:670-4 (acesso em 22 janeiro 2008). Disponível em http://bmj.com/cgi/content/full/319/7211/670 
Monte CMG, Giugliani ERJ. Recomendações para a alimentação complementar da criança em aleitamento materno. J Pediatr (Rio J). 2004;80(5 Sup):S131-S141.

MS - Ministério da Saúde. Guia alimentar para crianças menores de 2 anos. Brasília: Ministério da Saúde, 2002.

MS - Ministério da Saúde. Manejo e Promoção do Aleitamento Materno: curso de 18 horas para equipes de maternidades. Brasília, 2003.

Oliveira MIC, Camacho LAB, Souza IEO. Promoção, proteção e apoio à amamentação na atenção primária à saúde no Estado do Rio de Janeiro, Brasil: uma política de saúde pública baseada em evidências. Cad Saúde Pública. 2005;21(6):1901-10.

Oliveira RG, Marcon SS. Opinião de enfermeiros acerca do que é trabalhar com famílias no Programa Saúde da Família. Rev Latinoam Enferm. 2007;15(3). (acesso em 30 outubro 2007). Disponível em: http:// www.scielo.br/pdf/rlae/v15n3/pt_v15n3a11.pdf

OMS e UNICEF - Organização Mundial da Saúde e Fundo das Nações Unidas para a Infância. Promoção do aleitamento materno nas instituições de saúde: curso intensivo para planejadores e gestores de saúde. Rea MF (coord.). Instituto de Saúde, 1999.

OMS e UNICEF - Organização Mundial da Saúde e Fundo das Nações Unidas para a Infância. Aconselhamento em amamentação: um curso de treinamento. Edição em português revisada. Rea MF (coord.). Trad. de Cristina M. G. Monte. Instituto de Saúde, 1997.

OMS, UNICEF e UNAIDS. Organização Mundial da Saúde, Fundo das Nações Unidas para a Infância e Programa das Nações Unidas para Aids. Aconselhamento em HIV e alimentação infantil: um curso de treinamento. Edição em português. Rea MF (coord.). Trad. de Cristina M. G. Monte. Instituto de Saúde, 2003.

OMS - Organização Mundial da Saúde. Estratégia global para a alimentação de lactentes e crianças de primeira infância. São Paulo: IBFAN Brasil; 2005. (acesso em 11 agosto 2007). Disponível em: http://www.ibfan.org.br/documentos.

Rea MF, Venancio SI, Martines JC, Savage F. Counselling on breastfeeding: assessing knowledge and skills. Bull World Health Organ. 1999;77(6):492-8.

Rea MF. Reflexões sobre a amamentação no Brasil: de como passamos a 10 meses de duração. Cad Saúde Pública. 2003;19(1 Supl):S37-S45. 
Rowe AK, De Savigny D, Lanata CF, Victora CG. How can we achieve and maintain high-quality performance of health workers in low-resource settings? Lancet. 2005;9 (acesso em 30 outubro 2007). Disponível em: http:// info.worldbank.org/etools/docs/library/206759/Rowe\%20Lancet.pdf

Santos IS, Victora CG, Martines J, Gonçalves H, Gigante DP, Valle NJ, Pelto G. Avaliação da eficácia do aconselhamento nutricional dentro da estratégia do AIDPI (OMS/UNICEF). Rev Bras Epidemiol. 2002;5(1):15-29.

Shimizu HE, Dytz JLG, Lima MG, Moura AS. A prática do auxiliary de enfermagem do Programa Saúde da Família. Rev Latinoam Enferm. 2004;12(5):713-20.

Temporão JG. Apresentação. Revista Brasileira Saúde da Família $n^{\circ} 15$. Brasília: Ministério da Saúde, 2007. (acesso em 23 janeiro 2008). Disponível em

http://dtr2004.saude.gov.br/dab/docs/publicacoes/revistas/revista_saude_ familia 15. pdf

UNICEF - The United Nations Children's Fund. Celebrating the Innocenti Declaration on the Protection, Promotion and Support of Breastfeeding: past achievements, present challenges and the way forward for infant and young child feeding. Florencia: UNICEF Innocenti Research Centre, 2005.

Wass V, van der Vleuten C, Shatzer J, Jones R. Assessment of clinical competence. Lancet 2001;357:945-9.

WHO - World Health Organization. Counselling on complementary feeding: a training course. Geneva, 2003.

WHO - World Health Organization. Integrated Infant Feeding Counselling: a training course. Third draft. Geneva, 2005. 
Tabela 1. Distribuição dos profissionais que atendem as crianças cadastradas no Programa Saúde da Família, segundo algumas características selecionadas, nos Grupos Intervenção (GI) e Controle (GC). Itapira e Peruíbe, SP, 2007.

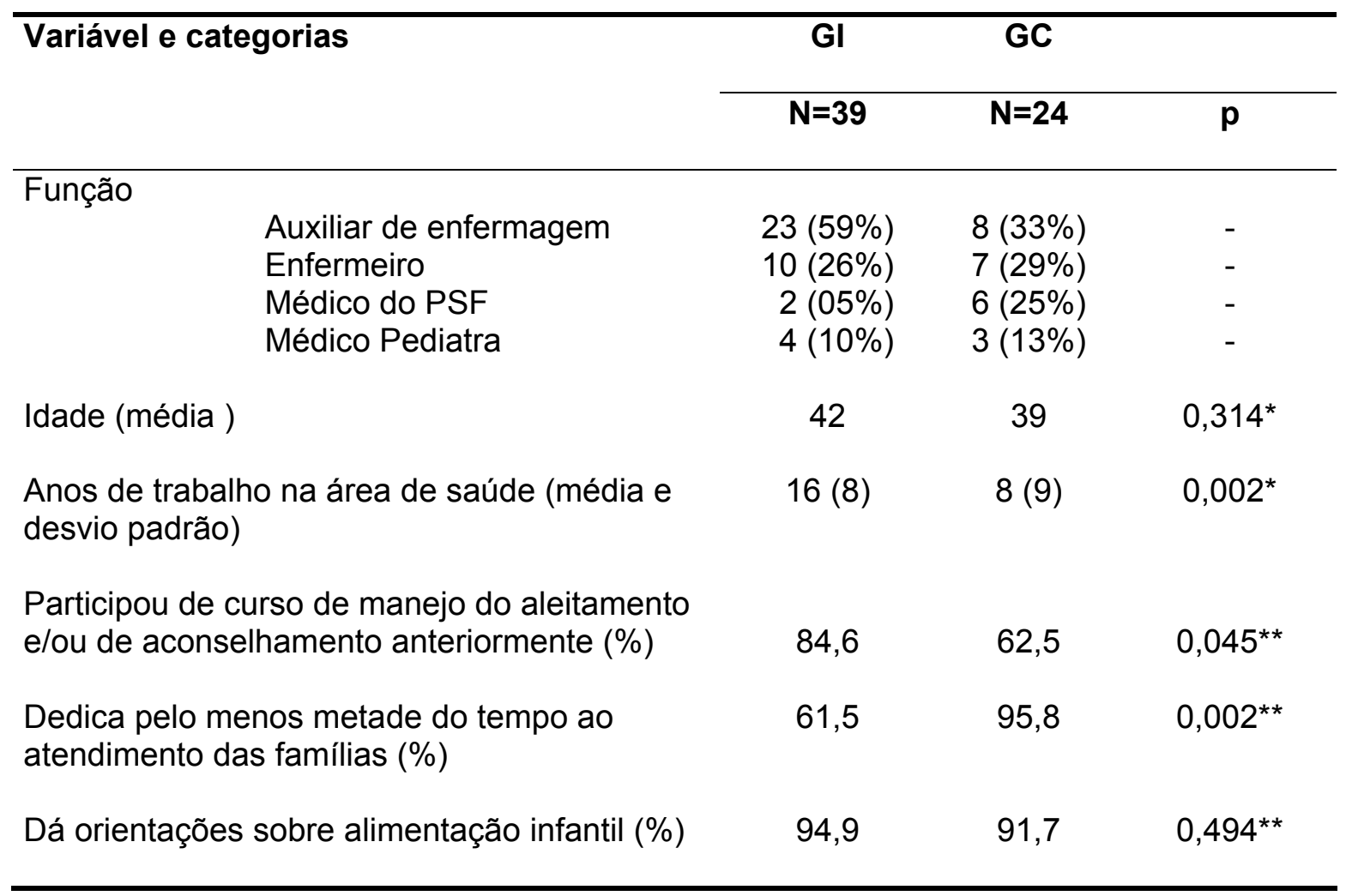

*Teste $t$-Student para duas amostras independentes com IC 95\%.

**Qui-quadrado ou teste exato de Fisher quando as células contêm menos de 5 casos. 
Quadro. Sessões do "Aconselhamento em Alimentação de Lactentes e Crianças de Primeira Infância: um curso integrado" e porcentagem de freqüência dos 31 participantes a cada sessão. Itapira e Peruíbe, SP, 2007.

\begin{tabular}{|c|c|}
\hline Sessões do curso & $\begin{array}{c}\text { Freqüência } \\
\%\end{array}$ \\
\hline 01. Introdução ao tema da alimentação de lactentes e crianças de primeira infância & 67,7 \\
\hline 02. Por que a amamentação é importante? & 67,7 \\
\hline 03. Como a amamentação funciona & 54,8 \\
\hline 04. Como avaliar uma mamada & 77,4 \\
\hline 05. Como ouvir e aprender & 74,2 \\
\hline 06. Exercícios sobre como ouvir e aprender & 74,2 \\
\hline 07. Prática 1: Como ouvir e aprender; como avaliar uma mamada & 61,3 \\
\hline 08. Como posicionar o bebê para mamar & 58,1 \\
\hline 09. Gráficos de crescimento & 29,0 \\
\hline 10. Como construir a confiança e dar apoio & 29,0 \\
\hline 11. Exercícios sobre como construir a confiança e dar apoio - Parte 1 & 25,8 \\
\hline 12. Prática 2: Como construir a confiança e dar apoio; como posicionar o bebê para mamar & 51,6 \\
\hline 13. Como colher uma história alimentar & 48,4 \\
\hline 14. Dificuldades comuns na amamentação & 22,6 \\
\hline 15. Ordenha do leite materno & 45,2 \\
\hline 16. Como alimentar com xícara & 41,9 \\
\hline 17. Visão geral sobre HIV e alimentação infantil & 41,9 \\
\hline 18. Aconselhamento para as decisões sobre alimentação infantil & 41,9 \\
\hline 19. Relactação e lactação induzida & 41,9 \\
\hline 20. Condições da mama & 38,7 \\
\hline 21. Alimentação de substituição nos primeiros seis meses & 41,9 \\
\hline 22. Preparação higiênica dos alimentos & 35,5 \\
\hline 23. Como preparar as refeições de leite - medidas & 35,5 \\
\hline 24. Prática 3: Como preparar as refeições de leite & 35,5 \\
\hline 25. Práticas de atenção à saúde & 38,7 \\
\hline $\begin{array}{l}\text { 26. Código Internacional de Comercialização de Substitutos do Leite Materno e } \\
\text { legislação nacional }\end{array}$ & 41,9 \\
\hline 27. Cartões e instrumentos para aconselhamento de mulheres HIV-positivo & Não houve \\
\hline 28. Importância da alimentação complementar & 58,1 \\
\hline 29. Alimentos para suprir a lacuna de energia & 58,1 \\
\hline 30. Alimentos para suprir as lacunas de Ferro e vitamina $A$ & 58,1 \\
\hline 31. Quantidade, variedade e freqüência da alimentação & 54,8 \\
\hline 32. Exercícios sobre como construir a confiança e dar apoio - Parte 2 & 51,6 \\
\hline 33. Como colher informações sobre práticas de alimentação complementar & 51,6 \\
\hline 34. Técnicas de alimentação & 54,8 \\
\hline 35. Prática 4: Como colher informações sobre práticas de alimentação complementar & 51,6 \\
\hline 36. Como confirmar o entendimento e marcar consulta de acompanhamento & 67,7 \\
\hline 37. Como alimentar bebês de baixo peso ao nascer e crianças doentes & 67,7 \\
\hline 38. Demonstração do preparo de alimentos & 64,5 \\
\hline 39. Seguimento após o curso & Não houve \\
\hline
\end{tabular}


Tabela 2. Média da nota inicial dos profissionais que atendem crianças cadastradas no Programa Saúde da Família segundo blocos de questões sobre nutrição e alimentação infantil, nos Grupos Intervenção (GI) e Controle (GC). Itapira e Peruíbe, SP, 2007.

\section{Blocos de questões}

Média (desvio padrão) da nota inicial

\begin{tabular}{ccc}
\hline GI & GC & \\
\hline $\mathbf{N}=39$ & $\mathbf{N}=24$ & $\mathbf{p}^{*}$
\end{tabular}

Amamentação - fundamentos

$0,78(0,15)$

$0,80(0,14)$

0,582

Amamentação - práticas

$0,60(0,13)$

$0,57(0,11)$

0,333

Amamentação - políticas

$0,66(0,21)$

$0,65(0,19)$

0,971

HIV e alimentação infantil

$0,37(0,22)$

$0,43(0,20)$

0,340

Alimentação complementar

$0,51(0,17)$

$0,60(0,14) \quad 0,066$

TOTAL

$0,60(0,12)$

$0,62(0,09)$

0,387

* Mann-Whitney, teste não paramétrico para comparar duas amostras independentes. 
Tabela 3. Médias das notas inicial e final dos profissionais que atendem crianças cadastradas no Programa Saúde da Família, segundo blocos de questões, nos Grupos Intervenção (GI) e Controle (GC). Itapira e Peruíbe, SP, 2007.

\begin{tabular}{|c|c|c|c|c|c|c|}
\hline \multirow[t]{3}{*}{ Blocos de questões } & \multicolumn{6}{|c|}{ Média (desvio padrão) das notas inicial e final } \\
\hline & \multicolumn{3}{|c|}{ GI (N=39) } & \multicolumn{3}{|c|}{$G C(N=24)$} \\
\hline & Inicial & Final & $\mathbf{p}^{*}$ & Inicial & Final & $\mathbf{p}^{*}$ \\
\hline Amamentação: fundamentos & $0,78(0,15)$ & $0,83(0,12)$ & 0,003 & $0,80(0,14)$ & $0,81(0,12)$ & 0,955 \\
\hline Amamentação: práticas & $0,60(0,13)$ & $0,69(0,13)$ & 0,000 & $0,57(0,11)$ & $0,63(0,10)$ & 0,028 \\
\hline Amamentação: políticas & $0,66(0,21)$ & $0,80(0,18)$ & 0,001 & $0,65(0,19)$ & $0,79(0,17)$ & 0,009 \\
\hline HIV e alimentação infantil & $0,37(0,22)$ & $0,60(0,20)$ & 0,000 & $0,43(0,20)$ & $0,57(0,19)$ & 0,007 \\
\hline Alimentação complementar & $0,51(0,17)$ & $0,67(0,17)$ & 0,000 & $0,60(0,14)$ & $0,72(0,14)$ & 0,003 \\
\hline TOTAL & $0,60(0,12)$ & $0,72(0,11)$ & 0,000 & $0,62(0,09)$ & $0,70(0,08)$ & 0,000 \\
\hline
\end{tabular}

* Wilcoxon, teste não paramétrico para comparar duas amostras pareadas. 
Tabela 4. Incremento médio das notas dos profissionais que atendem crianças cadastradas no Programa Saúde da Família, segundo blocos de questões, nos Grupos Intervenção (GI) e Controle (GC). Itapira e Peruíbe, SP, 2007.

Blocos de questões

Incremento médio das notas (desvio padrão)

Gl $\quad$ GC

\begin{tabular}{lcccc} 
& $\mathbf{N}=\mathbf{3 9}$ & $\mathbf{N}=\mathbf{2 4}$ & $\mathbf{p}^{*}$ & $\mathbf{p}^{* *}$ \\
\hline Amamentação - fundamentos & $0,05(0,11)$ & $0,01(0,12)$ & 0,514 & 0,126 \\
Amamentação - práticas & $0,09(0,11)$ & $0,06(0,11)$ & 0,250 & 0,370 \\
Amamentação - políticas & $0,14(0,21)$ & $0,14(0,22)$ & 0,803 & 0,977 \\
HIV e alimentação infantil & $0,23(0,24)$ & $0,14(0,22)$ & 0,137 & 0,154 \\
Alimentação complementar & $0,15(0,17)$ & $0,12(0,15)$ & 0,569 & 0,468 \\
TOTAL & $0,12(0,09)$ & $0,08(0,08)$ & 0,044 & 0,047
\end{tabular}

* Mann-Whitney, teste não paramétrico para comparar duas amostras independentes.

${ }^{* *}$ Teste $t$-Student, para comparar médias entre duas amostras independentes. 
Figura. Histograma do incremento médio das notas dos profissionais que atendem crianças cadastradas no Programa Saúde da Família. Itapira e Peruíbe, SP, 2007.

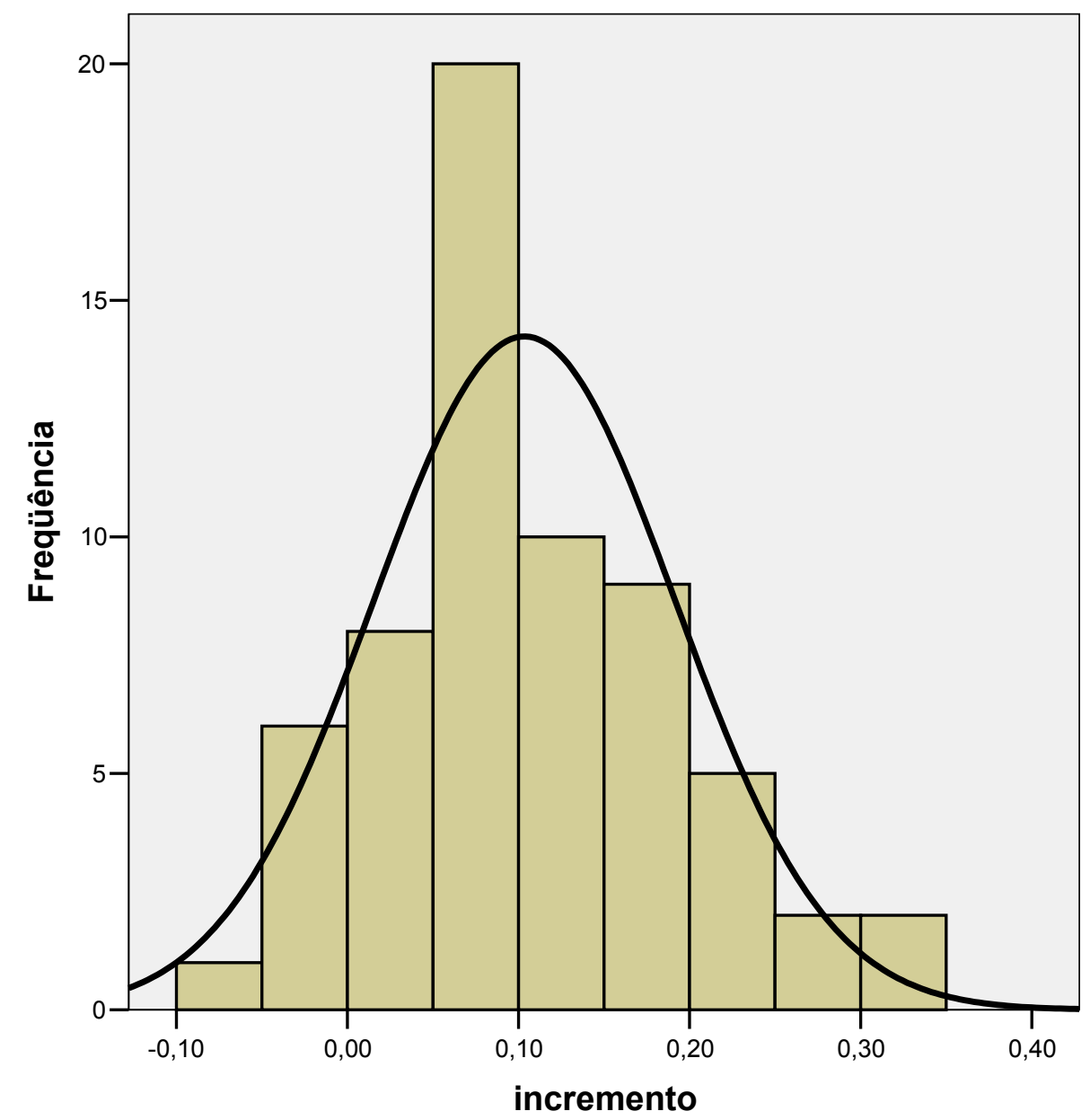

Mean $=0,1035$

Std. Dev. $=0,08827$

$\mathrm{N}=63$ 
Tabela 5. Análise de regressão linear bivariada e múltipla $(N=63)$ : efeito da intervenção e das variáveis de confundimento sobre o incremento médio das notas dos profissionais que atendem crianças cadastradas no Programa Saúde da Família. Itapira e Peruíbe, SP, 2007.

\begin{tabular}{llll}
\hline Variável & $\beta$ & IC 95\% & $p$
\end{tabular}

\section{Análise bivariada}

\begin{tabular}{llll}
\hline Grupo & 0,045 & $(0,001 ; 0,090)$ & 0,047
\end{tabular}

(0. controle; 1 . intervenção)

Tempo de atuação na área da saúde

$$
-0,002 \quad(-0,006 ; 0,001) \quad 0,210
$$

(1 a 29 anos)

Ter recebido previamente curso de

$$
0,000 \quad(-0,052 ; 0,053) \quad 0,994
$$
aconselhamento ou de manejo da lactação

(0. não; 1. sim)

Categoria profissional

(0. não médico; 1 . médico)

$-0,059 \quad(-0,109 ;-0,008) \quad 0,023$

\section{Análise múltipla*}

Grupo

$$
0,063 \quad(0,012 ; 0,115) \quad 0,018
$$

(0. controle; 1 . intervenção)

* Ajustado por tempo de atuação na área da saúde. 
Tabela 6. Análise de regressão linear bivariada e múltipla $(N=39)$ : efeito da freqüência ao Curso Integrado e das variáveis de confundimento sobre o incremento médio das notas dos profissionais que atendem crianças cadastradas no Programa Saúde da Família. Itapira e Peruíbe, SP, 2007.

\begin{tabular}{|c|c|c|c|}
\hline Variável & $\beta$ & IC 95\% & $p$ \\
\hline \multicolumn{4}{|c|}{ Análise bivariada } \\
\hline $\begin{array}{l}\text { Percentual de freqüência ao curso } \\
\qquad(0 \text { a } 89 \%)\end{array}$ & 0,127 & $(0,040 ; 0,214)$ & 0,005 \\
\hline $\begin{array}{l}\text { Tempo de atuação na área da saúde } \\
\qquad(1 \text { a } 27 \text { anos) }\end{array}$ & $-0,003$ & $(-0,007 ; 0,002)$ & 0,255 \\
\hline $\begin{array}{l}\text { Ter recebido previamente curso de } \\
\text { aconselhamento ou de manejo da lactação } \\
\text { (0. não; } 1 \text {. sim) }\end{array}$ & $-0,021$ & $(-0,101 ; 0,059)$ & 0,603 \\
\hline $\begin{array}{l}\text { Categoria profissional } \\
\text { (0.não médico; 1.médico) }\end{array}$ & $-0,082$ & $(-0,157 ;-0,006)$ & 0,035 \\
\hline
\end{tabular}

\section{Análise múltipla*}

\begin{tabular}{rrrr}
\hline Percentual de freqüência ao curso & 0,091 & $(0,001 ; 0,181)$ & 0,047 \\
(0 a 89\% ) & & &
\end{tabular}

* Ajustado por tempo de atuação na área da saúde. 


\section{RELATÓRIO TÉCNICO}

Introdução

Objetivos

Métodos

Área de estudo 96

Grupos de estudo 97

Intervenção e logística 98

Coleta de dados 99

Instrumentos de pesquisa 100

Controle de qualidade 100

Aspectos éticos 


\section{INTRODUÇÃO}

Em 2005, técnicos da Organização Mundial da Saúde (OMS) elaboraram um novo curso denominado "Aconselhamento em alimentação de lactentes e crianças de primeira infância: um curso integrado", conhecido e divulgado como Curso Integrado, por reunir o conteúdo dos três cursos anteriormente desenvolvidos em separado e nessa seqüência Aconselhamento em amamentação, Aconselhamento em alimentação infantil e HIV, Aconselhamento em alimentação complementar.

O Aconselhamento em amamentação, lançado em meados da década de noventa foi traduzido, avaliado e bem aceito aqui no Brasil. O Ministério da Saúde o levou para várias regiões do país, capacitando facilitadores em seus centros de referência. Esse curso trazia a novidade de lidar com técnicas de aconselhamento, muito pouco abordadas no curso de capacitação proposto para a Iniciativa Hospital Amigo da Criança (conhecido como curso de 18 horas).

O curso de Aconselhamento em alimentação infantil e HIV também foi traduzido e aplicado em São Paulo para verificar sua adequação ao nosso meio, considerando a política bem estruturada nessa área em nosso país. Apesar de trazer conteúdos novos e relevantes sobre aconselhamento em situações particularmente difíceis como o HIV, ele não teve a mesma aceitação por aqui.

Quanto ao Aconselhamento em alimentação complementar foi parcialmente traduzido, discutido entre poucos profissionais interessados, porém nunca foi implementado no Brasil.

Essa nova proposta, o Curso Integrado, teria como vantagem trabalhar todo esse conteúdo em 35 horas, ao passo que dar os cursos de 
aconselhamento separadamente implicaria em praticamente três vezes o número de horas.

O Curso Integrado foi avaliado em 2005, pela nutricionista Kátia C. Bassichetto, cuja tese de doutorado teve como orientadora a Dra. Marina F. Rea. Ele foi utilizado na capacitação de médicos pediatras e nutricionistas de Unidades Básicas de Saúde (UBS) no município de São Paulo, sendo um grupo intervenção e outro controle. Avaliaram-se conhecimentos e práticas desses profissionais antes e após intervenção, por meio de teste de múltipla escolha e observação de consultas.

Observa-se uma grande expansão do PSF no país e a crescente preocupação com os conhecimentos e habilidades das equipes em lidar com o aleitamento materno. Então, surgiu a curiosidade de verificar até que ponto o Curso Integrado poderia contribuir na capacitação dessas equipes, uma vez que a proposta se destina a diferentes tipos de profissionais e, inclusive a aconselhadores leigos.

O projeto que resultou nesta tese, está sob responsabilidade da Dra. Marina F. Rea, pesquisadora do Instituto de Saúde da SES-SP e coorientadora do doutorado, tendo sido aprovado pelo DECIT/CNPq em dezembro de 2005.

Outros dados, além dos apresentados nos três artigos, foram coletados e serão analisados posteriormente, tais como as práticas de alimentação das crianças acima dos seis meses de idade, os pesos das crianças de 0 a 18 meses, assim como as práticas dos profissionais de saúde a partir da análise das observações de consultas. 


\section{OBJETIVOS}

O objetivo geral foi avaliar a efetividade do Curso Integrado, seguido de 3 meses de supervisão sobre a alimentação apropriada de crianças pequenas assistidas pelo Programa Saúde da Família.

Este objetivo foi realizado parcialmente, uma vez que não foi possível viabilizar o seguimento de 3 meses, nem a avaliação das práticas alimentares das crianças após a intervenção dentro do prazo do doutoramento, devido a atraso na liberação dos recursos aprovados pelo CNPq, além das vicissitudes do campo.

Os objetivos específicos foram avaliar a efetividade do Curso Integrado sobre:

1. os conhecimentos e práticas dos trabalhadores do PSF sobre alimentação infantil;

2. as práticas de mães e/ou cuidadores assistidas pelo PSF com relação à alimentação de crianças pequenas

Os objetivos 1 e 2 foram alcançados parcialmente. Não foi possível avaliar dentro do prazo as práticas alimentares das crianças após a intervenção. As práticas dos trabalhadores foram avaliadas antes e após a intervenção, porém serão analisados futuramente.

\section{Hipóteses do estudo}

a. Hipótese nula 1: a melhoria nos conhecimentos é a mesma entre os trabalhadores de PSF submetidos ao Curso Integrado e os trabalhadores de PSF não submetidos à intervenção. Esta hipótese foi testada e é apresentada no Artigo 3. 
b. Hipótese nula 2: a melhoria na orientação às mães sobre alimentação apropriada de crianças de 0 a 18 meses é a mesma entre os trabalhadores de PSF submetidos ao Curso Integrado e os trabalhadores de PSF não submetidos à intervenção. Há dados para testar esta hipótese, porém serão processados posteriormente.

c. Hipótese nula 3: as práticas de mães e/ou cuidadores com relação à alimentação de crianças de 0 a 18 meses de idade é a mesma entre aquelas assistidas trabalhadores de PSF submetidos ao Curso Integrado e os trabalhadores de PSF não submetidos à intervenção. Foram colhidos dados apenas antes da intervenção, não sendo possível testar esta hipótese.

\section{MÉTODOS}

\section{Área de estudo}

O projeto apresentado no início previa a realização apenas no município de Itapira, que fora selecionado por contar com um Hospital Amigo da Criança e Unidades Básicas de Saúde relativamente bem organizadas com relação à promoção e apoio do aleitamento materno (conforme conhecimento prévio em visita de avaliação do hospital quando este era candidato ao título de Amigo da Criança, em 1994-5). Além disso, havia uma comunicação adequada com a Secretaria Municipal de Saúde e a distância de São Paulo era administrável.

$\mathrm{Na}$ fase de qualificação, membros da banca recomendaram que o estudo fosse realizado em dois municípios, uma vez que a amostra de profissionais era pequena e seria praticamente impossível evitar a "contaminação" entre os grupos intervenção e controle na cidade de Itapira. De fato, existem naquele município 10 equipes de PSF alocadas em 7 UBS, 
ou seja em 3 UBS há 2 equipes de PSF compartilhando o mesmo espaço. Em função disso, buscou-se um outro município que pudesse ser o controle, levando em conta os critérios de similaridade acima citados. Após levantamento das possibilidades, dois municípios se aproximavam desses critérios - Tupã e Peruíbe. Tupã foi descartada como opção dada a distância que a separa de São Paulo, restando então o município de Peruíbe.

\section{Grupos de Estudo}

a) trabalhadores de saúde de nível universitário (médicos, enfermeiras) e de nível médio (auxiliares de enfermagem);

b) mães e/ou cuidadores de crianças de 0 a 18 meses assistidas pelo PSF

Critérios de Inclusão dos trabalhadores de saúde:

1. fazer parte das equipes de PSF ou atender as crianças do PSF

2. consentir em participar do estudo

Critérios de Exclusão dos trabalhadores de saúde:

1. não atender crianças do PSF

2. atuar nos PACS que atendem a zona rural

Critérios de Inclusão das mães/cuidadores:

1. ter criança de 0 a 18 meses de idade.

2. ser assistida pelo PSF.

3. consentir em participar do estudo.

Critérios de exclusão das mães/cuidadores:

1. ter criança com problemas de saúde que exijam cuidados específicos sobre alimentação e nutrição, tais como doenças cardíaca, renal, hepática, metabólicas e malformações congênitas; 
2. ter criança com episódio grave de doença ou internada no momento da entrevista;

3. ter crianças gêmeas;

4. ser assistida pelo PACS.

\section{Intervenção e logística}

A intervenção consistiu na aplicação do Curso Integrado e distribuição do Manual do Participante a todos os profissionais do grupo intervenção.

Antes da intervenção, foi realizada uma avaliação das práticas das mães assistidas pelo PSF com relação à alimentação de suas crianças de 0 a 18 meses (período e tipos de alimentos oferecidos, entre os quais leites, alimentos líquidos e sólidos de consumo das famílias).

Os trabalhadores de saúde dos grupos intervenção e controle tiveram seus conhecimentos e práticas sobre alimentação de crianças pequenas avaliados antes e após o término da intervenção.

Para efetivação do curso, contava-se com um profissional que atuava na Secretaria Municipal de Saúde, mas que se desligou antes que a intervenção fosse realizada. No entanto, sua colaboração facilitou o acesso à infra-estrutura necessária, tais como providenciar o local para as sessões teóricas e práticas, materiais de apoio, etc.

O Curso Integrado, elaborado pela OMS com o objetivo de atender à demanda dos países quanto ao fortalecimento da amamentação e desenvolvimento de práticas apropriadas de alimentação complementar, tem duração aproximada de 35 horas e o conteúdo é abordado por meio de métodos de ensino variados, desde palestras até exercícios individuais, exercícios em grupo, demonstrações e 4 aulas práticas com mães em Maternidade e em Unidade Básica de Saúde e preparo de alimentos. O 
curso já foi previamente testado em 4 países com diferentes realidades de sistemas de saúde e as adaptações relevantes já foram incorporadas.

Na época de preparação do material, a versão sobre a qual se trabalhou foi o último rascunho. Houve necessidade de adaptação das sessões relativas a alimentação infantil e HIV, assim como algumas partes das sessões sobre alimentação complementar de acordo com as orientações recomendadas pelo Ministério da Saúde. Uma sessão sobre HIV foi suprimida, sendo elaborada uma sobre Relactação e lactação induzida para substituí-la.

O Curso foi aplicado em três etapas:

1. na primeira, realizou-se a formação dos 12 facilitadores; contudo, não se conseguiu envolver líderes locais para serem futuros multiplicadores do curso na região;

2. na segunda, o curso foi oferecido aos trabalhadores das UBS que atendem crianças do PSF (médicos, enfermeiros e auxiliares de enfermagem);

3. na terceira, os agentes de saúde foram capacitados após adaptação do material para essa categoria de trabalhadores, com carga horária de 12 horas. No entanto, não foram realizadas avaliações deste grupo.

\section{Coleta de dados}

a. Os conhecimentos dos trabalhadores de saúde de níveis universitário (médicos, enfermeiras) e médio (auxiliares de enfermagem), dos grupos intervenção e controle, foram coletados por meio de questionário estruturado auto-aplicável em 2 momentos: antes e após a intervenção. 
b. As práticas dos trabalhadores de saúde dos grupos intervenção e controle foram obtidas em observação de consultas por meio de formulário estruturado, assim como nas entrevistas com as mães antes e após a intervenção.

c. As práticas das mães atendidas pelos trabalhadores dos grupos intervenção e controle foram coletados por meio de questionário semiestruturado em entrevistas domiciliares antes da intervenção. Além da entrevista, as crianças foram pesadas utilizando-se balança eletrônica.

\section{Instrumentos de pesquisa}

Os seguintes instrumentos foram utilizados para a obtenção dos dados da pesquisa e encontram-se em anexo:

- Questionário estruturado contendo 70 questões que aceitavam as respostas sim, não e não sei, para avaliar os conhecimentos dos trabalhadores de saúde sobre aconselhamento em alimentação de crianças pequenas (em anexo);

- Formulário estruturado para observação de consultas (em anexo);

- Questionário semi-estruturado para as entrevistas de mães no domicílio, com questões relativas a critérios de inclusão e de exclusão, dados sócio-econômicos e demográficos, recordatório alimentar das últimas 24 horas (em anexo);

Todos os instrumentos foram pré-testados e acompanhados por um manual detalhado de instruções. Todos os entrevistadores e observadores foram adequadamente treinados. Realizou-se uma checagem por telefone de cerca de $20 \%$ das entrevistas.

\section{Controle de qualidade}

O controle de qualidade foi feito mediante: 
- seleção, treinamento e padronização dos conhecimentos e utilização dos métodos de ensino dos facilitadores previamente à aplicação do curso;

- discussão de cada sessão entre os facilitadores;

- questionário de avaliação das sessões quanto ao conteúdo, tempo e didática preenchido por cada um dos participantes do curso;

- uso de questionários e formulários padronizados, pré-testados e acompanhados de um manual de instruções detalhado;

- seleção e avaliação cuidadosa dos entrevistadores;

- entrevistadores foram cegos quanto aos objetivos do estudo e à intervenção;

- treinamento dos entrevistadores com relação à aplicação dos questionários;

- checagem de pelo menos $10 \%$ das entrevistas;

- dupla digitação simultânea dos dados com checagem para variação e consistência.

\section{ASPECTOS ÉTICOS}

O estudo seguiu as recomendações estabelecidas pelas Portarias 196/96 e 251/97 do Conselho Nacional de Saúde.

Para garantir a salvaguarda ética foram considerados:

- Aprovação por um Comitê de Ética em Pesquisa: $O$ projeto foi submetido e aprovado pelo Comitê de Ética em Pesquisa da Faculdade de Saúde Pública (parecer em anexo).

- Consentimento informado individual (em anexo) foi obtido dos trabalhadores de saúde dos grupos intervenção e controle e das mães de crianças de 0 a 18 meses de idade selecionadas para o estudo. Todos esses sujeitos receberam uma descrição clara sobre os objetivos do 
estudo e os procedimentos a que serão submetidos. Após completa compreensão das informações foram convidados a assinar o Termo de Consentimento, estando livres para declinar de sua participação em qualquer período do estudo. Os trabalhadores receberam previamente informações sobre a pesquisa, em reunião que será agendada pela coordenadora do PSF local.

- Confidencialidade: Os trabalhadores de saúde e as mães foram identificados por uma série numérica e as informações individuais serão mantidas em sigilo.

- Encaminhamento a serviços de saúde: Crianças desnutridas e/ou doentes no momento da entrevista com as mães foram orientadas a buscar os serviços de saúde para receberem o cuidado apropriado.

- Trabalhadores de saúde do grupo controle: após o término do estudo, será oferecido o mesmo curso para os trabalhadores de saúde que fizeram parte do grupo controle.

- Devolução dos resultados: será feita por meio de um seminário destinado aos trabalhadores do PSF e por outros meios sugeridos pelos participantes do projeto. 


\section{ANEXOS}

Anexo 1 - Formulário para entrevista com mãe ou cuidador

Anexo 2 - Guia para a entrevista com mãe ou cuidador

Anexo 3 - Orientações para a pesagem das crianças

Anexo 4 - Teste de conhecimentos

Anexo 5 - Formulário para observação de consultas

Anexo 6 - Guia de orientações para observação de consultas

Anexo 7 - Termo de consentimento livre e esclarecido para as mães

Anexo 8 - Termo de consentimento livre e esclarecido para os Profissionais

Anexo 9 - Termo de consentimento livre e esclarecido para as observações de consulta 


\section{ANEXO 1}

\section{FORMULÁRIO PARA ENTREVISTA COM MAE OU CUIDADOR}

Caro(a) entrevistador(a):

1. Apresente-se e mostre seu crachá.

2. Verifique se estão corretas as informações da sua listagem: nome da mãe, nome e data de nascimento da criança.

3. A pesquisa é para as crianças que nasceram no dia $1^{\circ}$ de agosto de 2005 ou depois.

4. A criança não deve ser gemelar, nem ter alguma doença que exija uma dieta especial (diferente da maioria das crianças).

5. Antes de começar a entrevista, leia o Termo de Consentimento Livre e Esclarecido para a pessoa entrevistada, explique sua importância, peça para que ela assine o Termo e deixe uma cópia com ela.

6. Durante a entrevista, procure sempre deixar a pessoa à vontade; chame-a pelo nome; evite interrompê-la enquanto fala; não faça qualquer comentário sobre os serviços e profissionais de saúde; não dê conselho sobre qualquer aspecto da alimentação e saúde da criança.

7. A qualidade do seu trabalho é fundamental para o bom resultado da pesquisa. Preencha com atenção todas as questões para que sua entrevista não seja recusada.

ANTES DE COMEÇAR A ENTREVISTA, PREENCHA OS DADOS DE IDENTIFICAÇÃO. NÃO ASSINALE NAS ÁREAS SOMBREADAS

1. $N^{\circ}$ de Identificação:

2. Fase de aplicação:

3. Município:

( ) 1.Pré

( ) 2.Pós 1

4. Posto de Saúde:

( ) 1.Itapira ( ) 2.Peruíbe

5. Equipe de PSF:

6. Micro-área:

7. Nome da criança:

8. Sexo da criança $\quad$ ( )1.menina ( )2.menino

9. Data de nascimento:

10. Nome da pessoa entrevistada:

11. A pessoa entrevistada é a mãe da criança?

( ) $1 . \operatorname{sim}$

( ) 2.não [ANOTE qual é a relação da pessoa com a criança]:

12. Nome do(a) entrevistador(a):

13. Data da entrevista:

/ $/ 2007$

14. Duração da entrevista:

Início: .......... horas ......... minutos

Término:

horas

minutos

[COMECE A ENTREVISTA]:

15. A senhora poderia me dar seu número de telefone? Isso é importante para o caso de 
precisar conversar novamente com a senhora.

"Vamos começar falando sobre a gravidez e o nascimento do(a) ...."[diga o nome da criança] PERGUNTE PARA TODAS AS MÃES

17. Durante o pré-natal, a senhora recebeu alguma orientação sobre aleitamento materno?
( )0.não
( ) $1 . \operatorname{sim}$

18. Onde ele(a) nasceu?

( )1. Hospital Municipal de Itapira

( ) 2. Santa Casa de Itapira

( ) 3. Santa Casa de Peruíbe

( ) 4 . Em casa

( ) 5.Outra resposta [ANOTE nome do hospital e cidade]:

19. Qual foi o tipo de parto?

( )1.vaginal ( )2.cesárea

20. Com quantos quilos ele(a) nasceu? [ANOTE]:

quilos e gramas

21. Ele(a) nasceu com saúde?

( )0.não

( )1.sim

22. Logo que nasceu, a senhora pegou ele(a) no colo?

23. Logo que nasceu, a senhora deu de mamar no peito?

( ) 0.não

( ) 0.não

( ) 0.não ( )1.sim [PULE para a questão 26]

25. Por que não ficou no quarto junto com a senhora? [ANOTE]:

26. Na maternidade, ele(a) mamou no peito?

27. Na maternidade, a senhora recebeu ajuda para dar de mamar no peito?

( ) 0.não [PULE para a questão 28]

( ) $1 . \operatorname{sim}$
( ) 0.não
( ) $1 . \operatorname{sim}$ 
28. Ele(a) saiu de alta da maternidade junto com a senhora?

( )0. não ( )1.sim [PULE para a questão 30]

29. Quantos dias ele(a) ficou na maternidade depois que a senhora saiu de alta? dias

30. Depois que saiu da maternidade e veio para casa a senhora deu de mamar no peito?

( )0.não [PULE para a questão 35] ( )1.sim

31. A senhora teve alguma dificuldade ou problema com a amamentação?

( ) 0.não [PULE para a questão 35] ( )1.sim

32. Qual foi a dificuldade ou problema que a senhora teve? [ANOTE o mais detalhado possível]:

33. A senhora teve ajuda de alguém para resolver esse problema ou dificuldade?

( )0.não [PULE para a questão 35] ( )1.sim

34. Quem ajudou a senhora a resolver este problema? [ANOTE]:

"Hoje em dia ele(a) está com quantos meses?" "Vamos falar sobre a alimentação dele(a) hoje em dia."

meses).

35. Ele(a) mama no peito?

( )0.não ( )1.sim

36. Ele(a) toma água?

( )0.não ( )1.sim

37. Ele(a) toma chá?

( )0.não ( )1.sim

38. Ele(a) toma suco?

( )0.não ( )1.sim

39. Ele(a) come frutas?

( )0.não ( )1.sim

40. Ele(a) toma leite não materno?

( )0.não ( )1.sim

41.Ele(a) come comida ou papinha salgada?

( )0.não ( )1.sim

42. Ele(a) come lanche entre as refeições principais (por exemplo, pão com manteiga, mingau de aveia, vitamina de frutas, pão com queijo)?

43. Ele(a) come salgadinhos ou frituras?

( )0.não ( )1.sim

44. Ele(a) toma refrigerantes?

( )0.não ( )1.sim

( )0.não ( )1.sim

45. Ele(a) come doces entre as refeições?

( )0.não ( )1.sim

46. Ele(a) usa mamadeira ou chuquinha?

( ) 0.não ( ) 1.sim 
48. Desde que idade ele(a) chupa chupeta? [ANOTE em dias se foi antes de 1 mês]:

\section{SE A CRIANÇA NÃO MAMA NO PEITO, FAÇA ESTAS PERGUNTAS}

49. Até que idade ele(a) mamou no peito? [ANOTE]:

50. A senhora poderia me contar porque ele(a) parou de mamar no peito? [ANOTE o mais detalhado possível]:

\section{SE A CRIANÇA TOMA LEITE NÃO MATERNO, FAÇA ESTAS PERGUNTAS}

\section{[ANOTE o nome do leite]:}

53. Ontem de dia e de noite, quantas vezes ele(a) tomou esse leite?

[AJUDE a mãe a lembrar]

..vezes

54. A senhora põe alguma coisa no leite? $\quad$ ( ) 0.não [PULE para a questão 56] ( ) 1.sim

55. O que a senhora costuma por? [ANOTE]:

56. A senhora prepara o leite a cada mamada ou deixa pronto para várias mamadas?
( ) 1.prepara a cada mamada
( )2.prepara para várias mamadas

57. A senhora ferve o leite ou a água para preparar o leite antes de dar para a criança?

( ) 0. não ( ) 1.sim

58. O que a senhora faz com a sobra do leite depois que ele(a) mamou?

( )1.joga fora

( )2.guarda na geladeira e dá mais tarde para a criança

( )3.outra resposta [ANOTE]:

59. Com quem a senhora aprendeu a preparar o leite? [ANOTE]: 
60. Quantas vezes por semana a senhora dá frutas para ele(a)?

( )1.todos os dias ( )2.três vezes/semana ( )3.menos de 3 vezes/semana

61. A senhora costuma dar frutas de cor amarela ou alaranjada (por exemplo, mamão, manga, laranja, abacaxi)?

( )0.não ( )1.sim

\section{SE A CRIANÇA COME COMIDA OU PAPA SALGADA, FAÇA ESTAS PERGUNTAS COD}

62. Ontem de dia e de noite, quantas vezes ele(a) comeu comida ou papinha salgada?

[AJUDE a mãe a lembrar]

vezes

63. Como a senhora costuma preparar a comida dele(a)? Eu vou ler as opções:
( ) 1.passa na peneira
( ) 4.corta em pedaços pequenos
( ) 2.bate no liquidificador
( ) 5.igual a do adulto
( ) 3.amassa com o garfo
( ) 6.outra resposta [ANOTE]:

64. Eu vou mostrar um cartão para a senhora e gostaria que me apontasse qual é a figura mais parecida com a comida ou papinha salgada que ele(a) come.
[MOSTRE o Cartão 1]
( ) 1.figura 1
( ) 2.figura 2
( ) 3.figura 3

\begin{tabular}{lc}
\hline $65 . E l e(a)$ come pão, arroz, macarrão ou polenta? & ( ) 0.não $($ ) 1.sim \\
\hline 66. Ele(a) come feijão, lentilha, soja ou grão de bico? & ( ) 0.não ( )1.sim \\
\hline 67. Ele(a) come batata, mandioca, cará ou inhame? & ( ) 0.não ( )1.sim
\end{tabular}

68. Ele(a) come carne, peixe, ovo ou miúdos?

( ) 0.não [PULE para a questão 70] （ )1.sim

69. Quantas vezes por semana a senhora dá carne, peixe, ovo ou miúdos para ele(a)?

( )1.todos os dias ( )2. três vezes/semana ( )3. menos de 3 vezes/semana

70. Ele(a) come legumes e verduras? $\quad$ ( )0.não [PULE para a questão 74] $\quad$ ( )1.sim

71. Quantas vezes por semana a senhora dá legumes e verduras para ele(a)?

( )1.todos os dias ( )2.três vezes/semana ( )3.menos de 3 vezes/semana 
72. A senhora costuma dar legumes de cor amarela

ou alaranjada (por exemplo, cenoura, abóbora, mandioquinha)?

( )0. não ( )1.sim

73. A senhora costuma dar verdura verde-escura

(por exemplo, couve, espinafre, brócolis, chicória)?

( )0. não ( )1.sim

74. Com quem a senhora aprendeu a preparar a comida ou papa salgada?

75. A senhora acha que ele(a) come bem? （ )0.não ( )1.sim [PULE para a questão 77]

76. Por que a senhora acha que ele(a) não come bem? [ANOTE]:

77. Ele(a) costuma comer sozinho ou junto com alguma pessoa?

( ) 1.sozinho ( ) 2.com um adulto do lado ( ) 3.junto com a família à mesa

( ) 4.outra resposta [ANOTE]:

78. Ele(a) tem seu próprio prato ou come do prato de outra pessoa?

( ) 1.come do próprio prato ( ) 2.come do prato de outra pessoa

79. A senhora costuma dar pedaços de comida para ele(a) comer com as mãos?

( ) 0.não ( ) 1.sim

\section{SE A CRIANÇA COME LANCHE NOS INTERVALOS, FAÇA ESTA PERGUNTA}

COD

80. Quantas vezes ele(a) comeu lanche ontem?.

[AJUDE a mãe a lembrar ]

..vezes

\section{PERGUNTE PARA TODAS AS MÃES}

COD

81. Algumas mães têm dificuldade em saber quando a criança quer mamar ou comer. Como a senhora sabe que está na hora de alimentar sua criança? [ANOTE]:

82. Algumas mães têm dificuldade em saber quando a criança está satisfeita. Como a senhora sabe que sua criança já está satisfeita? [ANOTE]: 
83. Algumas mães têm dificuldade em fazer a criança comer a comida ou papa salgada. O que a senhora acha que as mães podem fazer para ajudar as crianças pequenas a comer a comida salgada? [ANOTE]:

84. Todas as pessoas que cuidam de crianças pequenas precisam lembrar de lavar as mãos. Quando a senhora acha que é importante lavar as mãos? [ASSINALE tudo o que for citado]
( ) 1.depois de usar a privada
( ) 2.depois de trocar a criança
( ) 3.antes de cozinhar
() 5.outra resposta [ANOTE]:
( ) 4.antes de alimentar a criança

“Vamos conversar um pouco sobre a saúde do(a) .... [diga o nome da criança].

PERGUNTE PARA TODAS AS MÃES

85. Hoje ele(a) está bem de saúde?

( )0.não

( )1.sim [PULE para a questão 87]

86. O que ele(a) tem? [ASSINALE tudo o que for citado]
( ) 1 .febre
( ) 2.nariz escorrendo
( ) 3.nariz entupido
( ) 4.dor de ouvido
( ) 5 .tosse
( ) 7.chiado no peito
( ) 8.vômitos
( ) 6 .falta de ar
( ) 10.outra resposta [ANOTE]:
( ) 9.diarréia

[se a mãe referiu diarréia, pergunte como é essa diarréia]

87. Ele(a) esteve doente nos últimos 15 dias?

( )0.não [PULE para a questão 89] ( )1.sim

88. O que ele(a) teve?
( ) 1. febre
( ) 2.nariz escorrendo
( ) 3.nariz entupido
( ) 4.dor de ouvido
( ) 5 .tosse
( ) 7.chiado no peito
( ) 8.vômitos
( ) 6. falta de ar
( ) 10.outra resposta [ANOTE]:
( ) 9.diarréia

[se a mãe referiu diarréia, pergunte como é essa diarréia]

89. Desde que saiu da maternidade até hoje, ele(a) precisou ser internado(a)?

( ) 0.não [PULE para a questão 91] ( )1.sim

90. Quantas vezes ficou internada?

vezes

[INTERNAÇÃO é se a criança ficou mais de 24 horas no hospital] 
"Agora podemos falar um pouco sobre a senhora e sua família?"

PERGUNTE PARA TODAS AS MÃES

91. Quantos anos a senhora tem?

.anos

92. A senhora nasceu nesta cidade? $\quad$ ( )0.não $\quad$ ( )1.sim [PULE para a questão 95]

93. Em que cidade e estado a senhora nasceu? [ANOTE]:

94. Há quanto tempo mora nesta cidade? [ANOTE]:

95. Gostaria de saber de qual raça ou cor a senhora se considera. Eu vou ler as opções para a senhora escolher.
( ) 1. branca
( ) 2. preta
( ) 3. parda
( ) 4. amarela
( ) 5. indígena

96. [Se a pessoa não se encaixou em nenhuma das alternativas acima, ANOTE a cor/raça que ela disse]:

97. A senhora estudou até que série?
( ) 0.nunca freqüentou a escola
( ) 1. até $1^{\circ}$ série do $1^{\circ} \mathrm{grau}$
( ) 2.até $2^{\circ}$ série do $1^{\circ}$ grau
( ) 8.até $4^{\circ}$ série do $2^{\circ}$ grau
( ) 3.até $3^{\circ}$ série do $1^{\circ} \mathrm{grau}$
( ) 4.até $4^{\circ}$ série do $1^{\circ} \mathrm{grau}$
( ) 9. até $1^{\circ}$ série do ensino médio
( ) 10.até $2^{\circ}$ série do ensino médio
( ) 5 .até $1^{\circ}$ série do $2^{\circ}$ grau
( ) 11.até $3^{\circ}$ série do ensino médio
( ) 6.até $2^{\circ}$ série do $2^{\circ}$ grau
( ) 12.entrou na faculdade mas não terminou
( ) 13.fez faculdade
( ) 7.até $3^{\circ}$ série do $2^{\circ}$ grau
( ) 14. outra resposta [ANOTE]:

98. Quantas vezes a senhora ficou grávida? vezes

99. Quantos filhos vivos a senhora tem? filhos vivos

100. A senhora trabalha fora de casa? ( )0.não [PULE para a questão 103] ( )1.sim

101.A senhora trabalha todos os dias no mesmo horário ou em turnos?

( )1.todos os dias no mesmo horário ( ) 2.em turnos

102. Qual é o seu horário de trabalho? [ANOTE o horário de entrada e saída; se for em turnos anote os dias e horários]:

103. A senhora faz algum trabalho para ganhar dinheiro aqui em sua própria casa?

( )0.não

( )1.sim 
104. Quem costuma cuidar dele(a)?

( )1.eu mesma ( )2.avó ( )3.outro parente adulto ( )4.creche ( )5.outra resposta [ANOTE]:

105. Além da senhora e desta criança, quem mais mora nesta casa?

( ) 1.marido ou companheiro

( ) 2.outros filhos [ANOTE as idades]:

( ) 3.outras pessoas [ANOTE qual o parentesco com a mãe]:

106. Quantas pessoas trabalham nesta casa?

pessoas

107. A senhora poderia me dizer mais ou menos quanto é o

ganho da família por mês juntando todos os que trabalham nesta casa?

reais

[se houver rendimentos como aposentadoria ou auxílio desemprego, junte ao ganho da família]

108.A senhora está cadastrada no programa Bolsa Família?

( ) 0.não [PULE para a questão 110] ( )1.sim

109. Quanto a senhora recebe do Bolsa Família por mês?

.reais

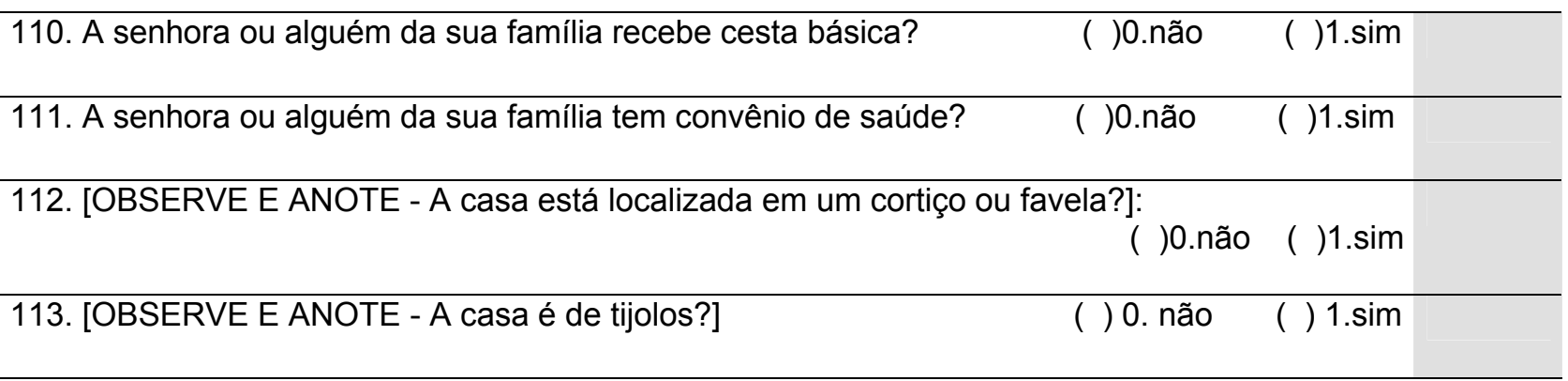

114. Esta casa é da senhora?

( )1.sim ( )2.não, é alugada

( )3.outra resposta [ANOTE]:

115. Quantos quartos tem a casa?

quartos

\begin{tabular}{lll}
\hline 116. O banheiro fica dentro da casa? & ( )0.não & ( )1.sim
\end{tabular}

117. O banheiro é ligado à rede pública de esgotos?

( )0.não ( )1.sim

118. Tem água encanada da rede pública na cozinha?

( )0.não ( )1.sim [PULE para a questão 120] 
119. De onde vem a água utilizada para beber e cozinhar? [ANOTE]:

120. Das coisas que vou falar, quais as que a senhora e sua família têm?
( )1.fogão a gás
( ) 2.geladeira
( ) 3.rádio
( ) 4.televisão
( ) 5.telefone fixo
( )6.telefone celular

121. Se não tem fogão a gás, que tipo de fogão a senhora tem? [ANOTE]:

"Eu vou perguntar o que a senhora acha do atendimento dos médicos, enfermeiros e agentes comunitários de saúde."

\begin{tabular}{l|l|l|l|l|l}
\hline NAS VISITAS D OS AGENTES COMUNITÁRIOS DE SAÚDE & $\begin{array}{l}\text { Não, } \\
\text { nunca }\end{array}$ & $\begin{array}{l}\text { Sim, às } \\
\text { vezes }\end{array}$ & $\begin{array}{l}\text { Sim, na } \\
\text { maioria } \\
\text { das vezes }\end{array}$ & $\begin{array}{l}\text { Sim, } \\
\text { sempre }\end{array}$ & COD \\
\hline 122. Ele(a) chama a senhora e o bebê pelo nome? & & & & & \\
\hline $\begin{array}{l}\text { 123. A senhora sente que ele(a) presta atenção no que a senhora } \\
\text { fala? }\end{array}$ & & & & & \\
\hline $\begin{array}{l}\text { 124. A senhora se sente à vontade para falar com ele(a) sobre } \\
\text { tudo o que quer? }\end{array}$ & & & & & \\
\hline $\begin{array}{l}\text { 125. A senhora sente se ele(a) tem pressa em terminar logo o } \\
\text { atendimento? }\end{array}$ & & & & & \\
\hline $\begin{array}{l}\text { 126. Ele(a) costuma elogiar como a senhora cuida da criança? } \\
\begin{array}{l}\text { 127. Ele(a) costuma explicar as coisas de um jeito fácil para a } \\
\text { senhora? }\end{array}\end{array}$ & & & & & \\
\hline $\begin{array}{l}\text { 128. A senhora consegue seguir a maioria das orientações que } \\
\text { são dadas? }\end{array}$ & & & & & \\
\hline $\begin{array}{l}\text { 129. Ele(a) faz a senhora se sentir culpada quando não segue as } \\
\text { orientações que foram dadas? }\end{array}$ & & & & & \\
\hline
\end{tabular}

130. Então, como a senhora avalia a qualidade das visitas do Agente Comunitário de Saúde? [MOSTRE o Cartão 2]

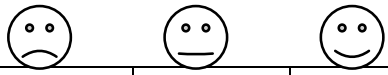




\begin{tabular}{|c|c|c|c|c|c|}
\hline NAS CONSULTAS DO POSTO DE SAÚDE & $\begin{array}{l}\text { Não, } \\
\text { nunca }\end{array}$ & $\begin{array}{l}\text { Sim, às } \\
\text { vezes }\end{array}$ & $\begin{array}{l}\text { Sim, na } \\
\text { maioria } \\
\text { das vezes }\end{array}$ & $\begin{array}{l}\text { Sim, } \\
\text { sempre }\end{array}$ & COD \\
\hline \multicolumn{6}{|l|}{ 131. Eles chamam a senhora e o bebê pelo nome? } \\
\hline \multicolumn{6}{|l|}{$\begin{array}{l}\text { 132. A senhora sente que eles prestam atenção no que a senhora } \\
\text { fala? }\end{array}$} \\
\hline \multicolumn{6}{|l|}{$\begin{array}{l}\text { 133. A senhora se sente à vontade para falar com eles sobre tudo } \\
\text { o que quer? }\end{array}$} \\
\hline \multicolumn{6}{|l|}{$\begin{array}{l}\text { 134. A senhora sente se eles tem pressa em terminar logo o } \\
\text { atendimento? }\end{array}$} \\
\hline \multicolumn{6}{|l|}{ 135. Eles costumam elogiar como a senhora cuida da criança? } \\
\hline \multicolumn{6}{|l|}{$\begin{array}{l}\text { 136. Eles costumam explicar as coisas de um jeito fácil para a } \\
\text { senhora? }\end{array}$} \\
\hline \multicolumn{6}{|l|}{$\begin{array}{l}\text { 137. A senhora consegue seguir a maioria das orientações que } \\
\text { são dadas? }\end{array}$} \\
\hline $\begin{array}{l}\text { 138. Eles fazem a senhora se sentir culpada quando não segue } \\
\text { as orientações que eles deram? }\end{array}$ & & & & & \\
\hline
\end{tabular}

139. Então, como a senhora avalia a qualidade do atendimento nas consultas do Posto de Saúde? [MOSTRE o Cartão 2]

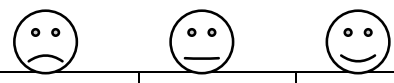

\begin{tabular}{ll|l|l} 
& & & \\
\hline
\end{tabular}

SE A CRIANÇA TEM MAIS DE 1 MÊS DE IDADE, FALE:

"Agora eu vou perguntar algumas coisas sobre o desenvolvimento da criança." 
140.SEA CRIANÇA TEM 1-2 MESES, PERGUNTE:

- fica assustada ou chora com barulhos fortes

( ) 0.não ( ) $1 . \operatorname{sim}$ ( ) 8. não sabe

- gosta de olhar para os olhos da mãe

( ) 0.não ( ) 1.sim ( ) 8. não sabe

- segura com força o dedo de uma pessoa

( ) 0.não ( ) 1.sim ( ) 8. não sabe

141.SEA CRIANÇA TEM 3-4 MESES, PERGUNTE:

- faz barulhos com a boca

( ) 0.não ( ) 1.sim ( ) 8. não sabe

- reconhece pessoas e vozes

( ) 0.não ( ) 1.sim ( ) 8. não sabe

- sorri quando alguém sorri para ela

- levanta a cabeça quando está de bruços

( ) 0. não ( ) $1 . \operatorname{sim}$ ( ) 8. não sabe

- gosta de olhar para as mãos e colocá-las na boca

( ) 0.não ( ) $1 . \operatorname{sim}$ ( ) 8. não sabe

( ) 0.não ( ) 1.sim ( ) 8. não sabe

142.SEA CRIANÇA TEM 5-6 MESES, PERGUNTE:

- quando deitado rola de um lado para outro sozinha

- senta com apoio

- leva os pés à boca

- quando ouve a voz de alguém vira a cabeça na direção dela

143.SEA CRIANÇA TEM 7-9 MESES, PERGUNTE:

- fica sentada sozinha, sem apoio

( ) 0.não ( ) 1.sim ( ) 8. não sabe

( ) 0.não ( ) 1.sim ( ) 8. não sabe

( ) 0.não ( ) $1 . \operatorname{sim}$ ( ) 8. não sabe

( ) 0. não ( ) $1 . \operatorname{sim}$ ( ) 8. não sabe

- se arrasta ou engatinha

144.SEA CRIANÇA TEM 10-12 MESES, PERGUNTE:

- gosta de imitar os pais

( ) 0.não ( ) 1.sim ( ) 8. não sabe ( ) 0.não ( ) 1.sim ( ) 8. não sabe

- dá tchau

( ) 0.não ( ) 1.sim ( ) 8. não sabe

- bate palmas

( ) 0.não ( ) $1 . \operatorname{sim~(~)~8.~não~sabe~}$

- fala algumas palavras

( ) 0.não ( ) $1 . \operatorname{sim}$ ( ) 8. não sabe

- aponta o que quer

( ) 0.não ( ) 1.sim ( ) 8. não sabe

- consegue pegar coisas com os dedos polegar e indicador

( ) 0.não

() $1 . \operatorname{sim}($ ) 8 . não sabe

- engatinha

( ) 0.não ( ) $1 . \operatorname{sim}$ ( ) 8. não sabe

( ) 0.não ( ) 1.sim ( ) 8. não sabe

- fica em pé com apoio

( ) 0.não ( ) 1.sim ( ) 8. não sabe

- anda com apoio

( ) 0.não ( ) 1.sim ( ) 8. não sabe

\section{SEA CRIANÇA TEM 13-18 MESES, PERGUNTE:}

- quer comer sozinha

( ) 0.não ( ) 1.sim ( ) 8. não sabe

- se reconhece ao olhar no espelho

- fala algumas palavras ou frases curtas

- dá alguns passos ou anda sozinha

( ) 0.não ( ) 1.sim ( ) 8. não sabe

( ) 0.não ( ) 1.sim ( ) 8. não sabe

() 0. não () 1.sim ( ) 8. não sabe

"Eu gostaria de pesar a criança. Ela precisa estar totalmente sem roupa. Vamos primeiro pesar a senhora junto com ela e depois só a senhora." [ANOTE OS PESOS].

$1^{\circ}$ Peso da mãe descalça com a criança nua:

$2^{\circ}$ Peso da mãe descalça com a criança nua:

$3^{\circ}$ Peso da mãe descalça com a criança nua (se a diferença entre os 2 pesos anteriores foi maior que 200 gramas)::

$1^{\circ}$ Peso da mãe descalça:

$2^{\circ}$ Peso da mãe descalça:

$3^{\circ}$ Peso da mãe descalça (se a diferença entre os 2 pesos anteriores foi maior que 200 gramas):: 


\title{
ANEXO 2 GUIA PARA A ENTREVISTA COM MÃE OU CUIDADOR
}

\author{
$\underline{\text { INTRODUCÃ̃O }}$
}

Aqui estão algumas informações essenciais para o primeiro contato com as pessoas a serem entrevistadas. LEIA mais de uma vez este Guia e o Formulário para se familiarizar com eles. Desta forma, será mais fácil ser natural ao conversar com as pessoas durante a entrevista.

AO SER ATENDIDO(A) FALE ALGO DO TIPO: "Bom dia, meu nome é ....... (mostre seu crachá). Eu sou entrevistador(a) da pesquisa que o Instituto de Saúde e a Secretaria Municipal de Saúde estão fazendo aqui na cidade. Eu gostaria de conversar com a mãe do(a) ....... (diga o nome da criança). "

CONFIRME COM A MÃE DIZENDO: "Na minha lista, vejo que o(a) .... (diga o nome da criança) nasceu no dia.... (diga a data anotada). É isso mesmo?"

SE A CRIANÇA NASCEU ANTES DE $1^{\circ}$ DE AGOSTO DE 2005, explique que a pesquisa é só com crianças nascidas do dia $1^{\circ}$ de agosto de 2005 em diante, agradeça e se despeça.

SE A CRIANÇA NASCEU EM $1^{\circ}$ DE AGOSTO DE 2005 OU DEPOIS, FALE: "Esta pesquisa é para conhecer as famílias e saber como vai a saúde e a alimentação das crianças atendidas pelo Programa Saúde da Família. Estou entrevistando todas as mães de crianças até 1 ano e meio de idade que moram aqui na região. Essas entrevistas com as mães são importantes porque podem ajudar a melhorar o atendimento. Eu poderia conversar com a senhora?"

VERIFIQUE se a criança é gemelar, se tem alguma doença grave ou se por algum motivo come uma dieta especial (diferente das crianças em geral). Neste caso, explique que a pesquisa não inclui os gêmeos ou crianças com necessidades especiais, agradeça, se despeça.

SE A MÃE RECUSOU, agradeça e se despeça.

SE ALGUMA CRIANÇA for excluída da entrevista, anote o motivo em sua listagem.

Entreviste outra pessoa que não seja a mãe (um CUIDADOR), apenas se ela pode responder a maioria das questões sobre a criança (por exemplo, se a mãe trabalha fora e essa outra pessoa é quem cuida da criança a maior parte do tempo).

SE A MÃE NÃO PUDER ATENDÊ-LA NO MOMENTO, pergunte quando poderá retornar para conversar com ela.

SE A MÃE OU CUIDADOR ACEITOU, FALE: "Tem um lugar onde nós podemos conversar com calma?"

ANTES DE INICIAR A ENTREVISTA, FALE: "É importante para qualquer pessoa antes de dar entrevista saber do que se trata a pesquisa. Por isso, vou explicar para a senhora."

LEIA EM VOZ ALTA o Termo de Consentimento e verifique se ela compreendeu tudo. Se necessário repita as informações.

DEPOIS FALE: "Gostaria que a senhora assinasse o Termo. Uma cópia fica com a senhora; assim se quiser mais informações tem um número de telefone para consulta." 
DURANTE A ENTREVISTA, procure sempre deixar a pessoa à vontade; chame-a pelo nome; evite interrompê-la enquanto fala; não faça qualquer comentário sobre os serviços e profissionais de saúde; não dê conselho sobre qualquer aspecto da alimentação e saúde da criança.

SE A CRIANÇA ESTIVER COM ALGUM PROBLEMA que necessite de atenção dos serviços de saúde, oriente a mãe a procurar o serviço de referência.

ATENÇÃO - A qualidade do seu trabalho é fundamental para o sucesso da pesquisa. Preencha com atenção todas as questões para que sua entrevista não seja recusada.

Antes de iniciar a entrevista, preencha os dados de identificação. Não anote nas áreas sombreadas.

\section{ESCLARECIMENTO DE ALGUMAS QUESTÕES}

\section{IDENTIFICAÇÃO}

Questões 5 e 6 - Veja os dados em sua listagem.e anote.

Questão 7, 9 e 10 - Veja em sua listagem e confirme com a mãe se o nome dela, da criança e a data de nascimento estão corretos.

Questão 11 - Se a pessoa entrevistada não é a mãe da criança, anote qual é a relação dessa pessoa com a criança (por exemplo, pai, avó, babá, etc) 
A PARTIR DAQUI, PROCURE LER AS PERGUNTAS DA MANEIRA QUE ESTÃO ESCRITAS.

VOCÊ VERÁ QUE ENTRE [ ] ESTÃO INFORMAÇÕES SOBRE O QUE VOCÊ DEVE FAZER (por exemplo, pular alguma questão, anotar as falas, ajudar a mãe a se lembrar de algumas coisas, etc).. Você não deve ler para a mãe o que está entre [ ].

\section{PRESTE BASTANTE ATENÇÃO NAS QUESTÕES QUE PRECISAM SER PULADAS.}

Questão 19 - Parto vaginal inclui o parto normal e o fórceps.

Questão 22 - Logo que nasceu significa quando ainda estava na sala de partos.

Questão 23 - Deu de mamar é se o bebê abocanhou o seio materno. Se ele foi posto para mamar mas não quis a resposta é não.

Questão 27 - Ajuda para mamar na maternidade significa, por exemplo, que alguém orientou e ajudou a colocar o bebê para mamar ou respondeu as dúvidas ou ensinou e ajudou a mãe a retirar leite se o peito estava cheio.

Questão 28 - Se o bebê nasceu de baixo peso ou teve algum problema de saúde, pode ter tido a necessidade de ficar mais tempo internado e a mãe pode ter ido para casa antes dele.

Questão 30 - Mesmo que a mãe tenha tentado só por alguns dias considera-se que ela amamentou.

Faça as perguntas 35 a 47 para todas as mães mesmo que o bebê tenha poucos dias.

Estas questões servem como filtro para poder explorar mais adiante a alimentação da criança. Explique que você tem que perguntar tudo, mesmo que pareça estranho.

Questão 40 - Leite não materno refere-se a leite de outros animais, tais como leite de vaca, de cabra; ou de soja.

Questão 42 - Salgadinhos, frituras e doces não são considerados lanches.

Questão 43 - Salgadinhos são aqueles do tipo cheetos, batatinha chips. Frituras são as caseiras, como batata frita, coxinha, pastel, etc.

Questão 48 - A idade pode ser anotada em meses. Se foi antes de 1 mês de idade, anote em dias.

\section{SE A CRIANÇA NÃO MAMA NO PEITO}

Questão 49 - Anote em meses; se foi antes de 1 mês anote em dias. 


\section{SE A CRIANÇA MAMA NO PEITO}

Questão 51 - Aqui você pode ajudar a mãe a se lembrar do dia anterior, perguntando a que horas a criança acordou e ir lembrando junto com ela em quais horários a criança mamou durante todo o dia e toda a noite. Se a mãe disser que a criança mama toda hora, tente chegar ao número de vezes.

\section{SE A CRIANÇA TOMA LEITE NÃO MATERNO}

Questão 52 - Além de anotar se o leite é líquido ou em pó, procure saber o nome do leite. Anote também se o leite vem de alguma fazenda por perto (leite fresco ou cru).

Questão 53 - Aqui também ajude a mãe a recordar o dia e a noite anterior, desde que a criança acordou.

Questão 54 e 55 - Alguma coisa significa açúcar ou alguma farinha ou cereal (do tipo maisena, cremogema, farinha láctea, nescau ou outro).

Questão 59 - O que queremos saber é se foi um médico, enfermeiro, avó da criança, vizinha, etc.

\section{SE A CRIANÇA COME FRUTAS}

Questão 60 - Ajude a mãe a lembrar que dias da semana passada ela deu frutas para a criança.

Questão 61 - Dê os exemplos de frutas de cor amarela ou alaranjada para facilitar.

\section{SE A CRIANÇA COME COMIDA OU PAPA SALGADA}

Questão 62 - Ajude a mãe a lembrar, recordando com ela o dia e a noite anterior.

Questão 64 - As figuras do Cartão parecem bem diferentes, mas pode acontecer da mãe ficar em dúvida entre uma e outra. Você pode ajudar dizendo que na Figura 1 o alimento escorre com facilidade da colher, na Figura 2 o alimento fica mais grudado e na Figura 3 o alimento se parece mais com a comida de um adulto, como arroz e feijão amassados.

Questões 65, 66, 67 e 68 - Queremos saber se a criança come algum desses alimentos; não precisa comer todos.

Questão 70 - Legumes são, por exemplo, chuchu, abobrinha, berinjela, cenoura, beterraba. Verduras são as folhas como alface, agrião, chicória, couve, etc. 


\section{SAÚDE DA CRIANÇA}

Questão 86 e 88 - Se a mãe referir diarréia pergunte como era essa diarréia. Diarréia significa fezes líquidas mais de 3 vezes ao dia. Quando a criança mama só no peito ela pode evacuar muitas vezes ao dia e não ser diarréia; nesse caso considere diarréia se as fezes são malcheirosas ou têm sangue ou catarro.

Questão 90 - Considere como internação se a criança ficou mais de um dia inteiro (24 horas) no hospital para tratamento.

\section{MAE E FAMÍLIA}

Questão 95 - O IBGE utiliza esta classificação e pedimos para que a própria pessoa diga qual é sua cor ou raça/etnia. Se a pessoa disser algo diferente das opções oferecidas, aceite e anote na Questão 96.

Questão 102. Anote o total de horas por dia se a mãe trabalha todos os dias no mesmo horário. Se a mãe trabalha em turnos, escreva os dias e horários durante a semana.

Questão 107 - Veja o ganho de cada pessoa da família e depois faça a soma. Não se esqueça de perguntar se alguém recebe aposentadoria (por exemplo, se tem uma avó que mora junto) ou seguro-desemprego (se tem alguém desempregado) e inclua na soma.

Questões 112 e 113 - Não precisa perguntar. É melhor você só observar e anotar. 


\section{ANEXO 3 \\ ORIENTAÇÕES PARA A PESAGEM DAS CRIANÇAS}

1) Retire a balança do plástico protetor e coloque as 4 pilhas.

2) Coloque a balança no chão reto e longe de paredes ou outras coisas em que a pessoa possa se encostar.

3) Para ligar a balança, aperte o botão central, localizado entre os botões 2 e 3 (aperte apenas uma vez).

\section{PRIMEIRA ETAPA}

4) Peça para a mãe descalça e com a criança nua no colo subir na balança; ajude-a a subir.

5) Ao ler o peso, verifique se a pessoa não está apoiada em qualquer coisa.

6) Espere o peso se estabilizar e quando começar a piscar, anote o $1^{\circ}$ peso.

7) Desça a mãe, desligue e ligue a balança novamente.

8) Repita a pesagem da mãe com a criança no colo e anote o $2^{\circ}$ peso.

9) Se a diferença entre $\circ 1^{\circ}$ e $\circ 2^{\circ}$ pesos for maior do que 200 gramas, desligue/ligue a balança novamente e faça mais uma pesagem da mãe com a criança no colo e anote o $3^{\circ}$ peso.

\section{SEGUNDA ETAPA}

10) Peça para a mãe descalça e sem a criança subir na balança.

11) Ao ler o peso, verifique se a pessoa não está apoiada em qualquer coisa.

12) Espere o peso se estabilizar e quando começar a piscar, anote o $1^{\circ}$ peso.

13) Desça a mãe, desligue e ligue a balança novamente.

14) Repita a pesagem da mãe e anote o $2^{\circ}$ peso.

15) Se a diferença entre $\circ 1^{\circ}$ e $\circ 2^{\circ}$ pesos for maior do que 200 gramas, desligue/ligue a balança novamente e faça mais uma pesagem da mãe e anote $03^{\circ}$ peso.

16) Desligue e guarde a balança. 


\section{ANEXO 4 \\ TESTE DE CONHECIMENTOS COM GABARITO}

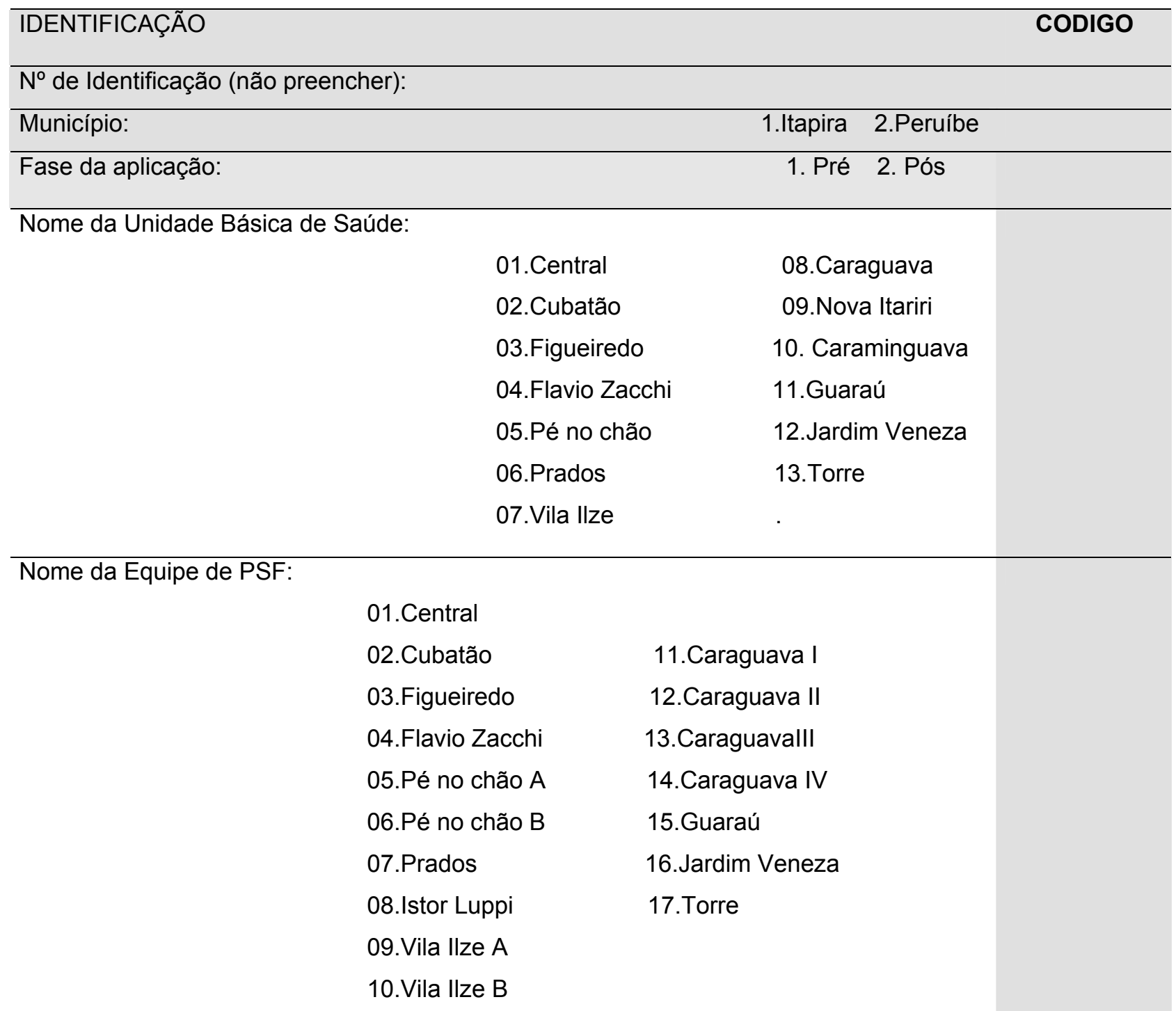

Seu nome:

Sua função: 1.Agente de saúde (

2.Auxiliar /técnica de enfermagem ( )

3.Enfermeiro(a) ( )

4.Médico(a) generalista PSF ( )

5. Médico(a) pediatra PSF ( )

6.Médico(a) pediatra Não PSF ( )

Data: 


\begin{tabular}{|c|c|c|c|}
\hline ASSINALE CERTO, ERRADO OU NÃO SEI & CERTO & ERRADO & NÃO SEI \\
\hline $\begin{array}{l}\text { 1, Durante os primeiros seis meses de vida das crianças devemos } \\
\text { recomendar o aleitamento materno exclusivo. }\end{array}$ & $\mathrm{X}$ & & \\
\hline $\begin{array}{l}\text { 2. Aleitamento materno exclusivo é quando a criança recebe apenas } \\
\text { leite materno, sem água, chá ou suco. }\end{array}$ & $\mathrm{X}$ & & \\
\hline $\begin{array}{l}\text { 3. Se uma criança mama só no peito, mas também toma } \\
\text { medicamentos e suplementos vitamínicos, consideramos que ela está } \\
\text { em aleitamento materno exclusivo. }\end{array}$ & $\mathrm{X}$ & & \\
\hline $\begin{array}{l}\text { 4. Depois dos seis meses as crianças precisam receber outros } \\
\text { alimentos para complementar o leite materno. }\end{array}$ & $\mathrm{X}$ & & \\
\hline $\begin{array}{l}\text { 5. Depois de iniciada a alimentação complementar é importante } \\
\text { manter a amamentação até pelo menos os dois anos de idade. }\end{array}$ & $\mathrm{X}$ & & \\
\hline 6. A amamentação protege as crianças contra diarréia e pneumonia. & $\mathrm{X}$ & & \\
\hline $\begin{array}{l}\text { 7. A amamentação protege as crianças contra diabetes e alguns tipos } \\
\text { de câncer. }\end{array}$ & $\mathrm{X}$ & & \\
\hline $\begin{array}{l}\text { 8. A amamentação é importante para a mulher porque ajuda a adiar } \\
\text { uma nova gestação. }\end{array}$ & $\mathrm{X}$ & & \\
\hline $\begin{array}{l}\text { 9. A amamentação protege as mulheres contra câncer de mama e de } \\
\text { ovário. }\end{array}$ & $\mathrm{X}$ & & \\
\hline $\begin{array}{l}\text { 10. Uma desvantagem do leite de vaca é que ele contém muito mais } \\
\text { proteína do que o leite humano. }\end{array}$ & $\mathrm{X}$ & & \\
\hline 11. O colostro tem um efeito laxante e ajuda a prevenir a icterícia. & $\mathrm{X}$ & & \\
\hline $\begin{array}{l}\text { 12. A amamentação durante o segundo ano de vida é importante } \\
\text { porque fornece cerca de } 75 \% \text { das necessidades de vitamina A para a } \\
\text { criança. }\end{array}$ & $\mathrm{X}$ & & \\
\hline $\begin{array}{l}\text { 13. A prolactina é o hormônio responsável pela produção do leite } \\
\text { materno. }\end{array}$ & $\mathrm{X}$ & & \\
\hline $\begin{array}{l}\text { 14. A prolactina é liberada quando o bebê está mamando e por isso } \\
\text { garante a produção de leite materno para a próxima mamada. }\end{array}$ & $\mathrm{X}$ & & \\
\hline $\begin{array}{l}\text { 15. A ocitocina é o hormônio responsável pela ejeção do leite } \\
\text { materno. }\end{array}$ & $\mathrm{X}$ & & \\
\hline $\begin{array}{l}\text { 16. A ocitocina pode começar a funcionar antes do bebê mamar, } \\
\text { quando a mãe sente que está na hora de amamentar. }\end{array}$ & $x$ & & \\
\hline $\begin{array}{l}\text { 17. Quando a aréola é grande, um sinal de boa pega é a aréola mais } \\
\text { visível na parte de cima da boca do bebê. }\end{array}$ & $\mathrm{X}$ & & \\
\hline $\begin{array}{l}\text { 18. É importante a criança abocanhar uma boa porção da mama } \\
\text { porque os seios lactíferos ficam embaixo da aréola. }\end{array}$ & $\mathrm{X}$ & & \\
\hline $\begin{array}{l}\text { 19. Uma pega ineficaz pode causar dor e rachadura nos mamilos e } \\
\text { levar à diminuição na produção do leite materno. }\end{array}$ & $\mathrm{X}$ & & \\
\hline $\begin{array}{l}\text { 20. Ao ajudar a mãe a colocar o bebê para mamar é recomendável } \\
\text { empurrar levemente atrás da cabeça do bebê para facilitar a pega. }\end{array}$ & & $\mathrm{X}$ & \\
\hline $\begin{array}{l}\text { 21. Durante a consulta ou abordagem, é importante que o profissional } \\
\text { seja simpático, concordando com tudo o que a mãe diz. }\end{array}$ & & $\mathrm{X}$ & \\
\hline $\begin{array}{l}\text { 22. Aconselhar significa dar conselhos à mãe para que ela faça aquilo } \\
\text { que é o recomendado para a alimentação adequada da criança. }\end{array}$ & & $\mathrm{X}$ & \\
\hline $\begin{array}{l}\text { 23. Para desenvolver a confiança da mãe devemos criar uma relação } \\
\text { de sinceridade e deixar claro quando não concordamos com ela. }\end{array}$ & & $x$ & \\
\hline
\end{tabular}




\begin{tabular}{|c|c|c|c|}
\hline ASSINALE CERTO, ERRADO OU NÃO SEI & CERTO & ERRADO & NÃO SEI \\
\hline $\begin{array}{l}\text { 24. Entre as mães pobres é mais freqüente a baixa produção de leite } \\
\text { materno. }\end{array}$ & & $\mathrm{X}$ & \\
\hline $\begin{array}{l}\text { 25. Urinar menos do que } 6 \text { vezes ao dia é um indicador de que o bebê } \\
\text { pode não estar recebendo leite materno suficiente. }\end{array}$ & $\mathrm{X}$ & & \\
\hline $\begin{array}{l}\text { 26. O início retardado da amamentação e as mamadas em horários } \\
\text { fixos podem fazer com que o bebê não receba leite materno } \\
\text { suficiente. }\end{array}$ & $\mathrm{X}$ & & \\
\hline $\begin{array}{l}\text { 27. Alguns tipos de pílulas anticoncepcionais, álcool e fumo podem } \\
\text { diminuir a produção do leite. }\end{array}$ & $\mathrm{X}$ & & \\
\hline $\begin{array}{l}\text { 28. Quando um bebê recusa o peito devemos verificar se houve uma } \\
\text { mudança na rotina familiar. }\end{array}$ & $\mathrm{X}$ & & \\
\hline $\begin{array}{l}\text { 29. Nos primeiros seis meses de vida, um ganho de peso satisfatório é } \\
\text { pelo menos } 500 \text { gramas por mês. }\end{array}$ & $\mathrm{X}$ & & \\
\hline $\begin{array}{l}\text { 30. Um sinal confiável de que um bebê não está recebendo leite } \\
\text { suficiente é quando ele não fica satisfeito ao terminar a mamada. }\end{array}$ & & $\mathrm{X}$ & \\
\hline $\begin{array}{l}\text { 31. Nos primeiros dias após o parto, a ordenha das mamas pode } \\
\text { ajudar o bebê a fazer uma boa pega.. }\end{array}$ & $\mathrm{X}$ & & \\
\hline $\begin{array}{l}\text { 32. A alimentação com xícara ou copinho é mais segura do que com } \\
\text { mamadeira porque evita diarréias, infecções de ouvido e cáries. }\end{array}$ & $\mathrm{X}$ & & \\
\hline $\begin{array}{l}\text { 33. Na alimentação com xícara ou copinho devemos derramar o leite } \\
\text { aos poucos na boca do bebê para evitar engasgo. }\end{array}$ & & $\mathrm{X}$ & \\
\hline $\begin{array}{l}\text { 34. O bico de mamadeira para ser higienizado deve ser virado do } \\
\text { avesso e esfregado com escova ou sal e depois fervido. }\end{array}$ & $\mathrm{X}$ & & \\
\hline $\begin{array}{l}\text { 35. Se uma mãe desconhece seu estado sorológico para o HIV } \\
\text { devemos orientar a alimentação da criança como se ela fosse HIV } \\
\text { positivo. }\end{array}$ & & $\mathrm{X}$ & \\
\hline $\begin{array}{l}\text { 36. O aconselhamento de uma mulher HIV positivo sobre a } \\
\text { alimentação da criança deve ser iniciado junto com a revelação do } \\
\text { resultado. }\end{array}$ & & $\mathrm{X}$ & \\
\hline $\begin{array}{l}\text { 37. Se a mãe é HIV positivo deve-se dar medicamento para secar seu } \\
\text { leite. }\end{array}$ & & $\mathrm{X}$ & \\
\hline $\begin{array}{l}\text { 38. A oferta de leite da mãe HIV positivo ordenhado e pasteurizado } \\
\text { em bancos de leite humano é uma opção que deve ser considerada. }\end{array}$ & $\mathrm{X}$ & & \\
\hline $\begin{array}{l}\text { 39. Um alimento de substituição do leite materno para ser seguro } \\
\text { precisa ser fabricado por uma empresa renomada. }\end{array}$ & & $\mathrm{X}$ & \\
\hline $\begin{array}{l}\text { 40. Toda criança que toma leite de vaca integral deveria receber } \\
\text { suplementos de micronutrientes, tais como ferro, zinco e vitaminas. }\end{array}$ & $\mathrm{X}$ & & \\
\hline $\begin{array}{l}\text { 41. O leite de vaca pasteurizado, depois de aberto por mais de uma } \\
\text { hora, deve ser fervido antes de dar à criança pequena. }\end{array}$ & $\mathrm{X}$ & & \\
\hline $\begin{array}{l}\text { 42. Mulheres com mamas pequenas podem produzir tanto leite quanto } \\
\text { mulheres com mamas grandes. }\end{array}$ & $\mathrm{X}$ & & \\
\hline $\begin{array}{l}\text { 43. Não se recomenda a realização de exercícios nas mamas durante } \\
\text { o pré-natal porque, em geral, não ajudam a melhorar os mamilos } \\
\text { planos e invertidos. }\end{array}$ & $\mathrm{X}$ & & \\
\hline $\begin{array}{l}\text { 44. Uma diferença entre mamas cheias e ingurgitadas é que nas } \\
\text { mamas cheias há um bom fluxo de leite. }\end{array}$ & $\mathrm{X}$ & & \\
\hline
\end{tabular}




\begin{tabular}{|c|c|c|c|}
\hline ASSINALE CERTO, ERRADO OU NÃO SEI & CERTO & ERRADO & NÃO SEI \\
\hline 45. Uma sucção ineficaz pode levar ao desenvolvimento da mastite. & $\mathrm{X}$ & & \\
\hline $\begin{array}{l}\text { 46. O uso de sutiã apertado ou a forma como a mãe segura as mamas } \\
\text { ao amamentar pode levar ao desenvolvimento de um ducto } \\
\text { bloqueado. }\end{array}$ & $\mathrm{X}$ & & \\
\hline $\begin{array}{l}\text { 47. Na infecção da mama por Cândida, um sinal característico é a } \\
\text { despigmentação do mamilo e da aréola.. }\end{array}$ & $\mathrm{X}$ & & \\
\hline $\begin{array}{l}\text { 48. O processo de relactação é um método simples, que pode ser } \\
\text { aplicado em qualquer situação. }\end{array}$ & & $\mathrm{X}$ & \\
\hline $\begin{array}{l}\text { 49. A relactação deve ser recomendada apenas se o período de } \\
\text { interrupção da amamentação for menor que } 15 \text { dias. }\end{array}$ & & $\mathrm{X}$ & \\
\hline $\begin{array}{l}\text { 50. A diferença entre relactação e lactação induzida é que na } \\
\text { relactação as mamas já foram estimuladas por uma gravidez ou } \\
\text { amamentação. }\end{array}$ & $\mathrm{X}$ & & \\
\hline $\begin{array}{l}\text { 51. Em um Hospital Amigo da Criança espera-se que os bebês } \\
\text { tenham contato pele a pele prolongado com suas mães logo ao } \\
\text { nascer. }\end{array}$ & $\mathrm{X}$ & & \\
\hline $\begin{array}{l}\text { 52. É importante que ao nascer seja feito um teste de sucção } \\
\text { oferecendo água para os bebês. }\end{array}$ & & $\mathrm{X}$ & \\
\hline $\begin{array}{l}\text { 53. Ao nascer os bebês devem ser cobertos com manta e levados ao } \\
\text { berço para evitar o resfriamento do corpo. }\end{array}$ & & $\mathrm{X}$ & \\
\hline $\begin{array}{l}\text { 54. Bebês muito grandes ou de baixo peso devem receber soro } \\
\text { glicosado para evitar a hipoglicemia. nas primeiras horas de vida. }\end{array}$ & & $\mathrm{X}$ & \\
\hline $\begin{array}{l}\text { 55. Todas as crianças, inclusive as filhas de mulheres HIV positivo, } \\
\text { devem permanecer em alojamento conjunto com suas mães. }\end{array}$ & $\mathrm{X}$ & & \\
\hline $\begin{array}{l}\text { 56. A Norma Brasileira de Comercialização de Alimentos para } \\
\text { Lactentes e Crianças de Primeira Infância proíbe a doação de leites a } \\
\text { maternidades, mas permite que sejam doados leites infantis para } \\
\text { instituições de caridade. }\end{array}$ & & $\mathrm{X}$ & \\
\hline $\begin{array}{l}\text { 57. A Norma Brasileira de Comercialização de Alimentos para } \\
\text { Lactentes e Crianças de Primeira Infância foi criada apenas para } \\
\text { melhorar a rotulagem dos alimentos infantis, mamadeiras e chupetas. }\end{array}$ & & $\mathrm{X}$ & \\
\hline $\begin{array}{l}\text { 58. Com relação à alimentação complementar recomenda-se iniciar } \\
\text { após os } 6 \text { meses na criança amamentada e aos } 4 \text { meses na criança } \\
\text { em aleitamento artificial. }\end{array}$ & $\mathrm{X}$ & & \\
\hline $\begin{array}{l}\text { 59. Com relação à alimentação complementar recomenda-se iniciar } \\
\text { com alimentos mais líquidos para facilitar a ingestão da criança. }\end{array}$ & & $\mathrm{X}$ & \\
\hline $\begin{array}{l}\text { 60. Com relação à alimentação complementar recomenda-se insistir } \\
\text { para que a criança coma tudo o que está no prato. }\end{array}$ & & $\mathrm{X}$ & \\
\hline $\begin{array}{l}\text { 61. Com relação à alimentação complementar recomenda-se oferecer } \\
\text { sempre frutas como maçã raspada e banana amassada. }\end{array}$ & & $\mathrm{X}$ & \\
\hline $\begin{array}{l}\text { 62. A maior consistência da alimentação da criança tem como } \\
\text { principal objetivo aumentar o aporte protéico necessário para um } \\
\text { crescimento adequado. }\end{array}$ & & $\mathrm{X}$ & \\
\hline $\begin{array}{l}\text { 63. Com relação à alimentação complementar pode-se afirmar que os } \\
\text { alimentos de origem animal e os vegetais verde-escuros são } \\
\text { importantes fontes de ferro para a criança. }\end{array}$ & $\mathrm{X}$ & & \\
\hline
\end{tabular}




\begin{tabular}{|c|c|c|c|}
\hline ASSINALE CERTO, ERRADO OU NÃO SEI & CERTO & ERRADO & NÃO SEI \\
\hline $\begin{array}{l}\text { 64. Com relação à alimentação complementar pode-se afirmar que } \\
\text { frutas e legumes amarelados ou alaranjados ajudam a criança a } \\
\text { desenvolver olhos saudáveis e menos infeç̧ões. }\end{array}$ & $\mathrm{X}$ & & \\
\hline $\begin{array}{l}\text { 65. Com relação à alimentação complementar pode-se afirmar que se } \\
\text { a criança come devagar e suja-se muito, provavelmente não está } \\
\text { recebendo o tipo de alimento adequado. }\end{array}$ & & $\mathrm{X}$ & \\
\hline $\begin{array}{l}\text { 66. Com relação à alimentação complementar pode-se afirmar que } \\
\text { propiciar distrações variadas durante a refeição permite que a criança } \\
\text { fique mais relaxada e coma melhor. }\end{array}$ & & $\mathrm{X}$ & \\
\hline $\begin{array}{l}\text { 67. É útil informar os pais que se a criança empurra a comida para } \\
\text { fora da boca pode ser sinal de algum problema. }\end{array}$ & & $\mathrm{X}$ & \\
\hline $\begin{array}{l}\text { 68. Quando uma criança está doente a quantidade total de alimentos } \\
\text { oferecidos deve ser geralmente menor que a habitual. }\end{array}$ & & $\mathrm{X}$ & \\
\hline $\begin{array}{l}\text { 69. Oferecer quantidades maiores de alimentos depois da doença } \\
\text { ajuda na recuperação do ritmo de crescimento. }\end{array}$ & $\mathrm{X}$ & & \\
\hline $\begin{array}{l}\text { 70. Durante a doença da criança deve-se procurar diminuir o número } \\
\text { de refeições, mas aumentar a quantidade oferecida em cada uma } \\
\text { delas. }\end{array}$ & & $\mathrm{X}$ & \\
\hline
\end{tabular}
delas. 


\section{ANEXO 5}

\section{FORMULÁRIO PARA OBSERVAÇÃO DE CONSULTA}

\begin{tabular}{|c|c|}
\hline IDENTIFICAÇÃO & COD \\
\hline No de Identificação (não preencher): & \\
\hline Município: & \\
\hline Nome da Unidade Básica de Saúde: & \\
\hline Nome da Equipe de PSF: & \\
\hline Nome do profissional: & \\
\hline $\begin{array}{ll}\text { Função: ( )1.Agente de saúde } & \text { ( ) 4.Médico(a) generalista PSF } \\
\text { ( ) 2.Auxiliar/técnico de enfermagem } & \text { ( ) 5. Médico(a) pediatra PSF } \\
\text { ( ) 3.Enfermeiro(a) } & \text { ( )6.Médico(a) pediatra Não PSF }\end{array}$ & \\
\hline Fase de aplicação: 1. Pré 2. Pós & \\
\hline Data da observação: & \\
\hline Observador(a): & \\
\hline $\begin{array}{l}\text { Duração da observação: } \\
\text { Início: _ horas _ horas minutos } \\
\text { Término: __ minutos }\end{array}$ & \\
\hline
\end{tabular}

LEMBRETE: Não esqueça de preencher todos os campos deste instrumento, exceto as áreas sombreadas. Procure sentar-se em um local de onde possa observar bem tanto o profissional quanto a mãe. Confira com o profissional se o local em que você se sentou é apropriado. Não se envolva na consulta de maneira alguma. Apenas observe a consulta de forma discreta e silenciosa. No final da consulta, agradeça ao profissional e à mãe pela permissão de realizar a observação. Explique o Termo de Consentimento Livre e Esclarecido e peça para assinarem. 
DADOS GERAIS

Idade da criança em meses:

Quem trouxe a criança para a consulta?

( ) 1.mãe ( ) 2.pai ( ) 3.outro familiar ( ) 4.outra pessoa (especificar):

É a primeira consulta com este profissional?

( ) 0.não ( )1.sim

Veio com alguma queixa?

( ) 0.não ( )1.sim (especificar):

\begin{tabular}{|l|l|l|l|l|}
\hline DADOS GERAIS & SIM & NÃO & NA & CÓD \\
\hline HISTÓRIA ALIMENTAR & & & & \\
\hline Cumprimentou a mãe e a chamou pelo nome & & & & \\
\hline Colheu uma história alimentar & & & & \\
\hline Usou um roteiro para colher a história alimentar & & & & \\
\hline Perguntou/relatou amamentação & & & & \\
\hline Perguntou/relatou água, chá ou suco & & & & \\
\hline Perguntou/relatou leite artificial & & & & \\
\hline Perguntou/relatou alimentação complementar & & & & \\
\hline Perguntou/relatou/viu mamadeira & & & & \\
\hline Perguntou/relatou/viu chupeta & & & & \\
\hline GRÁFICO DE CRESCIMENTO & & & & \\
\hline Anotou o peso em um gráfico de crescimento & & & & \\
\hline Comentou com a mãe sobre a curva de crescimento & & & & \\
\hline Usou habilidades de ouvir e aprender & & & & \\
\hline Usou habilidades de confiança e apoio & & & & \\
\hline
\end{tabular}

\begin{tabular}{|l|l|l|l|l|l|}
\hline ALIMENTAÇÃO DA CRIANÇA & SIM & NÃO & NA & NS & COD \\
\hline A criança mama no peito? & & & & & \\
\hline A criança toma água, chá ou suco? & & & & & \\
\hline A criança toma leite artificial? & & & & & \\
\hline A criança come alimentos complementares? & & & & & \\
\hline A criança toma vitaminas ou micronutrientes? & & & & & \\
\hline A criança usa mamadeira? & & & & & \\
\hline A criança usa chupeta? & & & & & \\
\hline
\end{tabular}


OBSERVAÇÃO: [NA= não se aplica, NS= não sabe, porque não foi observado, relatado ou perguntado]

\begin{tabular}{|l|l|l|l|l|}
\hline $\begin{array}{l}\text { AMAMENTAÇÃO (se a criança não mama mais no peito, SIM } \\
\text { essas questões não se aplicam) }\end{array}$ & NÃO & NA & CÓD \\
\hline AVALIAÇÃO DA MAMADA & & & & \\
\hline Avaliou a mamada & & & & \\
\hline Usou um roteiro para observação da mamada & & & & \\
\hline Usou habilidades de ouvir e aprender & & & & \\
\hline Usou habilidades de confiança e apoio & & & \\
\hline AMAMENTAÇÃO EXCLUSIVA (até os 6 meses) & & & & \\
\hline Explicou a importância da amamentação exclusiva & & & \\
\hline Usou habilidades de ouvir e aprender & & & \\
\hline Usou habilidades de confiança e apoio & & & \\
\hline AMAMENTAÇÃO CONTINUADA (após os 6 meses) & & & \\
\hline Explicou a importância de continuar amamentando & & & \\
\hline após os 6 meses de idade até os 2 anos & & & & \\
\hline Usou habilidades de ouvir e aprender & & & & \\
\hline Usou habilidades de confiança e apoio & & & & \\
\hline BEBÉ CHORÃO (apareceu) & & & & \\
\hline Levou em consideração a fala da mãe sobre o choro & & & & \\
\hline Explicou as possíveis razões para o choro & & & \\
\hline Explicou como lidar com o problema & & & \\
\hline Usou habilidades de ouvir e aprender & & & \\
\hline Usou habilidades de confiança e apoio & & & \\
\hline BEBÊ DE BAIXO PESO AO NASCER (apareceu) & & & \\
\hline Levou em consideração a fala da mãe sobre o baixo & & & \\
\hline Explicou as necessidades particulares do bebê & & & \\
\hline Explicou como lidar com a dificuldade & & & \\
\hline Usou habilidades de ouvir e aprender & & & \\
\hline Usou habilidades de confiança e apoio & & & \\
\hline
\end{tabular}




\begin{tabular}{|c|l|l|l|l|}
\hline $\begin{array}{l}\text { AMAMENTAÇÃO (se a criança não mama mais no peito, } \\
\text { essas questões não se aplicam) }\end{array}$ & NÃO & NA & CÓD \\
\hline BEBÉ QUE SE RECUSA A MAMAR (apareceu) & & & & \\
\hline Levou em consideração a fala da mãe sobre recusa & & & & \\
\hline Explicou as possíveis razões para a recusa & & & & \\
\hline Explicou como lidar com a dificuldade & & & & \\
\hline Usou habilidades de ouvir e aprender & & & & \\
\hline Usou habilidades de confiança e apoio & & & & \\
\hline DUCTO BLOQUEADO (apareceu) & & & & \\
\hline Reconheceu um ducto bloqueado & & & & \\
\hline Explicou as possíveis razões para o problema & & & & \\
\hline Explicou como lidar com o problema & & & & \\
\hline Usou habilidades de ouvir e aprender & & & & \\
\hline Usou habilidades de confiança e apoio & & & & \\
\hline
\end{tabular}

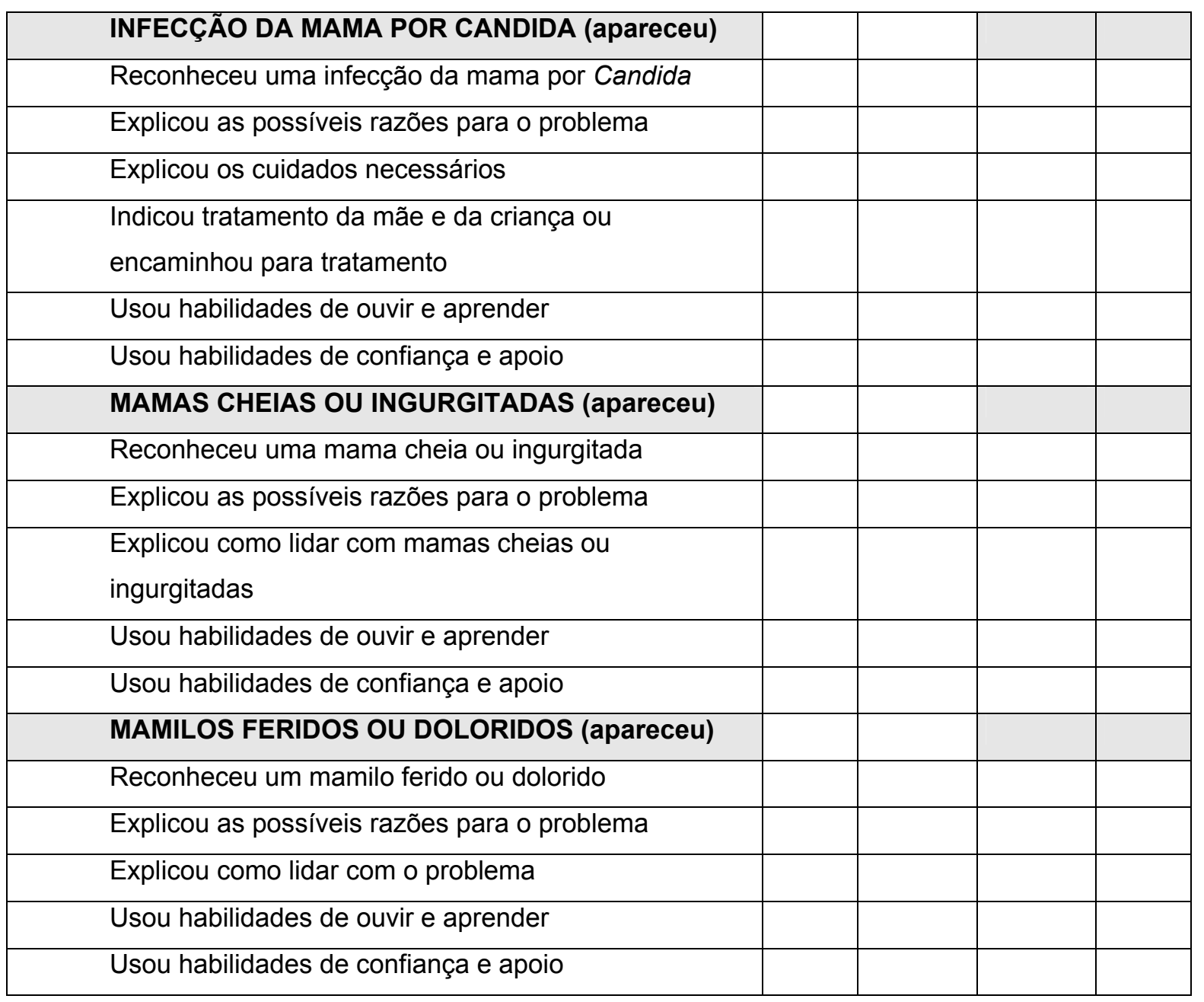




\begin{tabular}{|c|c|c|c|c|}
\hline $\begin{array}{l}\text { AMAMENTAÇÃO (se a criança não mama mais no peito, } \\
\text { essas questões não se aplicam) }\end{array}$ & SIM & NÃO & NA & CÓD \\
\hline MAMILOS PLANOS OU INVERTIDOS (apareceu) & & & & \\
\hline Reconheceu um mamilo plano ou invertido & & & & \\
\hline Explicou como lidar com um mamilo plano ou invertido & & & & \\
\hline $\begin{array}{l}\text { Mostrou para uma mãe como usar o método da } \\
\text { seringa para o tratamento de mamilos invertidos }\end{array}$ & & & & \\
\hline Usou habilidades de ouvir e aprender & & & & \\
\hline Usou habilidades de confiança e apoio & & & & \\
\hline MASTITE (apareceu) & & & & \\
\hline Reconheceu uma mastite & & & & \\
\hline Explicou as possíveis razões para o problema & & & & \\
\hline Explicou como lidar com o problema & & & & \\
\hline Usou habilidades de ouvir e aprender & & & & \\
\hline Usou habilidades de confiança e apoio & & & & \\
\hline ORDENHA DAS MAMAS (apareceu) & & & & \\
\hline Reconheceu a necessidade da mãe realizar ordenha & & & & \\
\hline $\begin{array}{l}\text { Explicou os passos para realizar a ordenha das } \\
\text { mamas com as mãos }\end{array}$ & & & & \\
\hline $\begin{array}{l}\text { Fez ou orientou alguém para massagear as costas da } \\
\text { mãe e estimular o reflexo da ocitocina }\end{array}$ & & & & \\
\hline $\begin{array}{l}\text { Explicou como preparar um recipiente para o leite } \\
\text { ordenhado }\end{array}$ & & & & \\
\hline Observou a mãe ordenhando as mamas com as mãos & & & & \\
\hline Usou habilidades de ouvir e aprender & & & & \\
\hline Usou habilidades de confiança e apoio & & & & \\
\hline
\end{tabular}

\begin{tabular}{|l|l|l|l|l|}
\hline PEGA INADEQUADA (apareceu) & & & & \\
\hline Reconheceu sinais de uma pega inadequada & & & & \\
\hline Explicou a importância de uma pega adequada & & & & \\
\hline Explicou como seria uma pega adequada & & & & \\
\hline $\begin{array}{l}\text { Ajudou a mãe a fazer com que o bebê estabelecesse } \\
\text { uma pega adequada }\end{array}$ & & & & \\
\hline Usou uma mama cobaia para demonstrar & & & & \\
\hline Usou habilidades de ouvir e aprender & & & & \\
\hline Usou habilidades de confiança e apoio & & & & \\
\hline
\end{tabular}




\begin{tabular}{|l|l|l|l|l|}
\hline $\begin{array}{l}\text { AMAMENTAÇÃO (se a criança não mama mais no peito, } \\
\text { essas questões não se aplicam) }\end{array}$ & NÃO & NA & CÓD \\
\hline POSICIONAMENTO INADEQUADO (apareceu) & & & & \\
\hline $\begin{array}{l}\text { Reconheceu um posicionamento inadequado do bebê } \\
\text { para mamar }\end{array}$ & & & & \\
\hline Explicou a importância de uma posição adequada & & & & \\
\hline Explicou como seria uma posição adequada & & & & \\
\hline Ajudou a mãe a posicionar o bebê para mamar & & & & \\
\hline Usou uma boneca para demonstrar & & & & \\
\hline Usou habilidades de ouvir e aprender & & & & \\
\hline Usou habilidades de confiança e apoio & & & & \\
\hline POUCO LEITE (apareceu) & & & & \\
\hline Levou em consideração a fala da mãe sobre pouco & & & & \\
\hline leite & & & & \\
\hline Explicou as possíveis razões para o problema & & & \\
\hline Explicou como lidar com o problema & & & \\
\hline Usou habilidades de ouvir e aprender & & & \\
\hline Usou habilidades de confiança e apoio & & & \\
\hline
\end{tabular}




\begin{tabular}{|l|l|l|l|l|}
\hline $\begin{array}{l}\text { LEITE ARTIFICIAL (se a criança não toma leite artificial, } \\
\text { essas questões não se aplicam) }\end{array}$ & NÃO & NA & CÓD \\
\hline $\begin{array}{l}\text { Perguntou/relatou tipo de leite que está usando. Se } \\
\text { sim, anote qual é o leite: }\end{array}$ & & & & \\
\hline $\begin{array}{l}\text { Perguntou/relatou como o leite é preparado } \\
\text { (ingredientes e medidas) }\end{array}$ & & & & \\
\hline $\begin{array}{l}\text { Perguntou/relatou se o leite é preparado a cada } \\
\text { mamada }\end{array}$ & & & & \\
\hline $\begin{array}{l}\text { Perguntou/relatou sobre condições de } \\
\text { armazenamento }\end{array}$ & & & & \\
\hline Perguntou/relatou como o leite é oferecido à criança & & & \\
\hline $\begin{array}{l}\text { Perguntou/relatou os cuidados higiênicos no preparo e } \\
\text { oferta do leite para a criança }\end{array}$ & & & & \\
\hline Perguntou/relatou quem oferece o leite à criança & & & & \\
\hline Explicou como preparar o leite de forma higiênica & & & & \\
\hline Explicou como medir os ingredientes & & & & \\
\hline $\begin{array}{l}\text { Utilizou algum recurso visual ou praticou o preparo do } \\
\text { leite com a mãe }\end{array}$ & & & & \\
\hline Explicou como saber se a criança está satisfeita & & & & \\
\hline Explicou o que fazer com as sobras de leite & & & & \\
\hline Falou sobre oferecer vitaminas e micronutrientes & & & & \\
\hline Usou habilidades de ouvir e aprender & & & & \\
\hline Usou habilidades de confiança e apoio & & & \\
\hline
\end{tabular}




\begin{tabular}{|c|c|c|c|c|}
\hline ALIMENTAÇÃO COMPLEMENTAR & SIM & NÃO & NA & PÓD \\
\hline $\begin{array}{l}\text { Perguntou/relatou sobre a consistência dos alimentos } \\
\text { oferecidos }\end{array}$ & & & & \\
\hline $\begin{array}{l}\text { Perguntou/relatou sobre a oferta de frutas e legumes } \\
\text { amarelos e alaranjados }\end{array}$ & & & & \\
\hline $\begin{array}{l}\text { Perguntou/relatou sobre a oferta de carnes ou } \\
\text { vísceras }\end{array}$ & & & & \\
\hline $\begin{array}{l}\text { Perguntou/relatou sobre a oferta de vegetais folhosos } \\
\text { verde-escuros }\end{array}$ & & & & \\
\hline $\begin{array}{l}\text { Perguntou/relatou se a alimentação da criança é } \\
\text { variada no dia a dia }\end{array}$ & & & & \\
\hline $\begin{array}{l}\text { Perguntou/relatou sobre cuidados de higiene ao } \\
\text { preparar e oferecer os alimentos }\end{array}$ & & & & \\
\hline $\begin{array}{l}\text { Perguntou/relatou sobre o número das refeições ao } \\
\text { dia }\end{array}$ & & & & \\
\hline $\begin{array}{l}\text { Perguntou/relatou sobre técnicas utilizadas para } \\
\text { estimular a alimentação da criança }\end{array}$ & & & & \\
\hline Explicou como oferecer alimentos complementares & & & & \\
\hline $\begin{array}{l}\text { Explicou a importância de oferecer alimentos de } \\
\text { consistência pastosa }\end{array}$ & & & & \\
\hline $\begin{array}{l}\text { Explicou a importância de oferecer alimentos de cor } \\
\text { amarelada ou alaranjada }\end{array}$ & & & & \\
\hline Explicou a importância de oferecer carnes ou vísceras & & & & \\
\hline $\begin{array}{l}\text { Explicou a importância de oferecer vegetais verde- } \\
\text { escuros }\end{array}$ & & & & \\
\hline $\begin{array}{l}\text { Explicou a importância de oferecer uma alimentação } \\
\text { variada }\end{array}$ & & & & \\
\hline $\begin{array}{l}\text { Falou sobre os cuidados higiênicos ao prepara e } \\
\text { oferecer os alimentos }\end{array}$ & & & & \\
\hline $\begin{array}{l}\text { Falou sobre o número de refeições apropriado para a } \\
\text { idade da criança }\end{array}$ & & & & \\
\hline $\begin{array}{l}\text { Falou sobre técnicas apropriadas para incentivar a } \\
\text { alimentação da criança }\end{array}$ & & & & \\
\hline $\begin{array}{l}\text { Utilizou recursos visuais para discutir algum aspecto } \\
\text { da alimentação complementar }\end{array}$ & & & & \\
\hline
\end{tabular}




\begin{tabular}{|l|l|l|l|l|}
\hline ALIMENTAÇÃO COMPLEMENTAR & SIM & NÃO & NA & FóD \\
\hline $\begin{array}{l}\text { A mãe referiu alguma dificuldade ou preocupação com } \\
\text { a alimentação complementar? Se sim, detalhe: }\end{array}$ & & & & \\
\hline $\begin{array}{l}\text { Levou em consideração a fala da mãe e explicou } \\
\text { como lidar com o problema }\end{array}$ & & & & \\
\hline Usou habilidades de ouvir e aprender & & & & \\
\hline Usou habilidades de confiança e apoio & & & & \\
\hline
\end{tabular}

\begin{tabular}{|l|l|l|l|l|}
\hline CRIANÇA DOENTE OU CONVALESCENTE & SIM & NÃO & NA & COD \\
\hline $\begin{array}{l}\text { A criança no momento está doente ou em fase de } \\
\text { recuperação de uma doença }\end{array}$ & & & & \\
\hline $\begin{array}{l}\text { Falou sobre a importância de uma alimentação } \\
\text { adequada para esse período }\end{array}$ & & & & \\
\hline Explicou como lidar com a alimentação da criança & & & & \\
\hline Usou habilidades de ouvir e aprender & & & & \\
\hline Usou habilidades de confiança e apoio & & & & \\
\hline USO DA XícARA OU COPO & NÃO & NA & COD \\
\hline Falou sobre possibilidade de uso da xícara & & & & \\
\hline $\begin{array}{l}\text { Explicou como preparar de forma higiênica a xícara ou } \\
\text { copo para alimentar o bebê }\end{array}$ & & & & \\
\hline $\begin{array}{l}\text { Explicou como alimentar o bebê com xícara de forma } \\
\text { segura }\end{array}$ & & & & \\
\hline $\begin{array}{l}\text { Praticou com a mãe como alimentar o bebê com } \\
\text { xícara }\end{array}$ & & & & \\
\hline $\begin{array}{l}\text { Explicou a quantidade de leite a oferecer para o bebê } \\
\text { e o número de mamadas em 24 horas }\end{array}$ & & & & \\
\hline $\begin{array}{l}\text { Usou habilidades de ouvir e aprender } \\
\text { Usou habilidades de confiança e apoio }\end{array}$ & & & & \\
\hline
\end{tabular}




\begin{tabular}{|c|c|c|c|c|c|}
\hline $\begin{array}{l}\text { HABILIDADES DE ACONSELHAMENTO dentre as habilidades } \\
\text { assinaladas anteriormente, detalhe e qualifique cada uma delas. }\end{array}$ & $\begin{array}{l}\text { FRACO } \\
\text { (0) }\end{array}$ & $\begin{array}{c}\text { REGULAR } \\
\text { (1) }\end{array}$ & $\begin{array}{l}\text { BOM } \\
\text { (2) }\end{array}$ & $\begin{array}{l}\text { MUITO } \\
\text { BOM } \\
\text { (3) }\end{array}$ & Cód \\
\hline COMO OUVIR E APRENDER & & & & & \\
\hline Manteve a cabeça no mesmo nível da mãe & & & & & \\
\hline Prestou atenção ao conversar com a mãe & & & & & \\
\hline Removeu possíveis barreiras & & & & & \\
\hline Dedicou tempo à consulta & & & & & \\
\hline Tocou de maneira apropriada & & & & & \\
\hline Fez perguntas abertas & & & & & \\
\hline $\begin{array}{l}\text { Usou respostas e gestos que demonstram } \\
\text { interesse }\end{array}$ & & & & & \\
\hline Devolveu com suas palavras o que a mãe diz & & & & & \\
\hline $\begin{array}{l}\text { Mostrou entender como a mãe pensa e sente } \\
\text { (empatia) }\end{array}$ & & & & & \\
\hline $\begin{array}{l}\text { Evitou usar palavras que soam como } \\
\text { julgamento }\end{array}$ & & & & & \\
\hline CONSTRUIR A CONFIANÇA E DAR APOIO & & & & & \\
\hline Aceitou o que a mãe pensa e sente & & & & & \\
\hline $\begin{array}{l}\text { Reconheceu e elogiou o que mãe e bebê } \\
\text { fazem certo }\end{array}$ & & & & & \\
\hline Deu ajuda prática & & & & & \\
\hline Deu pouca e relevante informação & & & & & \\
\hline Usou linguagem simples & & & & & \\
\hline Deu uma ou duas sugestões, não ordens & & & & & \\
\hline OUTRAS HABILIDADES & & & & & \\
\hline Confirmou o entendimento & & & & & \\
\hline Marcou uma consulta de seguimento & & & & & \\
\hline
\end{tabular}


Após o término da observação, agradeça o(a) profissional e verifique se ele(a) gostaria de fazer algum comentário. Não faça qualquer comentário, apenas anote.

Faça um breve comentário sobre aspectos relevantes da consulta observada (Por exemplo: O cuidador tinha as informações necessárias para responder ao que foi perguntado? Há alguma situação relevante que não tenha sido possível obter com as questões do formulário? Como você avalia o resultado desta consulta? Você sairia satisfeita? A mãe parece ter saído satisfeita?)

PARABÉNS E MUITO OBRIGADA! (Termo de Consentimento em anexo) 


\section{ANEXO 6 GUIA DE ORIENTAÇÕES PARA A OBSERVAÇÃO DE CONSULTAS}

A qualidade do seu trabalho é de extrema importância para o resultado final deste projeto de pesquisa. Leia com atenção todos os itens do Formulário para Observação de Consulta e deste Guia e esclareça todas as suas dúvidas previamente. Procure familiarizar-se com os termos utilizados no Formulário e, sempre que necessário, recorra aos conceitos que se encontram no final deste Guia.

Serão observados os atendimentos realizados por médicos, enfermeiros e auxiliares de enfermagem, conforme combinado com a coordenação do Programa Saúde da Família (PSF) dos municípios de Itapira e Peruíbe.

Todos esses profissionais receberam as informações necessárias sobre o projeto e assinaram um Termo de Consentimento Livre e Esclarecido (TCLE), concordando com a observação de suas consultas a crianças menores de 18 meses. Portanto, não é esperado encontrar resistências para a observação de consultas. Em todo caso, se ocorrer alguma dificuldade nesse sentido, não insista e informe a coordenadora do projeto.

Para a observação será utilizado o Formulário para Observação de Consulta, no qual constam os seguintes tópicos: Identificação, Dados Gerais, Amamentação, Leite Artificial, Alimentação Complementar e Habilidade de Aconselhamento.

Como as consultas não seguem uma dinâmica padronizada, o preenchimento do Formulário não será linear. Além disso, para algumas questões provavelmente só será possível chegar a uma conclusão no final da consulta. Portanto, você deverá estar bem atento(a) a todas as falas e ações do profissional de saúde e da mãe. Por isso é importante estar bem familiarizado com os itens a serem observados.

Antes de realizar a observação, converse com o profissional nos seguintes termos:

-"Bom dia, meu nome é .... Eu sou um(a) dos(as) observadores(as) da pesquisa que está sendo realizada aqui no município. Eu gostaria de observar duas consultas, uma de criança menor de 6 meses e outra de criança maior de 6 meses" (verifique se há crianças nessas condições).

- "Durante meu trabalho, eu ficarei sentado(a) em um local de onde possa observar tanto o(a) sr(a). quanto a mãe, porém de maneira a não atrapalhar sua consulta" (escolha um lugar e verifique com o profissional se ele concorda).

- "Gostaria de pedir que o(a) sr(a). me apresente à mãe, explique o que estou fazendo e verifique se ela concorda." (se for oportuno, peça para que ambos assinem o TCLE neste momento ou deixe para fazê-lo ao término da consulta).

Não se envolva na consulta, mesmo que a mãe requeira. Apenas observe de forma discreta e silenciosa.

No final da consulta, agradeça ao profissional e à mãe e não esqueça de preencher todos os campos do Formulário. Por isso, releia-o imediatamente após a consulta observada, o que facilitará a lembrança do que ocorreu. Se persistir alguma dúvida anote-a para ser discutida posteriormente com a coordenadora do projeto.

Verifique se o profissional gostaria de fazer algum comentário sobre a consulta observada. Apenas anote, não faça qualquer tipo de comentário.

Evite que seu trabalho seja recusado e não remunerado. Isso acontecerá se ele estiver incompleto ou com informações não consistentes e poderá ser necessário voltar a campo para fazer nova observação desse profissional.

Todos os dias ao final da tarde, a coordenadora do projeto entrará em contato para conversar sobre o andamento do trabalho e para dirimir dúvidas.

Muito obrigada e bom trabalho!

\section{CONCEITOS UTILIZADOS NO FORMULÁRIO}

\section{AMAMENTAÇÃO, LEITE ARTIFICIAL E ALIMENTAÇÃO COMPLEMENTAR:}


1.1. Amamentação exclusiva - recomenda-se que as crianças até os seis meses de idade recebam apenas o leite materno, sem outros líquidos (como, por exemplo, água ou chá); inclui o uso de medicamentos e vitaminas que a criança necessite receber.

1.2. Amamentação continuada - recomenda-se que após os seis meses as crianças comecem a receber alimentos complementares; porém, o leite materno deve ser 0 único leite a ser oferecido até pelo menos dois anos de idade.

1.3. Alimentação complementar - após os seis de idade, toda criança precisa receber alimentos semi-sólidos e depois sólidos (alimentos da família) para atender a suas necessidades nutricionais; a alimentação deve ser variada e incluir alimentos ricos em energia (alimentos básicos oferecidos em consistência pastosa), em ferro e vitamina A (carnes, miúdos e leguminosas, frutas e vegetais verde-escuros e alaranjados); os alimentos devem ser introduzidos gradualmente na dieta da criança e oferecidos de maneira a respeitar as habilidades da criança conforme sua idade e a incentivá-la a comer sem forçar.

1.4. Avaliação da mamada - consiste em observar uma criança sendo amamentada e avaliar se sua postura e a maneira como abocanha a mama são apropriados para uma alimentação efetiva e que não provoque problemas na mãe; há um formulário padronizado para observação, entretanto um profissional experiente pode prescindir deste instrumento durante a avaliação; é particularmente importante sua realização quando a criança é pequena ou quando a mãe apresenta alguma dificuldade com a amamentação.

1.5. Bebê chorão - o choro é uma queixa comum trazida pelas mães e, com freqüência, afeta sua auto-confiança sobre a suficiência do leite materno; há vários motivos para o choro, entre os quais uma amamentação não efetiva que pode ser corrigida (por exemplo, uma pega inadequada ou mamadas curtas).

1.6. Bebê de baixo peso ao nascer - é aquele que nasceu com menos de $2500 \mathrm{~g}$; a maioria deles não terá dificuldades específicas com a amamentação; entretanto, aqueles que nasceram prematuros ou com pesos abaixo de $1500 \mathrm{~g}$ podem ter tido problemas de saúde no início da vida, podem ter demorado a iniciar a amamentação e ter permanecido afastados de suas mães, necessitando de mais atenção dos profissionais.

1.7. Bebê que se recusa a mamar - neste caso, a mãe costuma referir que ao colocar o bebê para mamar ele se debate, resiste e chora; isto pode ser resultado, entre outras coisas, do uso de um bico artificial (mamadeira e chupeta).

1.8. Criança doente ou convalescente - nesta situação, é comum a criança não demonstrar o mesmo interesse pela comida, exigindo mais paciência e criatividade de quem cuida na hora das refeições; é importante que não se deixe de alimentar a criança de maneira apropriada à idade; pode haver uma tendência a oferecer comidas mais leves/diluídas, o que não é adequado.

1.9. Ducto bloqueado - quando o leite materno não é retirado uniformemente da mama, pode ocorrer o acúmulo em uma área; percebe-se na região uma área mais endurecida, dolorosa e avermelhada; orienta-se massagem e ordenha ou mudança de posição da criança ao mamar.

1.10. Infecção da mama por Cândida - infecção por fungo também conhecida como monilíase (ou sapinho); caracteriza-se por dor persistente em agulhadas e/ou despigmentação da aréola; tanto a mãe quanto o bebê precisam ser medicados.

1.11. Leite artificial - qualquer leite não humano, seja em sua forma líquida ou em pó.

1.12. Mamas cheias ou ingurgitadas - a diferença entre elas é que a mama ingurgitada é mais dolorosa, o leite materno tem dificuldade de sair, a pele parece tensa e com brilho, a mama toda está endurecida, os mamilos ficam menos salientes, a mãe pode sentir-se febril; é resultante de drenagem insuficiente do leite causado por um retardo no início da amamentação, por mamadas pouco freqüentes ou pega inadequada; em ambos os casos orienta-se a ordenha e mamadas freqüentes.

1.13. Mamilos feridos ou doloridos - é evento freqüente, em geral, decorrente de uma pega inadequada. 
1.14. Mamilo plano ou invertido - no mamilo plano, o bico é pouco saliente; no invertido, ao tocar o bico ele volta-se para dentro da mama; podem dificultar a pega, particularmente se as mamas estão muito cheias ou se o bebê é de baixo peso.

1.15. Mastite - é uma inflamação da mama decorrente de estase do leite e ferimento nos mamilos; a mãe sente-se doente, a mama avermelhada e pode haver saída de pus; é necessário tratar com antibióticos e repouso, mas não interromper a amamentação.

1.16. Ordenha das mamas - a extração de leite materno é recomendada em várias situações, por isso é importante que todas as mães saibam ordenhar com as próprias mãos; deve-se demonstrar a técnica para a mãe e depois observá-la realizando uma ordenha.

1.17. Pega inadequada - uma amamentação bem sucedida depende de uma pega adequada; pega é a forma como o bebê abocanha a mama; uma boa pega implica abocanhar não só o bico, mas uma boa porção da mama (como referência, orientase abocanhar toda a aréola); há sinais que podem ser observados para avaliar se a pega é adequada ou não.

1.18. Posicionamento inadequado - para uma pega adequada é importante que o bebê esteja bem posicionado no colo da mãe (de frente para ela, bem encostado ao corpo da mãe e com cabeça e tronco alinhados, muitas vezes, também com as nádegas apoiadas); há várias posições para amamentar.

1.19. Pouco leite - é uma queixa freqüente das mães, em geral, porque o bebê chora ou quer mamar muito; é comum as mães receberem muitos palpites de familiares que diminuem sua auto-confiança; uma pega inadequada, mamadas pouco freqüentes, uso de outros líquidos ou uso excessivo de chupeta podem levar à diminuição na produção do leite materno.

1.20. Uso da xícara - se, por algum motivo, a mãe não pode amamentar recomenda-se que a criança seja alimentada por meio de xícara/copo ao invés de mamadeira; a xícara é mais fácil de limpar e exige sempre uma pessoa para oferecer o alimento para a criança pequena.

2. HABILIDADES DE ACONSELHAMENTO:

2.1. Manter a cabeça no mesmo nível da mãe - Para facilitar a comunicação o profissional poderia adotar a postura de manter-se no mesmo nível da mãe.

Prestar atenção ao conversar com a mãe (olho no olho) - Espera-se que o profissional olhe para a mãe e preste atenção enquanto ela fala. Uma atitude que bloqueia a comunicação é olhar para outra coisa enquanto a pessoa está falando.

2.2. Remover possíveis barreiras - Deve-se evitar barreiras, tais como ficar sentado atrás de uma mesa ou fazer anotações enquanto a mãe fala.

2.3. Dedicar tempo à consulta - São posturas apropriadas sentar-se e cumprimentar sem pressa, permanecer calmo sorrindo, observando a mamada e esperando que a mãe responda, não olhar para o relógio ou interromper enquanto a mãe fala.

2.4. Tocar de maneira apropriada - $O$ toque é um gesto que pode ajudar ou atrapalhar a comunicação; em geral, aceita-se como apropriado o toque nos ombros e membros superiores da mãe ou corpo do bebê.

2.5. Fazer perguntas abertas - É importante fazer perguntas que levem a mãe a falar mais sobre suas dificuldades e sentimentos. Em geral, o uso de perguntas abertas ajuda a economizar perguntas, utilizar melhor o tempo e propiciar mais informações. Perguntas abertas geralmente começam com "Como? Que? Quem? Onde? Por que?".

Perguntas fechadas são normalmente menos úteis. Elas dizem à mãe a resposta que você espera e há grande possibilidade de obter apenas um "Sim" ou "Não". Perguntas fechadas geralmente começam com palavras como "Você está?" "Ele fez?" "Ela faz?" ou "Ele tem?".

2.6. Usar respostas e gestos que demonstram interesse - Se o profissional quer que a mãe continue falando, deve demonstrar que está ouvindo e que está interessado no que ela está dizendo. 
Formas importantes de demonstrar que alguém está ouvindo e está interessado são gestos, tais como olhar para a mãe, balançar a cabeça afirmativamente e sorrir, ou respostas simples do tipo "Aha", "Mmm", "Ah é?!".

2.7. Devolver (fazer eco) com suas palavras o que a mãe diz - Profissionais de saúde, às vezes, fazem uma porção de perguntas às mães referentes a fatos. Entretanto, as respostas a este tipo de pergunta freqüentemente são inúteis. A mãe pode falar cada vez menos em resposta a cada questão.

É mais interessante repetir o que a mãe diz devolvendo, fazendo eco. É melhor dizer de forma um pouco diferente, de forma que não pareça que está apenas repetindo o que ela disse.

2.8. Empatia - mostrar à mãe que você entende como ela se sente - Empatia é uma habilidade difícil de se adquirir. É difícil para as pessoas falarem sobre os sentimentos. Quando uma mãe diz alguma coisa que mostra como ela se sente, é útil responder de forma que demonstre que a ouviu e entendeu os sentimentos do ponto de vista dela. O uso da habilidade de fazer eco ao que a mãe diz pode ajudar. Empatia é diferente de simpatia. Ao expressar simpatia, por exemplo, ao dizer que entende a pessoa porque já viveu situação semelhante, a atenção está voltada para o seu ponto de vista.

2.9. Evitar palavras que soam como julgamento - Palavras que soam como julgamento são palavras do tipo "certo, errado, bem, mal, bastante, adequado, direitinho". O uso destas palavras pode fazer com que a mãe sinta que está errada ou que há alguma coisa errada com o bebê. Uma forma de evitar tais palavras é fazer perguntas abertas.

2.10. Aceitar o que a mãe pensa ou sente - Mesmo se a mãe pensa ou sente algo equivocado, em um bom relacionamento procura-se aceitar inicialmente (Ahhh, entendo..), para aos poucos procurar entender o que leva a pessoa a ter este pensamento ou sentimento.

2.11. Reconhecer e elogiar o que a mãe e o bebê estão fazendo certo - O elogio leva à melhora da auto-estima; sempre há uma boa coisa a elogiar.

2.12. Dar ajuda prática - Deve procurar oferecer ajuda concreta, que leve a mãe a se sentir melhor. Por exemplo, mostrar onde deixar a sacola ou carregar para ela; oferecer uma cadeira, etc.

2.13. Dar pouca e relevante informação - Informações em excesso não são guardadas pela memória; só se guarda o que é relevante para aquela ocasião, relacionado ao problema ou dificuldade que levou a pessoa à consulta.

2.14. Usar linguagem simples - Deve-se evitar o uso de termos desnecessários e difíceis de entender. Por exemplo, em vez de "amamentação exclusiva" é melhor falar "mamar só no peito".

2.15. Dar uma ou duas sugestões, não ordens - As orientações deveriam começar com "Sugiro que..." ou "Que tal se você..." ao invés de usar o imperativo "Faça o mingau", "Introduza a sopa", etc.

Tereza Setsuko Toma Instituto de Saúde

Rua Santo Antonio 590, $2^{\circ}$ andar

Bela Vista, São Paulo, SP

CEP: 01314-000

Fone: 11-32932233 ou 32932232

e-mail: ttoma@isaude.sp.gov.br 


\section{ANEXO 7 \\ TERMO DE CONSENTIMENTO LIVRE E ESCLARECIDO PARA AS MÃES}

Esta pesquisa está sendo realizada pelo Instituto de Saúde e Secretaria Municipal de Saúde.

Estamos visitando todas as mães de crianças menores de 18 meses atendidas pelo Programa Saúde da Família para serem entrevistadas.

O objetivo é conhecer as famílias e verificar a saúde e a alimentação das crianças pequenas.

Todas as informações pessoais (nome, endereço, telefone) serão mantidas em segredo.

A senhora pode desistir a qualquer momento, se não quiser mais participar da pesquisa.

Qualquer dúvida ou reclamação pode ser encaminhada para Dra. Tereza S. Toma, no Instituto de Saúde (Rua Santo Antonio 590, Bela Vista, São Paulo, SP, CEP: 01314-000; telefone: 11-32932233; e-mail:ttoma@isaude.sp.gov.br).

Se a senhora concorda em participar, por favor, assine este Termo e fique com uma cópia.

Sua participação é muito importante. Muito obrigada por sua colaboração.

Eu compreendi do que se trata a pesquisa e concordo em participar.

Nome:

Assinatura:

Cidade e data: .$/ 2007$ 


\title{
ANEXO 8 \\ TERMO DE CONSENTIMENTO LIVRE E ESCLARECIDO PARA OS PROFISSIONAIS
}

\author{
INFORMAÇÕES SOBRE O PROJETO (PERUÍBE) \\ (para médicos, enfermeiros, auxiliares e agentes de saúde)
}

Projeto realizado pelo Instituto de Saúde/Secretaria de Estado da Saúde de São Paulo, financiado pelo CNPq (Processo $n^{\circ}$ 402278/2005-4): APERFEIÇOAMENTO DAS COMPETÊNCIAS SOBRE ALIMENTAÇÃO APROPRIADA DE CRIANÇAS MENORES DE DOIS ANOS.

O objetivo desta pesquisa é verificar em que medida a participação de médicos, enfermeiros, auxiliares e agentes de saúde no curso proposto pela Organização Mundial da Saúde (chamado Aconselhamento em Alimentação de Lactentes e Crianças de Primeira Infância: um curso integrado) contribui para a melhoria da alimentação das crianças menores de dois anos de idade.

O curso tem duração de 35 horas, inclui 5 aulas práticas e aborda conteúdos relacionados à amamentação, alimentação de crianças filhas de mães HIV positivo e alimentação complementar.

O projeto foi aceito pela Secretaria de Saúde do seu município, assim como pela coordenação do PSF. A sua participação poderá contribuir para melhorar o curso proposto pela Organização Mundial da Saúde e avaliar sua utilidade para trabalhadores do Programa Saúde da Família.

Como participante do projeto espera-se que você:

1. permita que sejam realizadas observações de suas consultas com crianças menores de 18 meses (se você é um agente de saúde não será incluído nesta etapa);

2. participe de um dos curso sobre aconselhamento em alimentação infantil que serão realizados em seu município nos meses de setembro-outubro de 2007 , dirigido aos médicos, enfermeiros e auxiliares (se você é um agente de saúde receberá um curso adaptado de acordo com sua especificidade de trabalho, na data a ser agendada com a coordenadora do PSF);

3. responda a um teste de conhecimentos contendo questões sobre alimentação infantil;

4. concorde em participar das reuniões de supervisão após o curso, por um período de 3 meses;

5. colabore no sentido de facilitar nosso contato com as mães e famílias de crianças menores de 18 meses de idade, para realização de entrevistas.

Na primeira etapa do projeto, o seu município servirá de grupo controle ao outro município que receberá o curso durante os meses de fevereiro-abril de 2007.

Após considerar-se devidamente esclarecido, por favor assine o Termo de Consentimento Livre e Esclarecido e devolva uma cópia para a equipe do projeto.

Na próxima página você poderá verificar as sessões que serão abordadas durante o curso.

Todas as informações fornecidas pelos participantes deste projeto serão mantidas em segredo. 


\section{Sessões do "Aconselhamento em Alimentação de Lactentes e Crianças de Primeira Infância: um curso integrado":}

01. Introdução ao tema da alimentação de lactentes e crianças de primeira infância

02. Por que a amamentação é importante?

03. Como a amamentação funciona

04. Como avaliar uma mamada

05. Como ouvir e aprender

06. Exercícios sobre como ouvir e aprender

07. Prática 1: Como ouvir e aprender; como avaliar uma mamada

08. Como posicionar o bebê para mamar

09. Gráficos de crescimento

10. Como construir a confiança e dar apoio

11. Exercícios sobre como construir a confiança e dar apoio - Parte 1

12. Prática 2 : Como construir a confiança e dar apoio; como posicionar o bebê para mamar

13. Como colher uma história alimentar

14. Dificuldades comuns na amamentação

15. Ordenha do leite materno

16. Como alimentar com xícara

17. Visão geral sobre HIV e alimentação infantil

18. Aconselhamento para as decisões sobre alimentação infantil

19. Relactação e lactação induzida

20. Condições da mama

21. Alimentação de substituição nos primeiros seis meses

22. Preparação higiênica dos alimentos

23. Como preparar as refeições de leite - medidas

24. Prática 3: Como preparar as refeições de leite

25. Práticas de atenção à saúde

26. Código Internacional de Comercialização de Substitutos do Leite Materno e legislação nacional

27. Cartões e instrumentos para aconselhamento de mulheres HIV-positivo

28. Importância da alimentação complementar

29. Alimentos para suprir a lacuna de energia

30. Alimentos para suprir as lacunas de Ferro e vitamina $A$

31. Quantidade, variedade e freqüência da alimentação

32. Exercícios sobre como construir a confiança e dar apoio - Parte 2

33. Como colher informações sobre práticas de alimentação complementar

34. Técnicas de alimentação

35. Prática 4: Como colher informações sobre práticas de alimentação complementar

36. Como confirmar o entendimento e marcar consulta de acompanhamento

37. Como alimentar bebês de baixo peso ao nascer e crianças doentes

38. Demonstração do preparo de alimentos

39. Seguimento após o curso

Tereza Setsuko Toma

Instituto de Saúde

Rua Santo Antonio $590,2^{\circ}$ andar

Bela Vista, São Paulo, SP

CEP: 01314-000

Fone: $11-32932233$ ou 32932232

e-mail: ttoma@isaude.sp.gov.br 


\title{
ANEXO 9 \\ TERMO DE CONSENTIMENTO LIVRE E ESCLARECIDO PARA AS OBSERVAÇÕES DE CONSULTA
}

\author{
Projeto realizado pelo Instituto de Saúde/Secretaria de Estado da Saúde de São Paulo, \\ financiado pelo CNPq (Processo $n^{\circ}$ 402278/2005-4): APERFEIÇOAMENTO DAS \\ COMPETÊNCIAS SOBRE ALIMENTAÇÃO APROPRIADA DE CRIANÇAS MENORES DE \\ DOIS ANOS.
}

Eu, após ter sido devidamente esclarecido(a), aceito participar deste projeto de forma voluntária, nos seguintes termos:

- $\quad$ permitir que sejam realizadas observações de minhas consultas com crianças menores de 18 meses (exceto o agente de saúde);

- participar de um dos cursos sobre aconselhamento em alimentação infantil que serão realizados em seu município nos meses de fevereiro a abril de 2007 (de acordo com a data agendada com a coordenadora do PSF);

- $\quad$ responder ao teste de conhecimentos sobre alimentação infantil antes e após participar do curso;

- $\quad$ participar das reuniões de supervisão após o curso, por um período de 3 meses;

- colaborar no sentido de facilitar o contato da equipe de pesquisa com as mães e famílias de crianças menores de 18 meses de idade, para realização de entrevistas.

Estou ciente de que:

- tenho a liberdade de desistir de participar em qualquer etapa da pesquisa

- $\quad$ todas as minhas informações serão mantidas em segredo.

Peruíbe, .$/ 2006$

Assinatura:

Função:

Agente de Saúde ( )

Enfermeiro(a) ( )

Médico(a) pediatra PSF ( )
Auxiliar de enfermagem ( )

Médico(a) generalista PSF ( )

Médico(a) Não PSF ( )

Em qualquer etapa, dúvidas ou queixas poderão ser dirigidas às responsáveis pela pesquisa:

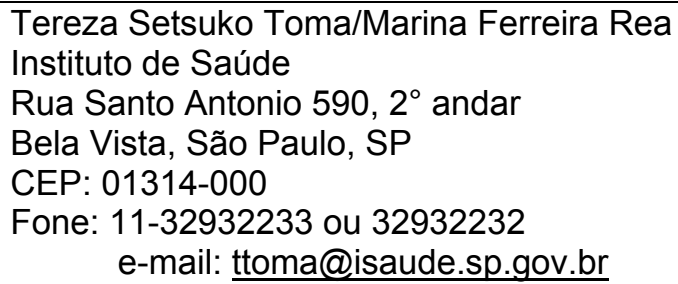

Maria Helena D’Aquino Benício Faculdade de Saúde Pública / Departamento de Nutrição

Av. Dr. Arnaldo 715

Cerqueira César, São Paulo, SP

CEP: 01246-904

Fone: 11-30626748 ramal 214

e-mail: benicio@usp.br 
ANEXO 10

PARECER DO COMITÊ DE ÉTICA EM PESQUISA DA FSP-USP

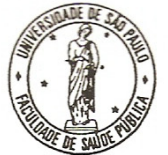 \\ Universidade de São Paulo \\ Faculdade de Saúde Pública \\ COMITÊ DE ÉTICA - COEP
}

Av. Dr. Arnaldo, 715 - Assessoria Acadêmica - CEP 01246-904 - São Paulo - Brasil Telefones: (55-11) 3066-7779 -e-mail: coep@fsp.usp.br

Of.COEP/29/06

09 de fevereiro de 2006

Pelo presente, informo que o Comitê de Ética em Pesquisa da Faculdade de Saúde Pública da Universidade de São Paulo-COEP analisou e aprovou, em sua 1. \%06 Sessão Ordinária, realizada em 08.02.06, de acordo com os requisitos da Resolução CNS/196/96 e suas complementares, o Protocolo de Pesquisa n. ${ }^{\circ}$ 1418, intitulado: "CONHECIMENTOS E PRÁTICAS DE TRABALHADORES DO PROGRAMA SAÚDE DA FAMÍLIA E DE MÃES DA CIDADE DE ITAPIRA SOBRE ALIMENTAÇÃO DE CRIANÇAS MENORES DE DOIS ANOS: UM ENSAIO COMUNITÁRIO CONTROLADO E RANDOMIZADO POR CLUSTER", apresentado pela pesquisadora Tereza Setsuko Toma.

Atenciosamente,

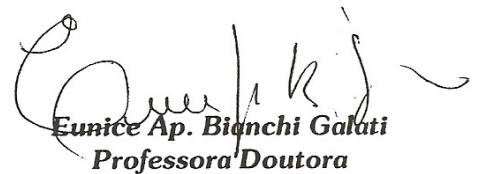

Coordenadora do Comitê de Ética em Pesquisa da FSP - COEP 